\title{
ANTICIPATORY LIFE CYCLE ASSESSMENT OF SOL-GEL DERIVED ANTI-REFLECTIVE COATING FOR GREENHOUSE GLASS
}

Natalya Tsoy

Master Thesis

M.Sc. Industrial Ecology

Leiden University \& Delft University of Technology

Supervising Committee:

Dr. Valentina Prado, CML, Leiden University

Dr. Jaco Quist, TPM, Delft University of Technology

Commissioner:

Dr. Aike Wypkema, Materials Solutions, TNO

07-13-2017 
M.Sc. Thesis // Natalya Tsoy / 07-13-2017 


\section{TABle Of CONTENTS}

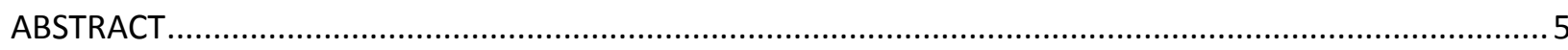

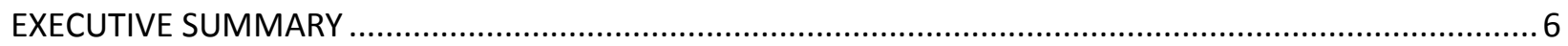

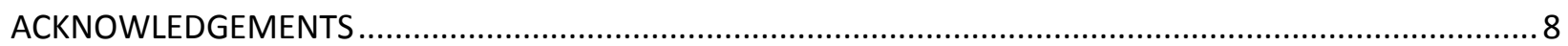

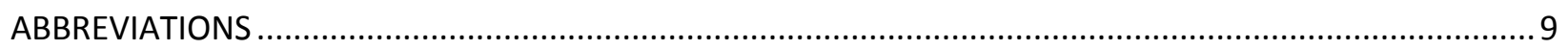

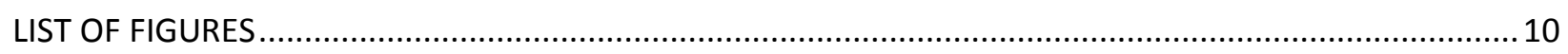

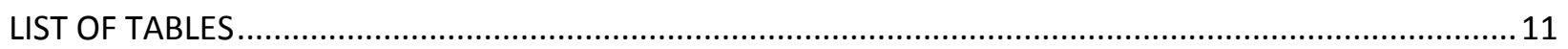

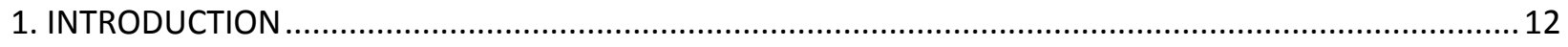

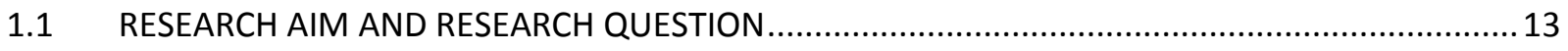

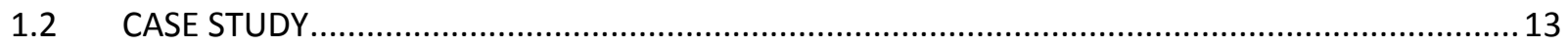

1.2.1 ANTI-REFLECTIVE COATINGS FOR GREENHOUSE GLASS ........................................ 13

1.2.2 ENVIRONMENTAL ASSESSMENT OF COATINGS ................................................. 16

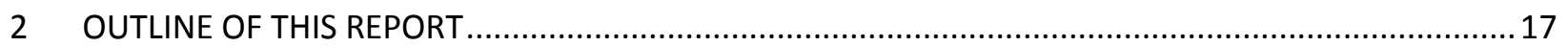

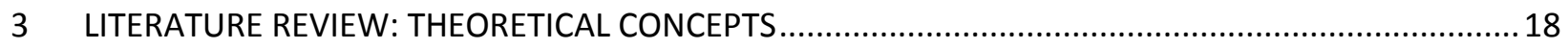

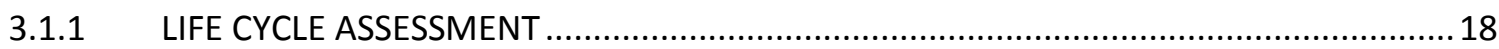

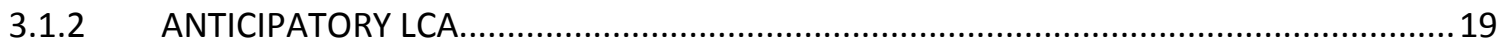

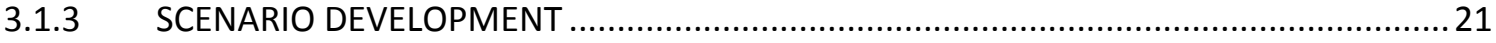

3.1.4 RESPONSIBLE RESEARCH AND INNOVATION AND TECHNOLOGY ASSESSMENT ..........23

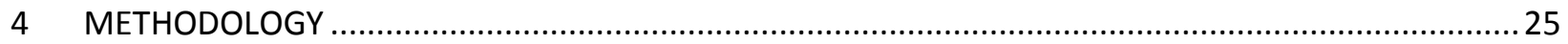

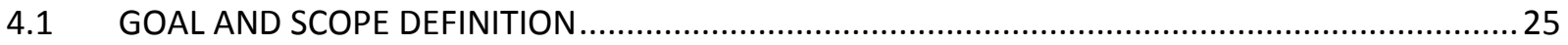

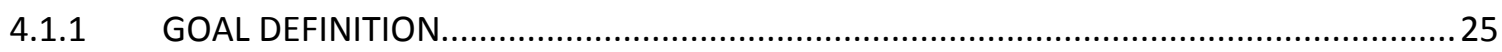

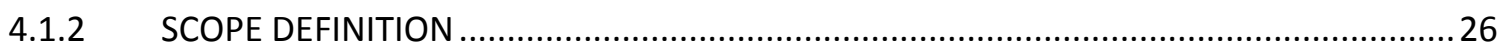

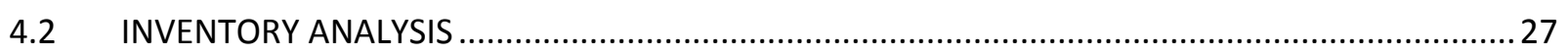

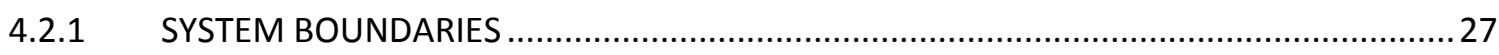

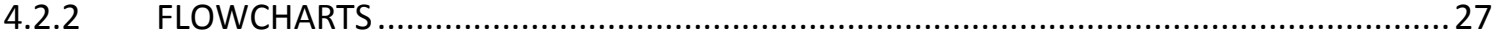

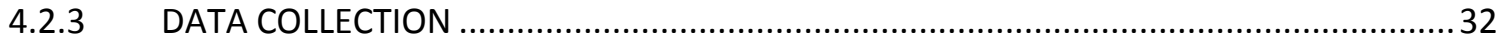

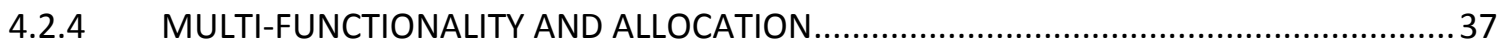

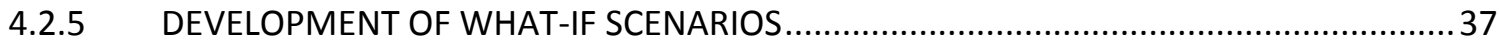

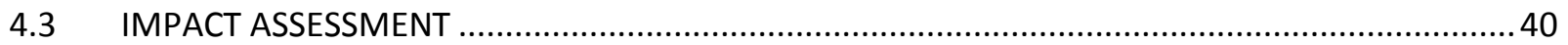

4.3.1 CLASSIFICATION, CHARACTERIZATION, AND NORMALIZATION ................................. 40

4.3.2 INTERVENTIONS FOR WHICH CHARACTERIZATION FACTORS ARE LACKING ................42

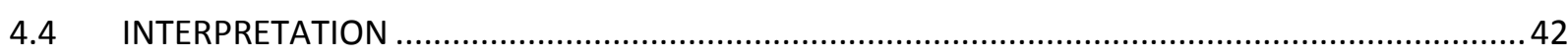

4.4.1 CONSISTENCY AND COMPLETENESS CHECK ........................................................... 42 


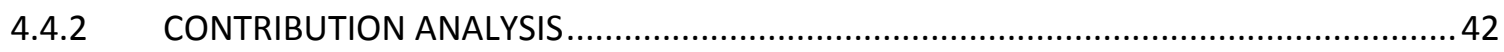

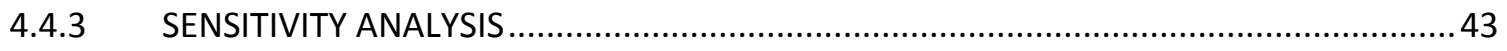

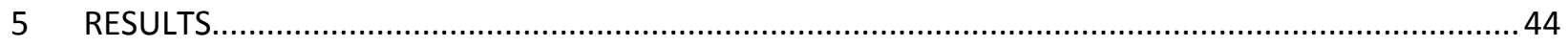

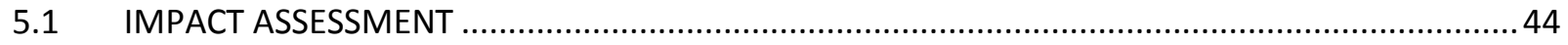

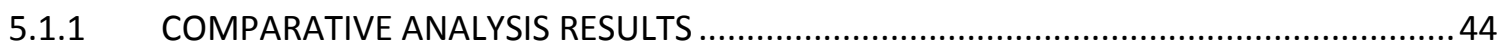

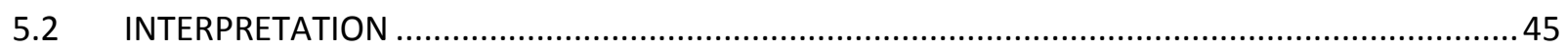

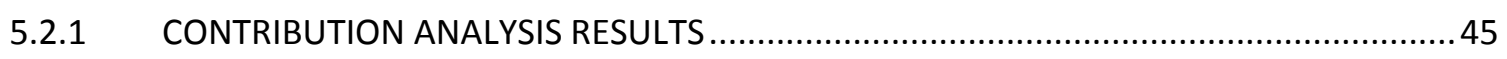

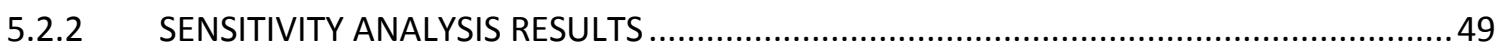

6 DISCUSSION

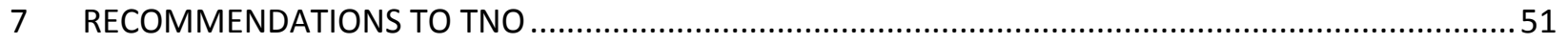

8 METHODOLOGICAL REFLECTION AND SUGGESTED IMPROVEMENTS..........................................52

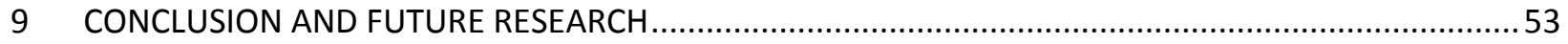

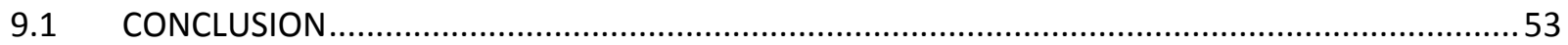

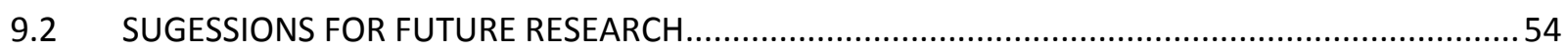

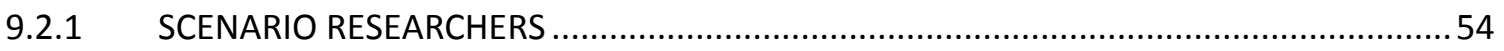

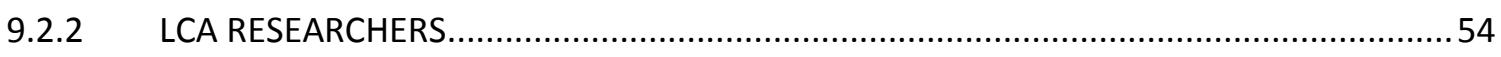

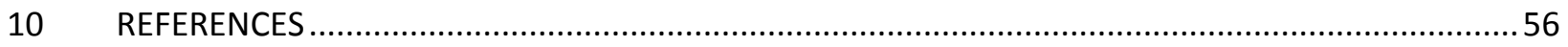

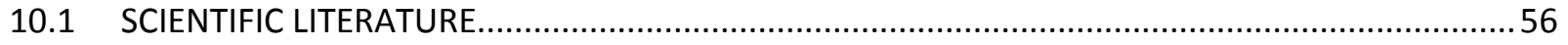

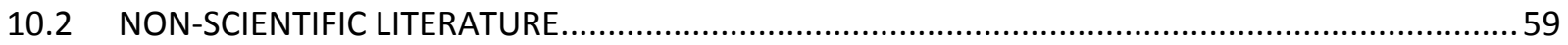

11 APPENDIX

11.1 APPENDIX A: MECHANIZM OF WORK OF ANTI-REFLECTIVE COATING ..................................62

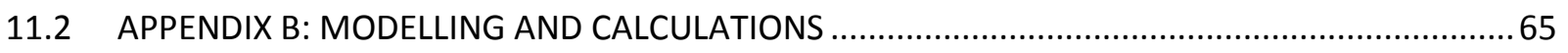

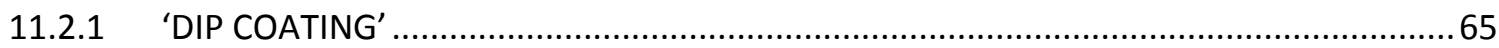

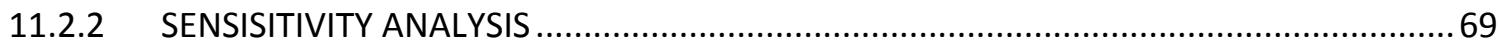

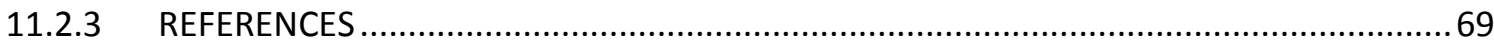

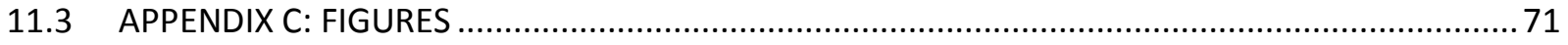

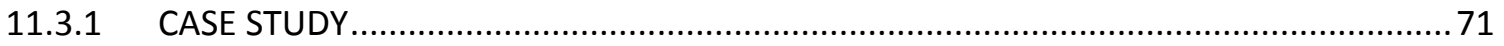

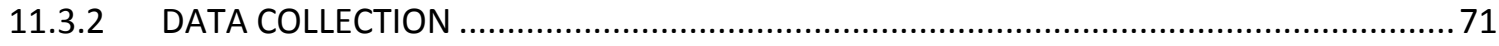

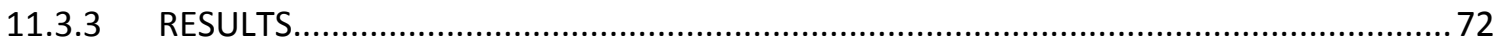

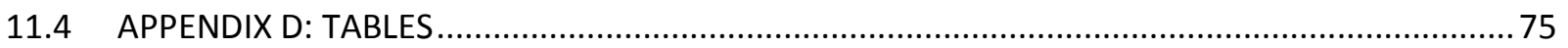

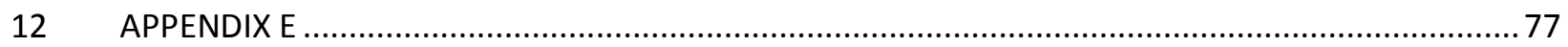




\section{ABSTRACT}

Innovation is essential for economic growth and sustainable development. Although novel technology can bring benefits and opportunities, it may cause undesirable consequences to environment and society. In order to prevent future ecological disadvantages, environmental analysis is carried out to estimate the impacts of a certain innovation. Environmental assessment of technologies is usually carried out when they have been already launched in the market. As a result, reoriention of the technological development towards better environmental performance in the later stages of Research and Development (R\&D) becomes more complicated. Anticipatory Life Cycle Assessment (LCA) has been developed as a framework to assess the environmental impacts of new technologies by exploring possible paths of the technological development.

The thesis project demonstrates the application of Anticipatory LCA for the analysis of the innovation at the early phase of R\&D. The aim of the following work is to guide the Netherlands Organization of Applied Scientific Research (TNO) coating innovation technology based on LCA impact results. The novel coating is being synthesized at laboratory scale and has a great potential to be launched in the market. The scenarios method was used to scale up the coating production process to pilot and industrial scales. The LCA results showed that the novel coating manufactured at industrial scale would have approximately the same environmental impacts as conventional coatings in the future. In this study, environmental impact of implementation of the new coating was studied with the help of Sensitivity analysis. Depending on feedstock and logistics, reductions could be achieved with respect to environmental impact while implementing the same innovation. 
Innovation is crucial for economic growth and sustainable development. A new technology can bring lots of benefits to society but at the same time can lead to unfavorable ecological consequences. Awareness of the need in the environmental analysis of technologies early in R\&D has been raised over recent years. Environmental assessment is usually conducted for the mature technologies and is not being effectively implemented at the early stages of the technological development. As a result, a problem of lock-in of the environmental impacts of novel technologies can emerge. Life Cycle Assessment (LCA) has been used as a framework for the analysis of the environmental implications of products/technologies and services considering the whole life-cycle starting from the raw material extraction until the end-oflife stage. Obstacles can be met in the application of LCA for the analysis of innovations as it is not able to solve the uncertainty issues related to them. LCA has been widely used in the assessment of technologies which have been already introduced into market, and is based on the collection of existing data. Anticipatory LCA was emerged as a new explorative and non-predictive approach for the assessment of innovations.

Anticipatory LCA was used as a framework to assess environmental performance of the coating innovation technology in the following thesis work. The new coating, referred as 'Dip coating' in this study, is being synthesized by the Netherlands Organization of Applied Scientific Research (TNO) at laboratory scale. The technology has not been commercially used yet. What-if scenarios method was applied to scale-up 'Dip coating' to pilot and industrial scales. Data for 'Dip coating' was collected from the laboratory at TNO, and then optimization of the laboratory parameters were done based on the contribution analysis results. Modified General Morphological Field was used in the development of What-if scenarios. The optimized parameters were discussed with the experts in the curing and glass coatings technologies from Delft University of Technology and TNO, respectively. LCA of three What-if scenarios 'Dip coating at laboratory scale', 'Dip coating at pilot scale', and 'Dip coating at industrial scale' was done, and the results were compared to the impacts of the reference alternatives such as 'Uncoated glass', 'Acid etching', and 'Sputtering'.

The LCA results show that 'Dip coating at industrial scale' scenario would have approximately the same environmental impacts as conventional coatings in the future. It should be noted that 'Uncoated glass' shows competitive results in terms of environmental impacts to other alternatives though it was expected that it would have significantly greater impacts than its counterparts. It can be concluded that coated glass does not bring noticeable advantages in the environmental performance of the greenhouse glass compared to 'Uncoated glass'. Instead, it has the economic benefits from the increased yield of tomatoes.

Sensitivity analysis of different technological development pathways for 'Dip coating' to achieve better environmental performance at industrial scale was done. Such options as slowing down of degradation time and increased light transmittance of the novel coating, change of the source of ethanol production from biomass to ethene, and the locations for glass production plant and coating factory were considered. The LCA results show that the case when the glass manufacturing plant is situated in the Netherlands rather than in China results in the lowest environmental impact results compared to other possible alternatives. 
The methodological pathway of Anticipatory LCA developed in this study was reviewed and some improvements were suggested. It could be recommended to perform stakeholder analysis at the start of the project as various stakeholders were actively participated in the work such as TNO, Universities, experts in the curing and coating technology, companies in greenhouse cleaning service, and coating factories. The stakeholder analysis would give the insights of their level of influence and interest in the project. Other possible stakeholders should be taken into account, and probably, they could participate in the development of the scenarios.

Data collection was performed using data from TNO, Ecoinvent V2.2 database, literature, and websites. Companies such as Poot Kasdekreiniging and Van der Waay shared required information via emails and phone conversations.

Some obstacles were met during the data collection for What-if scenarios. The attempt to get data for 'Dip coating' from the coating factories was unsuccessful as the companies could not share information due to the confidentiality issue. It could be recommended to contact other coating companies, and if the confidentiality issue is raised, then probably, consensus between the researcher and the company could be met, and this company could become the second commissioner.

Sensitivity analysis of other options for the technological development of 'Dip coating' could be analyzed in the future research. This would give a broader view of other possibilities of reduced impacts of 'Dip coating' in the future. 


\section{ACKNOWLEDGEMENTS}

I would like to express my deepest gratitude to ERASMUS MUNDUS Master's programme in Industrial Ecology (MIND) for giving me an opportunity of doing my Master's degree in Industrial Ecology at KarlFranzens University of Graz in Austria, Leiden University and Delft University of Technology in the Netherlands.

My warmest thanks to my primary thesis supervisor Dr. Valentina Prado, Assistant Professor at Institute of Environmental Sciences at Leiden University. Her guidance and support helped me to overcome obstacles during my research. Many thanks to my secondary thesis supervisor Dr. Jaco Quist, Assistant Professor at Technology, Policy, and Management at Delft University of Technology, for sharing his extensive experience in the scenarios development field.

My sincere appreciation is extended to my technical supervisor at TNO Dr. Aike Wypkema without whom this project would not be possible. I would like to thank Dr. Fidel Valega Mackenzie, Dr. Maurice Mourad, and Mr. Jonathan van den Ham at Materials Solutions at TNO, for the advices given to me during my thesis work. I am grateful to the department of Materials Solutions at TNO. It was a great pleasure to work there.

I am also thankful to Poot Kasdekreiniging and Van der Waay companies who contributed to my thesis. Thanks to Mr. Erik Poot from Poot Kasdekreiniging, Mr. Jony Ket and Mr. Tom Zwanenburg from Van der Waay who shared data for my thesis. 


\author{
ABBREVIATIONS \\ AC Acidification \\ ATP Adenosine Triphosphate \\ CC Climate Change \\ $\mathrm{CML}$ Institute of Environmental Sciences \\ CN China \\ DI Deionized \\ EU Eutrophication \\ FP Framework Programs \\ FAE Freshwater Aquatic Ecotoxicity \\ GMA General Morphological Analysis \\ HT Human Toxicity \\ ISO International Organization for Standardization \\ LCA Life Cycle Assessment \\ LU Land Use \\ MGMA Modified General Morphological Analysis \\ MIND ERASMUS MUNDUS Master's programme in Industrial Ecology \\ $\mathrm{NL}$ the Netherlands \\ OCE Oceanic \\ OTA Office of Technology Assessment \\ PO Photochemical Oxidation \\ R\&D Research and Development \\ RER Europe \\ TE Terrestrial Ecotoxicity \\ SOD Stratospheric Ozone Depletion \\ TNO Netherlands Organization for Applied Scientific Research \\ TPM Technology, Policy, and Management
}




\section{LIST OF FIGURES}

Figure 1.1. Production of float glass (Schittich et al., 2007) .14

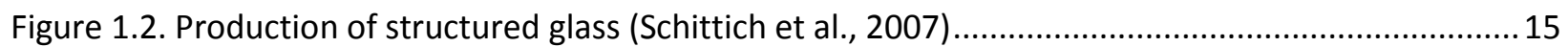

Figure 3.1. Stages of LCA (ISO 14040 International Standard, 2006) .................................................19

Figure 3.2. Intervention points for LCA and relevant actors as technology readiness increases (Wender et

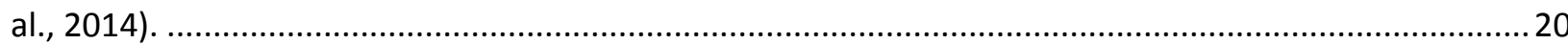

Figure 3.4. Scenario typology with three categories and six types (Börjeson et al., 2006) ........................22

Figure 4.1. Flowchart of the scope of the Anticipatory LCA for this study (author's image) ....................26

Figure 4.2. Flowchart for 'Uncoated glass' product system (author's image) ........................................28

Figure 4.3. Flowchart for 'Acid etching' product system (author's image) ............................................29

Figure 4.4. Flowchart for 'Sputtering' product system (author's image) ................................................ 30

Figure 4.5. Flowchart for 'Dip coating' product system (author's image) ...............................................31

Figure 4.6. Flowchart for sol-gel coating production unit process (author's image)..................................32

Figure 4.7. Shipment of glass from the port of Shanghai (A) to the port of Rotterdam (B) (Ports.com, n.d.)

Figure 4.8. DipMaster 201 and Heraeus D-6450 Hanau oven (Photo credits to Dr. Aike Wypkema and

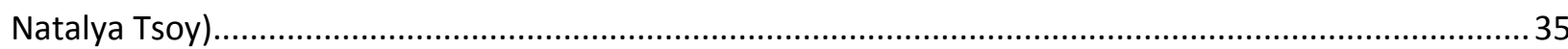

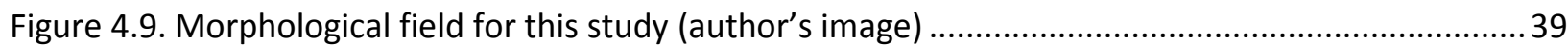

Figure 4.10. Yield of tomatoes obtained under 'Dip coating' over 30 years period (author's image) .......43

Figure 5.1. Comparative analysis of 'Dip coating' scenarios and the references (author's image)............45

Figure 5.2. Contribution analysis results of the processes for the references (author's image)................46

Figure 5.3. Contribution analysis results of coating production process for 'Acid etching' and 'Sputtering'

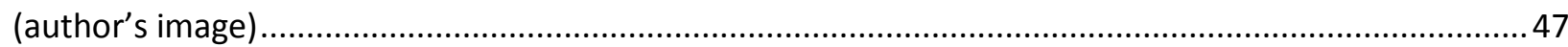

Figure 5.4. Contribution analysis of the processes for 'Dip coating' scenarios (author's image)...............48

Figure 5.5. Sensitivity analysis results for 'Dip coating at industrial scale' scenario (author's image)....... 49

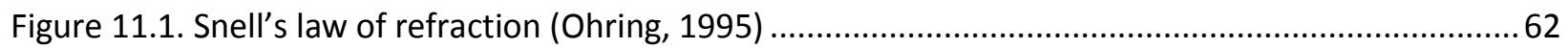

Figure 11.2. Destructive interference in anti-reflective coating (Quora, 2014). ....................................64

Figure 11.3. Locations of Greenports in the Netherlands (Greenport Holland, n.d.)..............................71

Figure 11.6. Van der Waay Aqua Jet roof cleaner (Van der Waay, n.d.-a) ..............................................71

Figure 11.7. Van der Waay Top roof cleaner (Van der Waay, n.d.-b) ......................................................72

Figure 11.8. Contribution analysis results of the processes for low-iron glass production (author's image)

Figure 11.9. Contribution analysis results for packing of greenhouse glass (author's image) ..................73

Figure 11.10. Contribution analysis of the use processes for the references (author's image).................73

Figure 11.11. Contribution analysis results of the use processes for 'Dip coating' (author's image) .........74 


\section{LIST OF TABLES}

Table 11.1 Weights of the wooden box parts used for transport of 20 sheets of $0.09 \mathrm{~m}^{2}$ float glass ....... 75

Table 11.2. Weights of the parts of Top Cleaner machine ....................................................................75

Table 11.3. Countries of electricity production and amounts of electricity required for coating production in different greenhouse glass life-cycle processes .................................................................................76 


\section{INTRODUCTION}

Innovations bring numbers of advantages to our lives but at the same time they can cause unfavorable impacts to environment and society. Those impacts were described comprehensively by Lord Robert Winston in his book "Bad Ideas? An arresting history of our inventions" (Winston, 2010). Thus, there should be "... a growing awareness of the need to innovate, but to innovate responsibly" (Owen et al., 2009 , p. 6902). Numbers of works call for the changes in agency regarding the ways of how science is being developed (Gibbons et al., 1994; Gorman et al., 2004; Fisher et al., 2006). Risk identification at the early phase in Research and Development (R\&D) is one of the important stages for the prevention of undesirable consequences in the future (Sutcliffe, 2011). Methods for quantifying the environmental impacts of technologies should be used in the avoidance of possible environmental issues. However, environmental assessment has not been effectively practiced early in R\&D, and this can cause at least three issues (Wender et al., 2014):

1. Most of the environmental impacts of innovations can be locked in by early R\&D decisions (Bhander et al., 2003).

2. There is less possibility to transform the technology development towards its better environmental performance in the later phases of the development (Stilgoe et al., 2013).

3. The environmental regulations are retrospective (Owen and Goldberg, 2010).

Life Cycle Assessment (LCA) has been proposed as a framework for the environmental analysis in Responsible Research and Innovation, but it needs to overcome some hurdles. Regular LCA cannot be used directly in the analysis of innovations. Initially it was designed with the purpose to evaluate the environmental impacts of existing technologies, and therefore, is retrospective in nature (Villares, et al., 2017). Modifications have been added to the LCA procedure by a number of LCA experts to make it suitable for the analysis of novel technologies. Those approaches include scaling-up techniques, scenario methods, and combination of LCA with other research fields. These advances in LCA fall under Prospective or/and Anticipatory LCA, both of which cater to new technologies.

Distinctions should be made between Prospective and Anticipatory LCAs. Prospective LCA takes a more predictive approach, it does not necessarily take uncertainty into account and does not involve comparison. In contrast, Anticipatory LCA has a more explorative approach to the potential of the technology development, it does include uncertainty, and it is done on a comparative basis.

Wender et al. (2014) pointed out that Prospective LCA has its disadvantages: the problem is that this assessment is based on the tools which try to predict the future models, and thus, uncertainty remains as one of the main issues. The authors introduced Anticipatory LCA as a new framework to evaluate the environmental performance of the emerging technologies (Wender et al., 2014).

Anticipatory LCA will be used in this research project to evaluate the environmental implications of innovation. The aim of the research is to guide the Netherlands Organization for Applied Scientific Research (TNO) coating technology development towards environmental improvements. This goal lies in accordance to Responsible Research Innovation and Technology Assessment concepts. 


\subsection{RESEARCH AIM AND RESEARCH QUESTION}

More realization of the need of the environmental analysis of technologies at the early phase of their development has been grown over the past decades. Environmental assessment of innovations has not been successfully implemented early on R\&D. LCA has been widely used in the analysis in various applications and has been recognized as a reliable type of assessment of the environmental impacts of technologies. However, regular LCA is not applicable for the analysis of innovations due to the fact that it relies on the data collected from mature technologies and cannot solve the problem related to uncertainties. Anticipatory LCA has been proposed as a framework which allows to explore possible environmental impacts of novel technologies.

The aim of the research will be to guide R\&D of TNO coating technology towards improved environmental performance based on the Anticipatory LCA results. Anticipatory LCA of sol-gel derived anti-reflective coating for greenhouse glass innovated by TNO and reference alternatives such as uncoated greenhouse glass, coatings manufactured by acid etching and sputtering methods will be performed. In this thesis work, these alternatives will be referred as 'Dip coating', 'Uncoated glass', 'Acid etching', and 'Sputtering', respectively. The main research question for this work is formulated as follows:

"What are the possible paths which could lead to improved environmental performance of 'Dip coating' in the future?"

'Dip coating' is produced at laboratory scale and has not been launched in the market yet, thus, scenarios will be developed in order to scale-up 'Dip coating' to pilot and industrial scales. Anticipatory LCA results will give the insights on which changes could be added to the processes of 'Dip coating' in order to decrease the environmental impacts of the coating in the larger scale.

\subsection{CASE STUDY}

\subsubsection{ANTI-REFLECTIVE COATINGS FOR GREENHOUSE GLASS}

Greenhouse horticulture is one of the technologies that will provide sufficient, sustainable and good quality food and ornamental plants for the global population in the future (Holland, 2016). The Netherlands is a world-leader in the greenhouse horticultural sector, producing $24 \%$ of the world trade of horticultural products (horti daily, 2016). The Netherlands has six greenports: Greenport WestlandOostland, Greenport Venlo, Greenport Aalsmeer, Greenport Duin en Bollenstreek, Greenport Boskoop, and Greenport Noord-Holland Noord (Appendix C, Figure 11.3). Tomatoes are the most commonly grown type of crop grown in Dutch greenhouses. The Netherlands is the second largest exporter of tomatoes in the world (Phillips, 2016). In this LCA study, production of tomatoes under different types of greenhouse glass will be considered for the modelling of the use process.

In the Netherlands, a country where there is a low intensity of natural light, especially in winter seasons, it is essential for the greenhouses to have the maximum possible light transmittance. The absorbed light is used by plants for the production of energy in the form of Adenosine triphosphate (ATP) which is essential for their life maintenance and growth. Light intensity is one of the most important factors for crop yield. It was reported that the increase of light by $1 \%$ results in the plant yield gain by $0.5 \%$ to $1 \%$ for most of the greenhouse crops (Marcelis et al., 2005). One of the problems in greenhouses, is that by protecting the crops, the glass can also result in decreased light transmittance. 
Anti-reflective coatings are glass coatings which have an ability of reducing the reflectivity of glass allowing greater amount of light to come inside the greenhouse than regular float. The mechanism of the work of anti-reflective coating is described in Appendix A. Various types of anti-reflective coatings are commercially used. They are manufactured via different techniques. The most common methods for the production of anti-reflective coatings for glass are acid etching and sputtering. It was reported that the use of anti-reflective coatings results in an increased light transmittance by $6.2 \%$ which leads to the gain of the tomatoes yield by $8.4 \%$ (Hemming et al., 2009). In this research, 'Uncoated glass', 'Acid etching', and 'Sputtering' serve as the references for LCA analysis. 'Uncoated glass' was included as a reference in this LCA analysis in order to see if there is the advantage of using anti-reflective coatings from the environmental point of view as their performance will be compared based on the amount of tomatoes produced under a greenhouse glass. The choice of 'Acid etching' and 'Sputtering' as the references was made due to the fact that these two methods are one of the most widely produced coatings nowadays. The descriptions of the references and the novel coating, which will be analyzed in this LCA study, are given in the following sections.

\subsubsection{1 'UNCOATED GLASS'}

Soda lime glass is a type of glass which is used for the float glass production (Shelby, 2005, p. 262). In greenhouses, a special type of glass such as structured soda lime glass with the low iron content is usually used to cover greenhouses. The production of float glass is divided into the processes such as raw material feed, melting, forming of the molten glass on the bath of liquid tin, and annealing (Figure 1.1). The manufacturing of structured glass consists of the same production processes as in the float glass production except of the forming step which is replaced by the patterning phase (Schittich et al., 2007) (Figure 1.2). In this process, molten glass flows through the rollers which provide pattern to the glass surface. The structured surface results in the diffused light going into the greenhouse which is more preferable for plants. The light can reach not only the top of the crop but penetrate deeper into it increasing photosynthetically active leaf area, and thus, increase the production yield of tomatoes by 7 to $9 \%$ compared to that obtained under float glass (Dueck et al., 2012). In this thesis work, it is assumed that the light transmittance of structured low-iron glass 'Uncoated glass' is $90.3 \%$, and the yield of tomatoes obtained under 'Uncoated glass' is $54 \mathrm{~kg} / \mathrm{m}^{2}$ per year (Hemming et al., 2009).

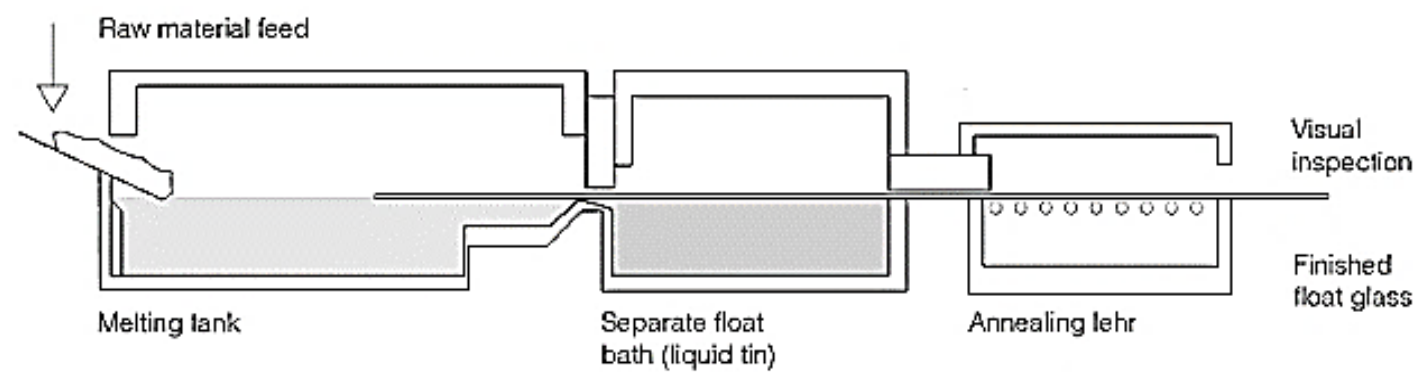

Figure 1.1. Production of float glass (Schittich et al., 2007) 


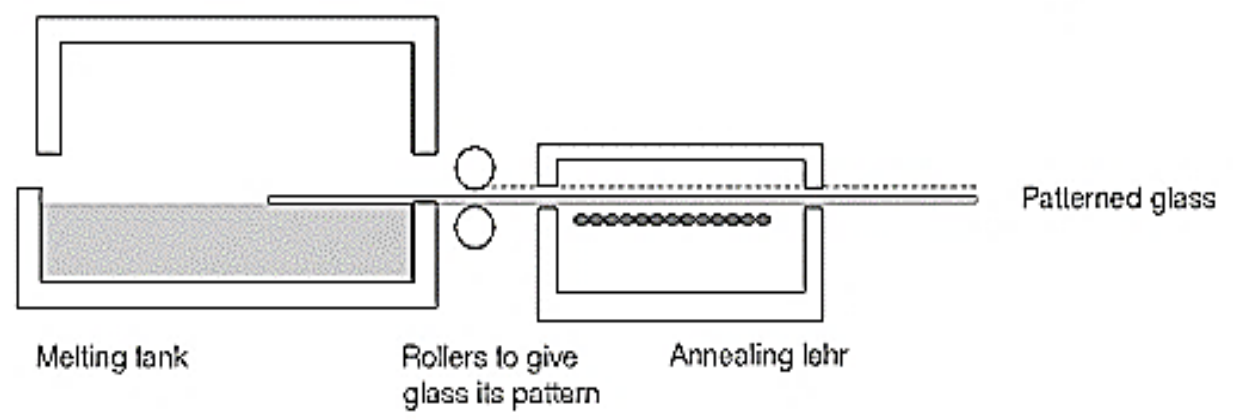

Figure 1.2. Production of structured glass (Schittich et al., 2007)

Structured low-iron glass can be covered by the anti-reflective coating so that transmittance could be improved up to $96.5 \%$, and the production yield of tomatoes could be increased by $8.4 \%$ per $1 \mathrm{~m}^{2}$ of glass (Hemming et al., 2009).

\subsubsection{2 'ACID ETCHING'}

One of the most widely used methods for the production of anti-reflective coating in the commercial scale is acid etching technique. In this method, the structured low-iron glass is immersed into the bath filled with fluosilicic acid solution, pulled out, and then rinsed with water (Pastirik, 1980). The soda lime glass is mainly composed of silica, sodium oxide, and calcium oxide (Shelby, 2005, p. 265). In the acid etching process, fluosilicic acid is used to remove soda-lime components from the glass surface leaving silica $\left(\mathrm{SiO}_{2}\right)$ structure unaffected to create the anti-reflective coating (Zuel, 1990).

\subsubsection{3 'SPUTTERING'}

Sputtering is another widely-used method for production of the anti-reflective coating on glass. In this process, a negative potential difference is applied between a cathode with the target and an anode with glass in the argon gas environment (Frey and Khan, 2010, p. 143). The electrons released from the target interact with the argon atoms and ionize them. The positively charged argon ions strike the target, causing sputtering and creating a coating on the glass surface (Oxford Vacuum Science, n.d.). A special type of sputtering method called Reactive sputtering is used to produce silica coating on glass surface. In this technique, oxygen gas is introduced into the inert argon environment. It reacts with the silicon atoms eroded from the target during the coating formation on the substrate (Monaco, 2016). As a result, $\mathrm{SiO}_{2}$ coating with a low refractive index is produced.

\subsubsection{4 'DIP COATING'}

Scientists are starting to apply dip coating technique for the production of the anti-reflective coating for glass as an alternative to acid etching and sputtering methods. It is predicted to be more environmentally friendly than acid etching technique and cheaper than sputtering method which requires expensive equipment. It is being tested for the production of anti-reflective coatings mostly at laboratory scale and has been started to be implemented at industrial scale recently (Aegerter and Mennig, 2013, p. 197). 
The Netherlands Organization for Applied Scientific Research (TNO) is a research organization that develops innovations which promote sustainable industry (TNO, 2016). The main research focus of TNO is applied science. Currently Materials Solutions at TNO in Eindhoven is developing the innovations in glass coatings for greenhouses. In one of the projects, TNO is testing dip coating method for the synthesis of sol-gel derived anti-reflective coatings. Sol-gel anti-reflective coating is produced by dipping the glass into solution of polymeric inorganic precursors (Brinker, 1991). A porous thin coating with the required refractive index can be obtained depending on the polymeric precursors used. The coated glass is dried at $50^{\circ} \mathrm{C}$ for $30 \mathrm{~min}$, and then cured at $400^{\circ} \mathrm{C}$ for 1 hour in the oven. The details of the preparation of sol-gel solution is not reported here as the information is confidential. The advantages of 'Dip coating' produced by TNO are predicted to be as follows:

1. 'Dip coating' is expected to have the light transmittance of $99 \%$ which is higher than that of 'Acid etching' and 'Sputtering'.

The conventional anti-reflective coatings have the light transmittance of $96.5 \%$. The increased light transmittance of 'Dip coating' will result in the increased gain of the tomatoes yield.

2. 'Dip coating' is predicted to have decreased degradation time than that of 'Acid etching' and 'Sputtering'.

The anti-reflective coatings degrade after 10 years. The greenhouse companies usually do not dispose greenhouse glass after 10 years but continue to use it for approximately 20 more years. As a result, the yield of tomatoes decreases over time with the reduction of light transmittance of the glass. Slowing down the degradation time of 'Dip coating' will lead to the increased mass of tomatoes. For example, if the degradation of 'Dip coating' is after 20 years rather than 10 years, the yield of tomatoes will be $1731.23 \mathrm{~kg}$ instead of $1708.53 \mathrm{~kg} / \mathrm{m}^{2}$ over 30 years period.

3. 'Dip coating' is expected to cost less compared to 'Sputtering'. Dip coating is a simple method, and does not require a complex equipment set up compared to the sputtering technique. This study will focus on the environmental assessment of the anti-reflective coatings, and the cost analysis is out of scope in this research project.

\subsubsection{ENVIRONMENTAL ASSESSMENT OF COATINGS}

TNO aims at producing a coating which would be environmentally friendly, and thus, it is essential that it would have lower environmental impacts compared to conventional coatings implemented in the market. Studies on the examination of the environmental performance of different greenhouse glass coatings were done in literature. In those research works, the focus was mostly on the $\mathrm{CO}_{2}$ emission and energy related issues. They did not analyze multiple impact categories and did not cover different processes through the whole life-cycle of the coatings. For example, Hemming et al. (2009) calculated $\mathrm{CO}_{2}$ concentration and energy consumption under different glass coatings using KASPRO model, a simulator which analyzes the optimum design for a greenhouse (FutureAg, 2014). It is essential to use a life-cycle approach in the analysis of the greenhouse coatings because the decision on the best coating in terms of the environmental performance could not be based by evaluating only one of the processes of the life-cycle. For instance, there could be a possibility that one of the alternatives could be more environmentally friendly in the production phase, but have high impacts in the end-of-life stage. Also, there could be a case that improved performance of the greenhouse glass is not compensated by more intensive manufacturing process. Consideration of the multiple impact categories is also important in 
the analysis. There could be a probability that the glass coatings could have different environmental performance regarding particular impact category. For example, one of the coatings could perform environmentally better in one impact category but worse in another. Identifying this is key in avoiding burden shifting.

A limited number of LCA studies of the coatings for the greenhouse glass was done in literature. One of the most recent one was performed by Pini et al. (2017). They conducted an LCA study of $\mathrm{TiO}_{2}$ nanoparticles self-cleaning coated glass produced by dip coating method covering different life-cycle stages of the coated glass and impact categories. The authors performed scaling-up of coated glass in order to compare its environmental performance to uncoated float glass using different life-time scenarios. The scaling-up of the production phase of the $\mathrm{TiO}_{2}$ coated glass from the laboratory scale to the industrial scale was done by first linear extrapolation. The highest environmental burden of the coated glass was at the production phase.

This study, to best of the author's knowledge, will be the first research on the Anticipatory LCA of sol-gel anti-reflective coating for greenhouse glass produced by dip coating method. The environmental performance of 'Dip coating' and reference alternatives will be compared. A whole range of the lifecycle stages and the impact categories will be evaluated. Scenarios will be used to scale-up 'Dip coating' to pilot and industrial scales. In this study, Sensitivity analysis will be performed to explore the paths of the implementation of 'Dip coating' which could lead to the decreased environmental impacts of the coating.

\section{OUTLINE OF THIS REPORT}

This section presents the structure of the thesis work. First of all, literature on the theoretical concepts relevant for this study will be reviewed to give the background information to a reader. The literature review will be started by the definition of Regular and Anticipatory LCAs. The description of the scenarios will be divided into two parts. The first part will give an overview of different types of scenarios and the reason of why particularly What-if scenarios were chosen among other types of scenarios for this study, and the second part describes Modified General Morphological Analysis, the methodology which was applied to structure the development of What-if scenarios. The last section of the literature review will be concluded by the description of Responsible Research Innovation and Technology Assessment. It is important to cover those two research fields as they share the same aim as Anticipatory LCA which is the guidance of R\&D towards sustainable development.

Secondly, the methodology of Anticipatory LCA will be discussed. The methodology part will describe LCA which is based on ISO 14040 framework and What-if scenarios development. In Anticipatory LCA analysis, the LCA impact results of the references and scenarios for 'Dip coating' will be compared assuming that the light transmittance of the coatings is the same $96.5 \%$. The cases of the increased light transmittance to $99 \%$ and slowing down of the degradation time for 'Dip coating' will be considered in Sensitivity analysis. Also, other options for the possibility of reducing the impact results of 'Dip coating' will be analyzed. After that the results of Anticipatory LCA will be discussed and recommendations to TNO will be given. Methodological reflection will be provided and suggestions for the improvements of the research will be drawn. Conclusion will be followed by the suggestions for future research for scenario and LCA researchers. 


\section{LITERATURE REVIEW: THEORETICAL CONCEPTS}

\subsubsection{LIFE CYCLE ASSESSMENT}

Life Cycle Assessment (LCA) is a methodological framework which analyzes environmental implications of a product or service throughout its life-cycle considering different processes covering a range of different impact categories (Guinée et al., 2002). Great number of researchers have used LCA for the environmental assessment of technologies worldwide. In order to avoid arbitrariness ISO 14040 International Standard (2006) introduced a standardized procedure for LCA. According to ISO 14040, four phases can be distinguished in LCA: 1) Goal and Scope definition, 2) Inventory Analysis, 3) Impact Assessment, and 4) Interpretation. Figure 3.1 depicts the framework of LCA.

1. Goal and Scope definition Goal definition describes the reasons for conducting the research, its application, and the target audience. The aim of scope definition is to determine a system boundary of the research, to define function, functional unit, alternatives, and reference flows of the product system, and to discuss data requirements and limitations.

2. Life Cycle Inventory Analysis

Life Cycle Inventory Analysis includes data collection and quantification of the inputs and outputs of the product system. As a result, the inventory table which reports on the environmental interventions of the product system is generated (Guinée et al., 2002). Life Cycle Inventory Analysis is an iterative phase so that changes in the procedure of the data collection could be made due to the emergence of new data requirements or limitations but at the same time Life Cycle Inventory Analysis still should meet the LCA goals. There could be a case when the goal and scope are needed to be revised.

3. Life Cycle Impact Assessment

Life Cycle Impact Assessment reports on the environmental impacts of the product system regarding specific impact categories. In this phase, those impact results are calculated using data from the inventory table. It is an iterative process so that goal and scope could be reviewed to check if they are in accordance with them. Also, changes could be made in the scope and goal definition if the analysis shows that they cannot be met.

4. Life Cycle Interpretation

Life Cycle Interpretation is present in all of the phases of LCA. In general, this stage includes an iterative process of reviewing goal and scope of the study, evaluates the data quality which was collected during Life Cycle Inventory Analysis, and involves recommendations and conclusions based on the Life Cycle Impact Assessment environmental impact results. 


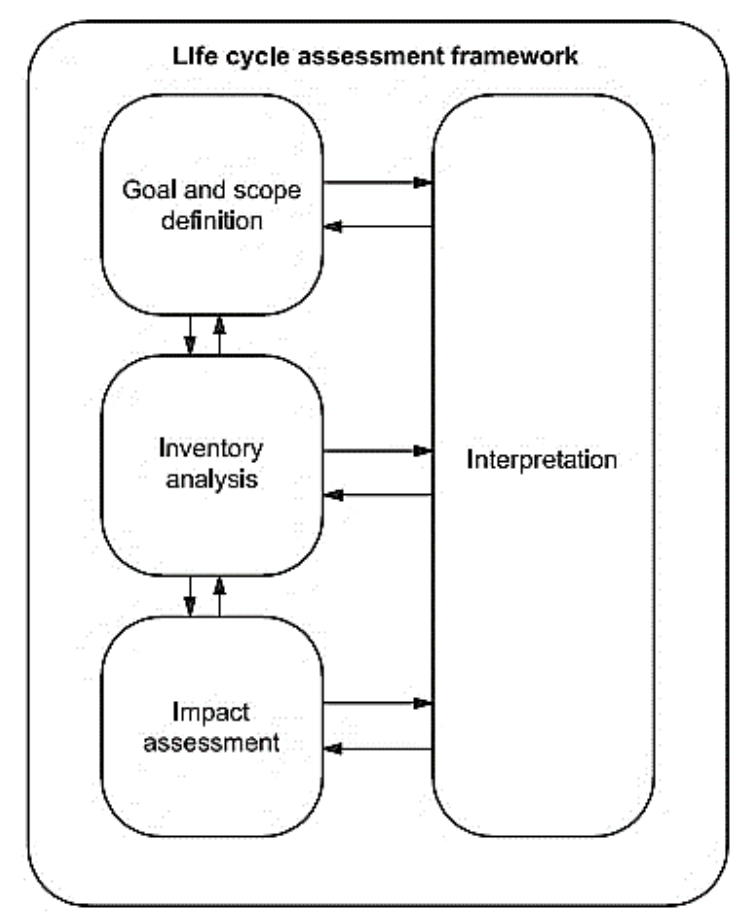

Figure 3.1. Stages of LCA (ISO 14040 International Standard, 2006)

Problems could arise using LCA in the analysis of emerging technologies as LCA is retrospective in nature. The original purpose of LCA was to analyze technologies which had been already commercialized. According to Wender et al. (2014), Retrospective LCA cannot be considered to be as an effective framework for Responsible Research and Innovation for at least two reasons:

1. Retrospective LCA is based on existing data collected from mature industries.

2. Retrospective LCA underemphasizes the importance of stakeholder participation.

Retrospective LCA cannot be applied in this case study as difficulties could arise due to the novelty of 'Dip coating'. In this work, Anticipatory LCA will be used to perform environmental analysis of the new technology.

\subsubsection{ANTICIPATORY LCA}

Wender et al. (2014) introduced Anticipatory LCA as a new approach for the analysis of the environmental implications of novel technologies. Anticipatory LCA is a forward-looking and nonpredictive method that expands uncertainty of the model using tools in prospective modelling and social perspectives. Anticipatory LCA is used not to make predictions but to prepare for the future. The use of this method in the early stage of the technology development could provide useful guidelines for Responsible Research and Innovation. Figure 3.2 describes a stage-gate model of the innovation development as its market readiness increases. It shows the actors involved in each stage and intervention points of Retrospective and Anticipatory LCAs. The innovation development undergoes three main stages such as bench scale, pilot scale, and commercial scale. The product passes through the gates (dotted lines) when certain requirements, e.g. legal, financial and technical, are met. Using Retrospective LCA after the market launch of innovation can result in temporal delays and technology lock-in. In contrast, Anticipatory LCA which is applied early in R\&D, enables to overcome those issues 
and reorganize research agenda by introducing broader environmental criteria into bench-scale stage, and as a result, can advance science (Wender et al., 2014).

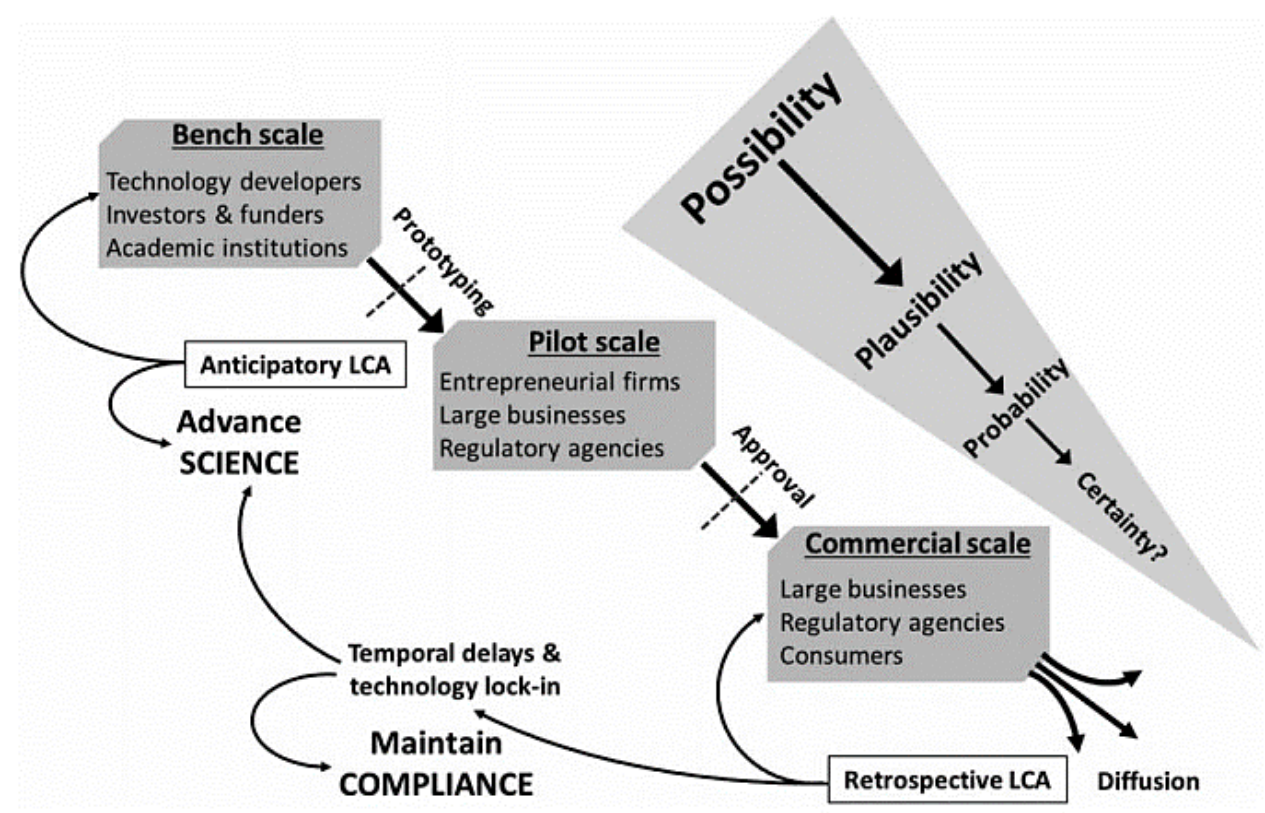

Figure 3.2. Intervention points for $L C A$ and relevant actors as technology readiness increases (Wender et al., 2014).

This study will apply Anticipatory LCA for the evaluation of 'Dip coating' as this framework is considered to be appropriate to explore the possible environmental impacts of the innovation at the early phase of its R\&D. Scenarios will help to explore the possibilities in Anticipatory LCA.

\subsubsection{MODIFIED GENERAL MORPHOLOGICAL ANALYSIS}

A framework which provides a structured methodology for the development of scenarios should be used. General Morphological Analysis (GMA) has been recognized as the appropriate methodology for the development of scenarios. Ritchey $(2011$, p.8) gives a comprehensive overview of GMA in his book "Wicked problems-social messes: Decision support modelling with morphological analysis", and defines GMA as '...a method for structuring and investigating the total set of relationships contained in multidimensional, non-quantifiable, problem complexes". GMA is composed of several iterative steps (Baran, 2016 , p. 267). Firstly, the variables which define the essential nature of scenario the best are determined, then a range of conditions for each variable is selected. Morphological field, a matrix composed of variables and variable conditions, is constructed. The consistency check is performed, and the solution space is generated. Iteration of the process is done if needed. In this matrix, cells in grey and white represent variables and variable conditions respectively, and cells in black show resulted combinations which could be used for scenarios.

A facilitated group plays a crucial role in GMA as besides of structuring the complex problem, shared concepts and common framework should be developed (Ritchey, 2011, p.14). According to Ritchey (2011, p.14), a specialist group should be composed of no more than six to seven persons, and they should participate between two to ten workshop days. Such workshops cannot be organized for 
GMA for this study due to the time constraints. In this research, Modified General Morphological Analysis (MGMA) will be performed. MGMA is the method derived from GMA and is composed of the same iterative phases. The difference between MGMA and GMA is that in MGMA, the facilitators are allowed to assist in the pre-selection of one or two variables and related variable conditions, and are not involved in the next steps of the modelling (Baran, 2016, p. 268). In this project, the variables and variable conditions will be selected to construct What-if scenarios for 'Dip coating' at laboratory, pilot, and industrial scales. Then MGMA will be discussed with Dr. Aike Wypkema, Professor at Material Solution at TNO.

\subsubsection{SCENARIO DEVELOPMENT}

Scenarios have been widely applied in LCA in order to predict or explore future environmental impacts of novel technologies. In general, they can be divided into three main types such as Predictive, Explorative, and Normative (Börjeson et al., 2006). Each of those scenarios are divided into two different types: Forecasts and What-if, External and Strategic, Preserving and Transforming, respectively (Figure 3.4).

\section{1) Predictive scenarios}

The purpose of Predictive scenarios is to foresee what is likely to be in the future based on present trends. They respond to the question "What will happen?" Two different types within this category are distinguished: Forecasts and What-if scenarios:

a) Forecasts aim to predict the future development if the likely development unfolds. This kind of scenarios is more suitable for the cases when the uncertainty level of the development is low. They are more often applied in Prospective LCA studies and for a short time frame.

b) What-if scenarios examine what will be in the future if some specified events happen. Whatif scenarios are usually composed of forecasts among which none of them could be necessarily treated as the most likely to unfold in the future. Those forecasts could be bifurcated from one event, and therefore, might be significantly different to each other. What-if scenarios are often designed for the short-term time frame.

\section{2) Explorative scenarios}

The aim of Explorative scenarios is to determine what can probably happen, and seek an answer to the question "What can happen?" Explorative scenarios are used to examine possible developments using a set of scenarios. From this perspective, this category of scenarios resembles What-if scenarios, however, explorative scenarios are used for a long-term time frame and often have their starting point in the future rather than at present as in What-if scenarios. Explorative scenarios are divided into two types which are External and Strategic:

a) External scenarios focus on the factors which are independent of the relevant actors. They answer the question: "What can happen to the development of external factors?"

b) Strategic scenarios are used with the aim to see potential results of strategic decisions. They respond to the question: "What can happen if we act in a certain way?" They can be used to explore internal factors (factors which it can influence) and external factors.

3) Normative scenarios are concerned about the future objectives and the ways of how those could be achieved. They look for an answer to the question: "How can a specific target be reached?" It is composed of Preserving and Transforming scenarios: 
a. Preserving scenarios are applied to explore the approaches of how the target could be reached efficiently (usually cost-efficiently). They seek an answer to the question: "How can the target be reached, by adjustments to current situation?" More often, they have a longtime perspective.

b. Transforming scenarios, e.g. Backcasting, result in the target-fulfilling approaches and show which changes should be made in order to reach the target. Transforming scenarios answer the question: "How can the target be reached, when the prevailing structure blocks necessary changes?" Backcasting can be used in Anticipatory LCA. It enables to cover longer time frame compared to other kinds of scenarios mentioned above. It is system oriented, often participatory, and is appropriate to be applied to sustainability (Quist, 2013).

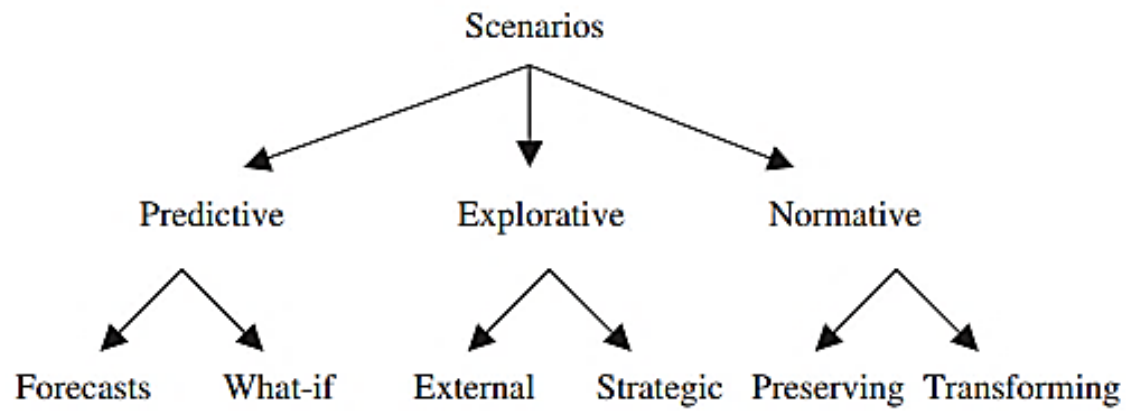

Figure 3.3. Scenario typology with three categories and six types (Börjeson et al., 2006)

Each of the previously discussed types of scenarios can be applied specifically to a certain case study. For example, Backcasting cannot be used for Anticipatory LCA of 'Dip coating'. The issue is that LCA of 'Dip coating' involves assessment of a specific product the technological development of which does not involve different options of complex contextual environment. In this regard, the purpose of the study is to analyze possible environmental impacts of 'Dip coating' technological development which will unfold in the most likely way in the future. Based on the results of LCA of these scenarios, recommendations could be drawn on which steps could be made by TNO in order to reach the improved environmental performance of 'Dip coating'.

Simplified What-if scenarios will be used in Anticipatory LCA to evaluate the environmental impacts of 'Dip coating'. What-if scenarios are preferred over other types of scenarios because the scope of the thesis is to explore the main possible environmental outcomes of 'Dip coating' in the short-term frame. What-if scenarios are usually used to assess under which conditions particular types of events could happen, and then to explore how to deal with them in today's decision-making processes (Swart et al., 2004). TNO is synthesizing 'Dip coating' at laboratory scale, and thus, one of the aims of the LCA research is to explore what will be in the future if 'Dip coating' is manufactured at larger scales in terms of the environmental impacts. Three scenarios such as 'Dip coating at laboratory scale', 'Dip coating at pilot scale', and 'Dip coating at industrial scale' will be developed. Those scenarios will answer the questions: 
1) "Which environmental impacts will be caused by 'Dip coating' in the condition if 'Dip coating' is produced at laboratory scale?"

2) "Which environmental impacts will be caused by 'Dip coating' in the condition if 'Dip coating' is produced at pilot scale?"

3) "Which environmental impacts will be caused by 'Dip coating' in the condition if 'Dip coating' is produced at industrial scale?"

Scenarios will be constructed to examine the case study for the short-term time frame covering 30 years period. Based on the Sensitivity analysis results for 'Dip coating at industrial scale' scenario, recommendations will be drawn on how the environmental performance of Dip coating could be improved.

\subsubsection{RESPONSIBLE RESEARCH AND INNOVATION AND TECHNOLOGY ASSESSMENT}

Anticipatory LCA of this research shares the concept of Responsible Research and Innovation and Technology Assessment. According to Grunwald (2014, p.16), "Responsible Innovation brings together TA (Technology Assessment) with its experiences on assessment procedures, actor involvement, foresighting and evaluation with engineering ethics, in particular under the framework of responsibility". In this project, Anticipatory LCA combines the approaches of LCA as one of the methods of the analysis of Technology Assessment (Van Den Ende et al., 1998, p.9), involvement of TNO researchers, and the use of scenarios for the foresighting purposes.

Responsible Research and Innovation has raised attention in the political discourse regarding $R \& D$ in the European Union. Its concept takes its roots as far back as the European Framework Programs (FP) for Research and Technological Development. The main focus was on the Ethical, Legal and Social Aspects of research in FP2 (1987-1991), integration of the socio-economic dimensions in FP4 (19941998), and socio-technical integration: FP5 (1998-2002), FP6 (2002-2006) and FP7 (2007-2013) (Rodríguez et al., 2013). It was the Directorate-General Research workshop held in Brussels on 16-17 May 2011 where the first public statements pointed out the importance of Responsible Research and Innovation in the European policy (Owen et al., 2012). The aim of this meeting was to gather key stakeholders in Europe to develop a shared understanding of Responsible Research and Innovation and create policy recommendations in accordance to it (European Commission, 2011a). Later another workshop on Responsible Research and Innovation was carried out at the French Embassy in London on 23-24 May in 2011 (France in the UK, 2011). In this event, the working definition of Responsible Research and Innovation was formulated by René von Schomberg: "Responsible Research and Innovation is a transparent, interactive process by which societal actors and innovators become mutually responsive to each other with a view to the (ethical) acceptability, sustainability and societal desirability of the innovation process and its marketable products (in order to allow a proper embedding of scientific and technological advances in our society)" (von Schomberg, 2012, p. 9). Responsible Research and Innovation continues to be one of the essential elements in the technology development in Europe. Recently, European Commission defined Responsible Research and Innovation as the main key action for one of the objectives of Research and Technological Development program called "Horizon 2020" (European Commission; December 13, 2016). The assessment of risks associated to 
novel technology through the innovation cycle is highly important in Responsible Research and Innovation (Hellström, 2003).

Technology Assessment is one of the approaches used for the analysis of the technological development. The concept of Technology Assessment has changed over time. Originally it was initiated by the U.S. Congress to provide an early warning system of the future unfavorable impacts of new technology (Coates, 2001). The Office of Technology Assessment was established in 1972 with the aim to study the technological consequences and guide the Congress on the policy-making process (Hill, 1996, June). At that time, Technology Assessment was based on Technological determinism and was focused on forecasting of the technological impacts and policy advice (Grunwald and Achternbosch, 2013). Technological determinism focused society on how to adapt to technological changes but not on how to shape it, arguing that technology changes either following science or of its own accord (Donald and Wajcman, 1986). This view changed in the 1980s when a theory of Social Constructivism emerged in opposition to deterministic believes claiming that technology can be built based on the societal values (Bijker et al., 1987). Social Constructivism states that technologies evolve as the result of choice of "relevant social groups" (Pinch and Bijker, 1984). Nowadays Technology Assessment guides on how to overcome the difficulties regarding society and technology on both directions: it evaluates future impacts of technology, and also introduces society's expectations regarding novel technology into relevant decision-making (Grunwald and Achternbosch, 2013). Numbers of Technology Assessment studies have been done to analyze technological development in recent years. Andersson and Jacobsson (2000) combined technology, market, and actor dynamics to evaluate development paths of solar cells in the future. Hillman and Sandén (2008) used socio-technical scenarios to find out how the policy choices could influence the development of the alternative transport fuels in Sweden until 2020. Kushnir and Sandén (2011) performed multi-level energy analysis of the application of new nanomaterials to replace the active materials in lithium ion batteries.

Social Shaping of Technology, a concept which supports Social Constructivism theory, has become one of the important views in Technology Assessment (Mackay and Gillespie, 1992). The core idea is that it is essential to determine technological change and impacts on society at the early phase of its development (Williams and Edge, 1996). The assessment of the innovations early on gives a higher probability of directing technological changes towards more sustainable development rather than analysis held after commercialization of technology. Thus, it is important to develop Technology Assessment tools which would analyze technologies at the early stage of technological development. In this regard, Anticipatory LCA has the same aim as Constructivism and Social Shaping of Technology, sharing the idea that the decisions made early in R\&D can determine the future impacts caused by innovations. 


\section{METHODOLOGY}

\subsection{GOAL AND SCOPE DEFINITION}

\subsubsection{GOAL DEFINITION}

The aim of the project is to guide R\&D of TNO coating technology towards better environmental performance based on the results of Anticipatory LCA. The research question for this Anticipatory LCA study is defined as follows:

"What are the possible paths which could lead to improved environmental performance of 'Dip coating' in the future?"

In order to answer this question, sub-questions are formulated:

a. "Do conventional coatings have lower environmental impacts than 'Dip coating' synthesized at laboratory scale?"

If yes, then:

b. "Which changes should be made in the life-cycle processes in order to optimize 'Dip coating' at laboratory scale?"

Scenarios will be used to scale-up 'Dip coating' to pilot and industrial scales, and evaluate its environmental performance in the future. Then Comparative Analysis of the scaled-up 'Dip coating' and the references will be done. It will answer the question:

c. 'Does 'Dip coating' have lower environmental impacts than 'Uncoated glass', 'Acid etching', and 'Sputtering'?"

Thus, Anticipatory LCA will be composed of three LCA studies (Figure 4.1):

1. LCA of 'Dip coating' at laboratory scale

2. LCA of the references

3. LCA of scaled-up 'Dip coating'

Sensitivity analysis for 'Dip coating at industrial scale' scenario will show which pathways could possibly lead to the improved environmental performance of 'Dip coating'. It will answer the main research question formulated at the beginning of this section. 


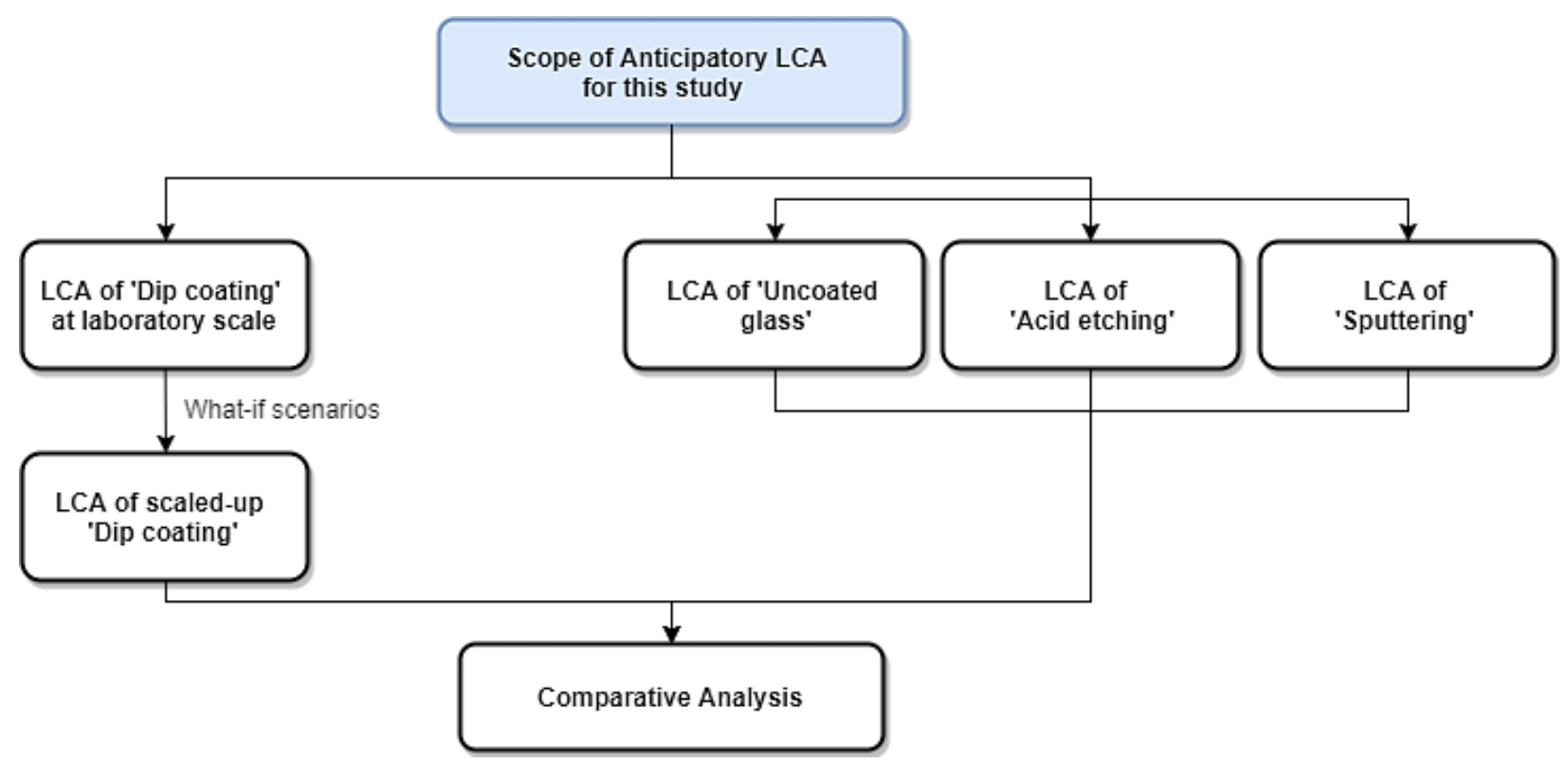

Figure 4.1. Flowchart of the scope of the Anticipatory LCA for this study (author's image)

\subsubsection{SCOPE DEFINITION}

The geographical boundary for Anticipatory LCA will be China where the greenhouse glass is produced and the Netherlands where the greenhouses are located. Thus, data will be relevant for the present state of technology in China and the Netherlands. The time boundary will be 30 years including both winter and summer seasons. Cradle-to-grave approach will be used in this LCA study as it enables to reveal the hotspots through the whole life-cycle of the product system.

CMLCA52beta software, developed by the Institute of Environmental Sciences at Leiden University, will be used for Anticipatory LCA analysis. The foreground processes for the product systems of the coatings will be designed using literature search and data provided by TNO and the companies such as Poot Kasdekreiniging and Van der Waay. The background processes will be based on the Ecoinvent V2.2 database developed by the Swiss Centre for Life Cycle Inventories (Frischknecht et al., 2005).

\subsubsection{FUNCTION, FUNCTIONAL UNIT, ALTERNATIVES, AND REFERENCE FLOWS}

Function and functional units will be the same for all three LCA analyses. The function of the coatings is the light transmittance to obtain a certain yield of tomatoes. The functional unit is the mass of tomatoes obtained under a certain area of the coated glass during 30 years. In this study, there are four alternatives: 'Dip coating' and three references such as 'Uncoated glass', 'Acid etching', and 'Sputtering'. The description of the alternatives is given in Section 1.2.1.

Different yield of the tomatoes can be obtained under uncoated and coated greenhouse glass. The mass of tomatoes produced in the Dutch greenhouse covered by uncoated structured glass with the light transmittance of $90.3 \%$ equals to $54 \mathrm{~kg} / \mathrm{m}^{2}$ per year (Hemming et al., 2009), and thus, the mass of tomatoes obtained in 30 years period under 'Uncoated glass' is $1620 \mathrm{~kg}$. The light transmittance of 'Dip coating', 'Acid etching', and 'Sputtering' is $96.5 \%$ for the first 10 years of use. After 10 years, they start 
to lose their anti-reflective property by $0.31 \%$ each year so that in the thirties year of use they have the same light transmittance as uncoated low-iron glass of $90.3 \%$. The mass of tomatoes obtained during the first 10 years of use of the coated greenhouse glass is $58.54 \mathrm{~kg}$ per year but with the decrease of the light transmittance of the coated glass by $0.31 \%$ the mass value of tomatoes reduces by $0.227 \mathrm{~kg}$ per year. In the thirtieth year, the mass of tomatoes is the same as the mass obtained under 'Uncoated glass' $54 \mathrm{~kg}$. As a result, the overall mass of tomatoes grown during 30 years is $1708.53 \mathrm{~kg}$. Therefore, this amount of tomatoes will be used for the reference flows:

A) $1708.53 \mathrm{~kg}$ of tomatoes obtained under 'Uncoated glass' during 30 years

B) $1708.53 \mathrm{~kg}$ of tomatoes obtained under 'Acid-etching' during 30 years

C) $1708.53 \mathrm{~kg}$ of tomatoes obtained under 'Sputtering' during 30 years

D) $1708.53 \mathrm{~kg}$ of tomatoes obtained under 'Dip coating' at laboratory scale during 30 years

E) $1708.53 \mathrm{~kg}$ of tomatoes obtained under 'Dip coating' at pilot scale during 30 years

F) $1708.53 \mathrm{~kg}$ of tomatoes obtained under 'Dip coating' at industrial scale during 30 years

\subsection{INVENTORY ANALYSIS}

\subsubsection{SYSTEM BOUNDARIES}

\subsubsection{ECONOMY-ENVIRONMENT SYSTEM BOUNDARY}

The economy-environment system boundary is defined according to Guinée et al. (2002, p.482). Some of the descriptions of the background processes regarding the economy-system boundary are given in this section. For instance, forestry is considered to be as economic process, but forestry soil and nonharvested part are referred to environment system. Natural forests are not included in the product system. Controlled landfills belong to the economic processes, while uncontrolled landfills are regarded as environmental processes. Wastewater treatment is a part of economic system where releases to sewage are not considered to be as emissions into the environment, but the releases after sewage treatment are referred to environment system. Sequestering of $\mathrm{CO}_{2}$ in biomass is counted as a negative emission.

\subsubsection{CUT-OFF}

The recycling of used glass cullet in the float glass, packaging glass, and glass wool production plants is out of scope of the research and is not considered in the modelling. The end-of-life stage of 'Dip coating' and the references will be modelled as preparation of glass for recycling process.

\subsubsection{FLOWCHARTS}

\subsubsection{REFERENCES}

The cradle-to-grave systems of 'Uncoated glass', 'Acid etching', and 'Sputtering' are shown in Figures $4.2,4.3$, and 4.4 , respectively. 
M.Sc. Thesis // Natalya Tsoy / 07-13-2017
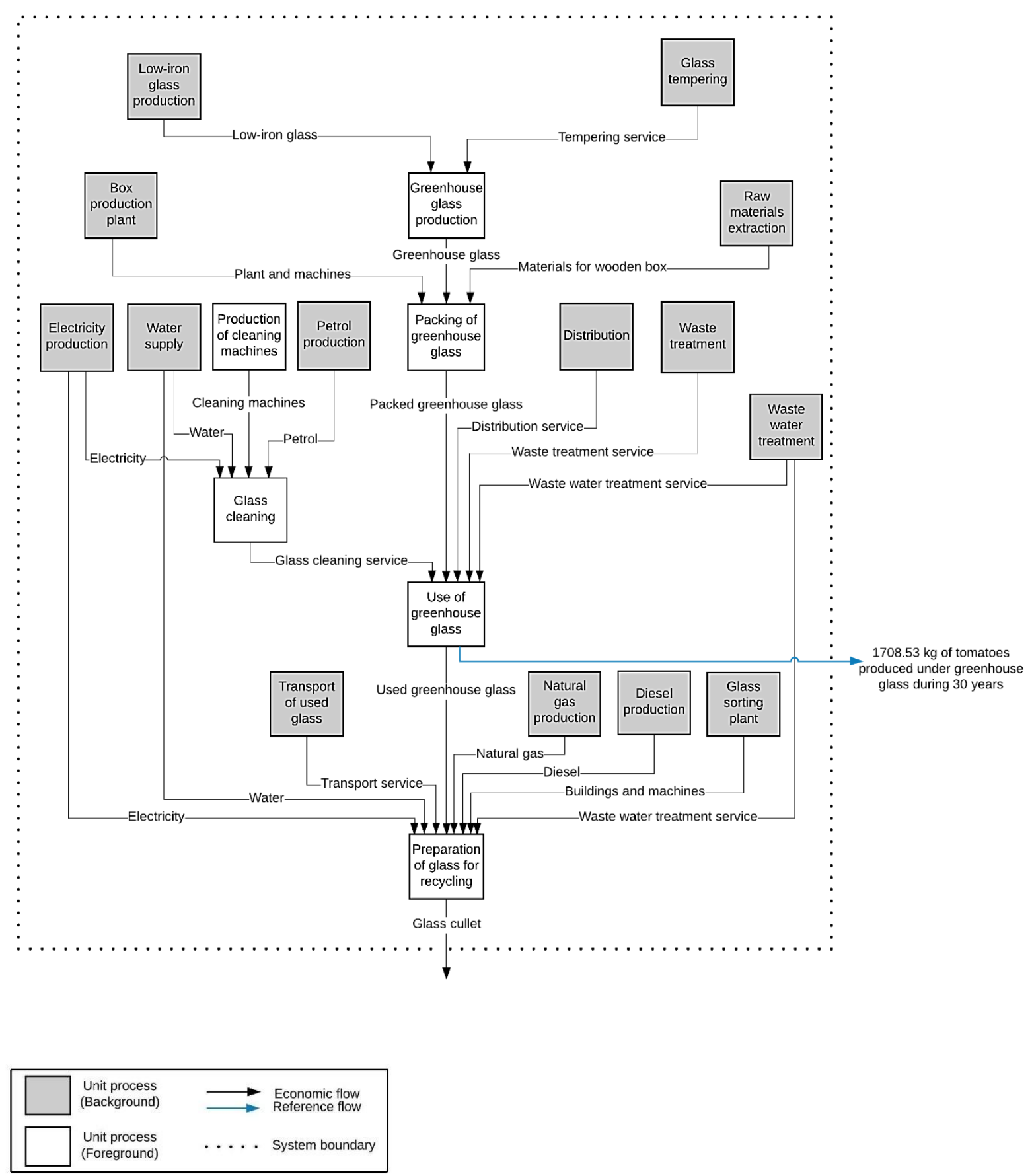

Figure 4.2. Flowchart for 'Uncoated glass' product system (author's image) 


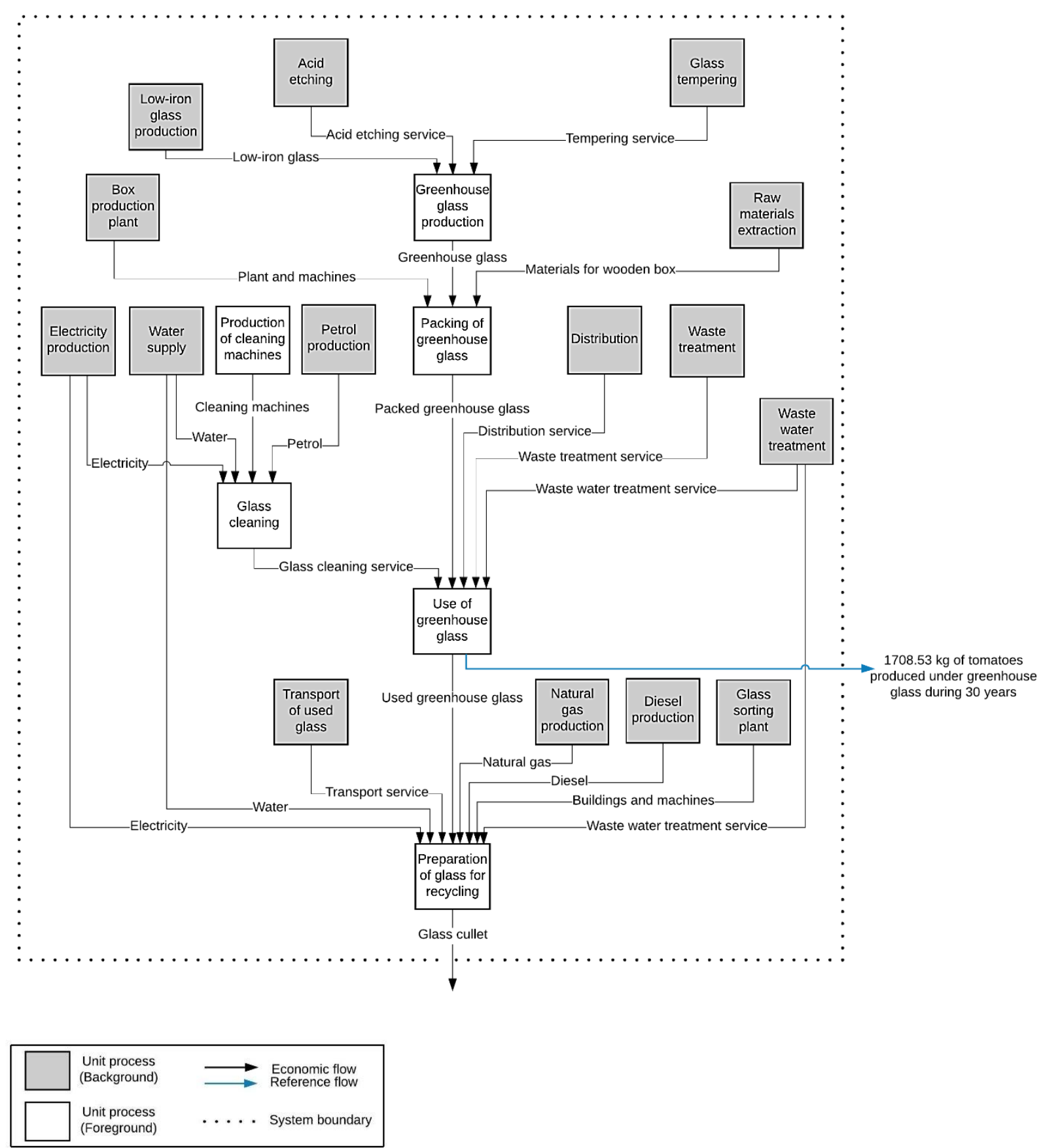

Figure 4.3. Flowchart for 'Acid etching' product system (author's image) 


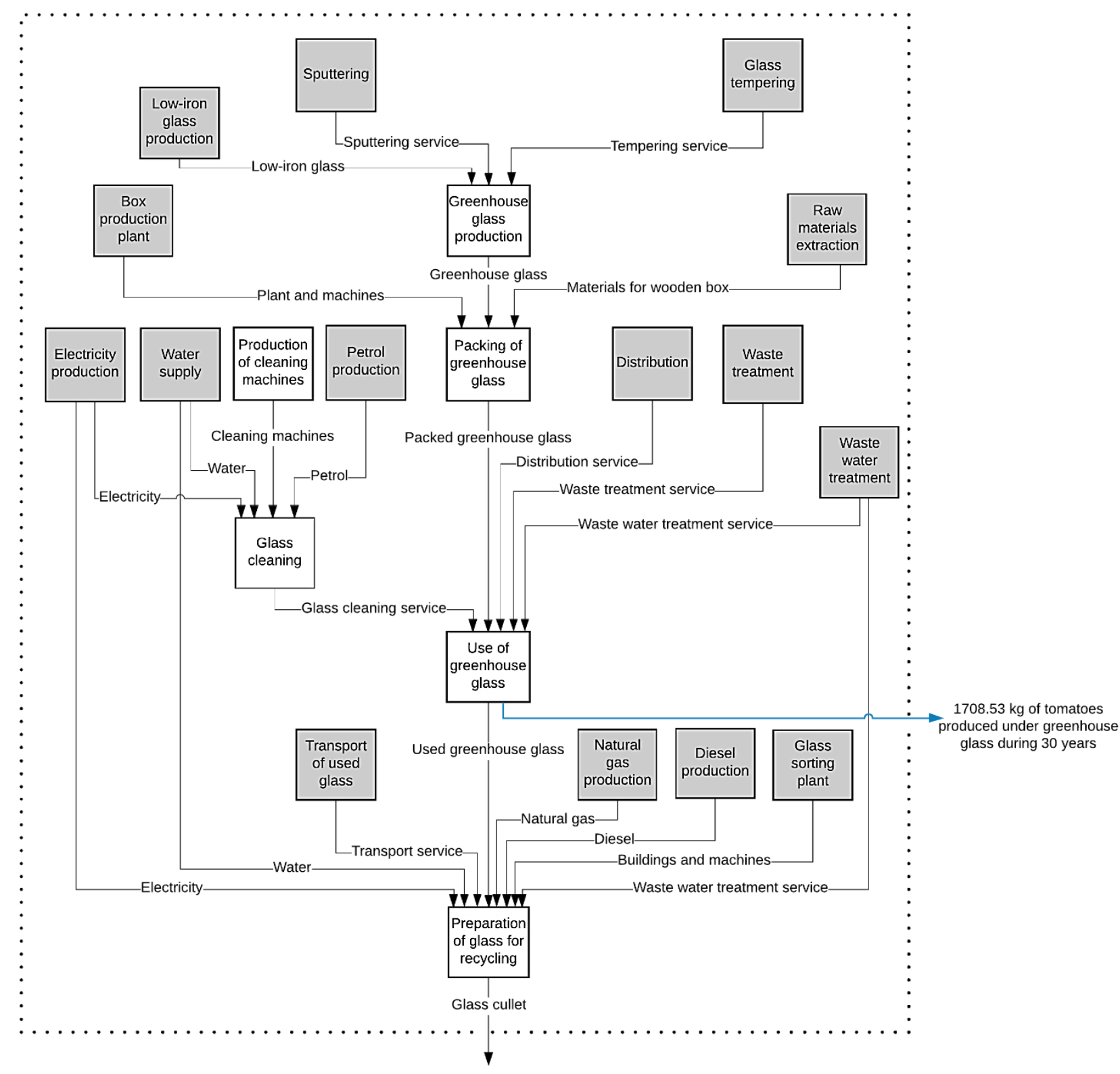

Unit process $\longrightarrow$ Economic flow

(Background) $\longrightarrow$ Economic flow

Unit process

(Foreground)

... System boundary

Figure 4.4. Flowchart for 'Sputtering' product system (author's image)

\subsubsection{2 'DIP COATING'}

Figure 4.5 depicts the flowchart for 'Dip coating' product system. The details of the inputs and outputs for sol-gel coating production unit process is shown in Figure 4.6. 

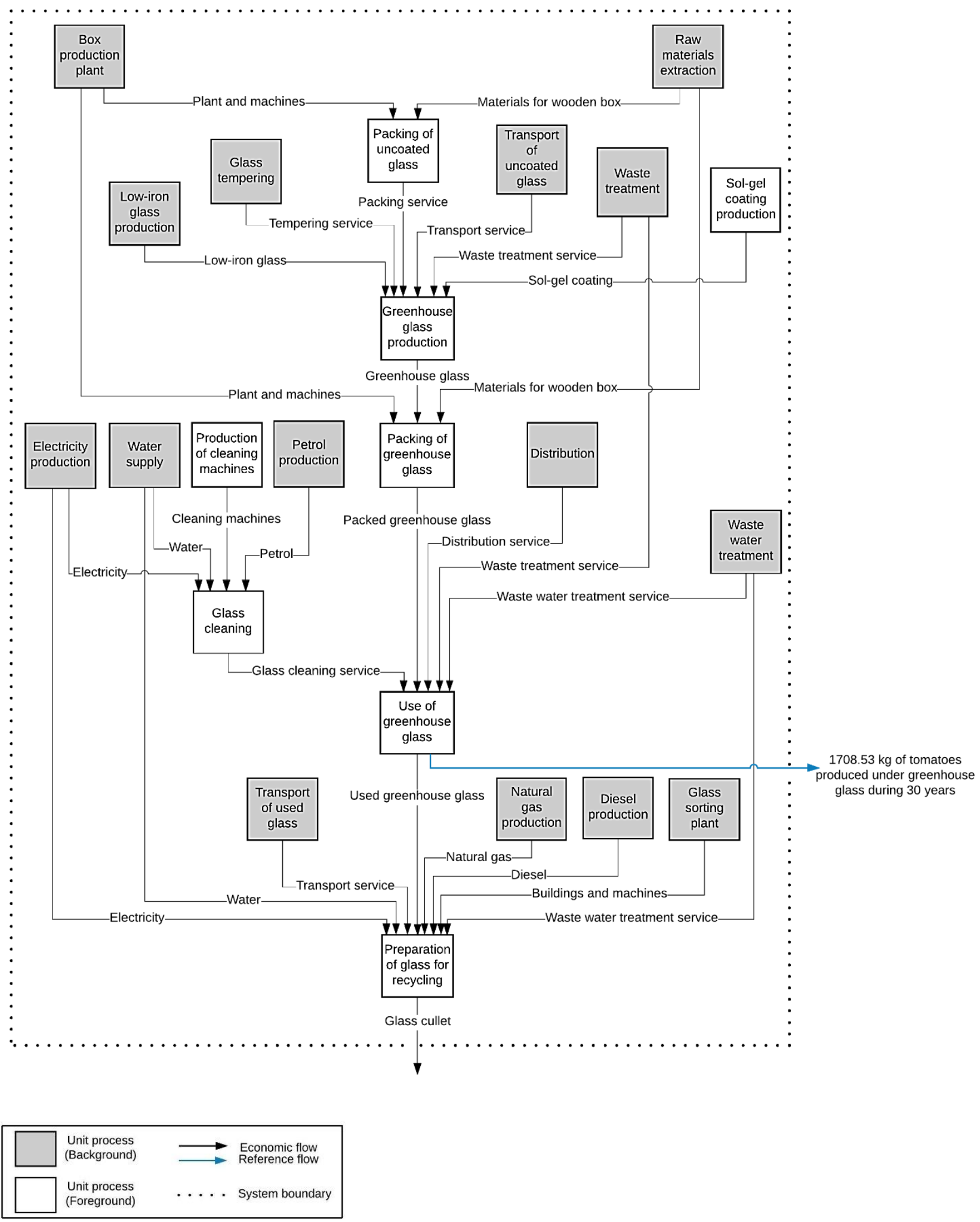

Figure 4.5. Flowchart for 'Dip coating' product system (author's image) 

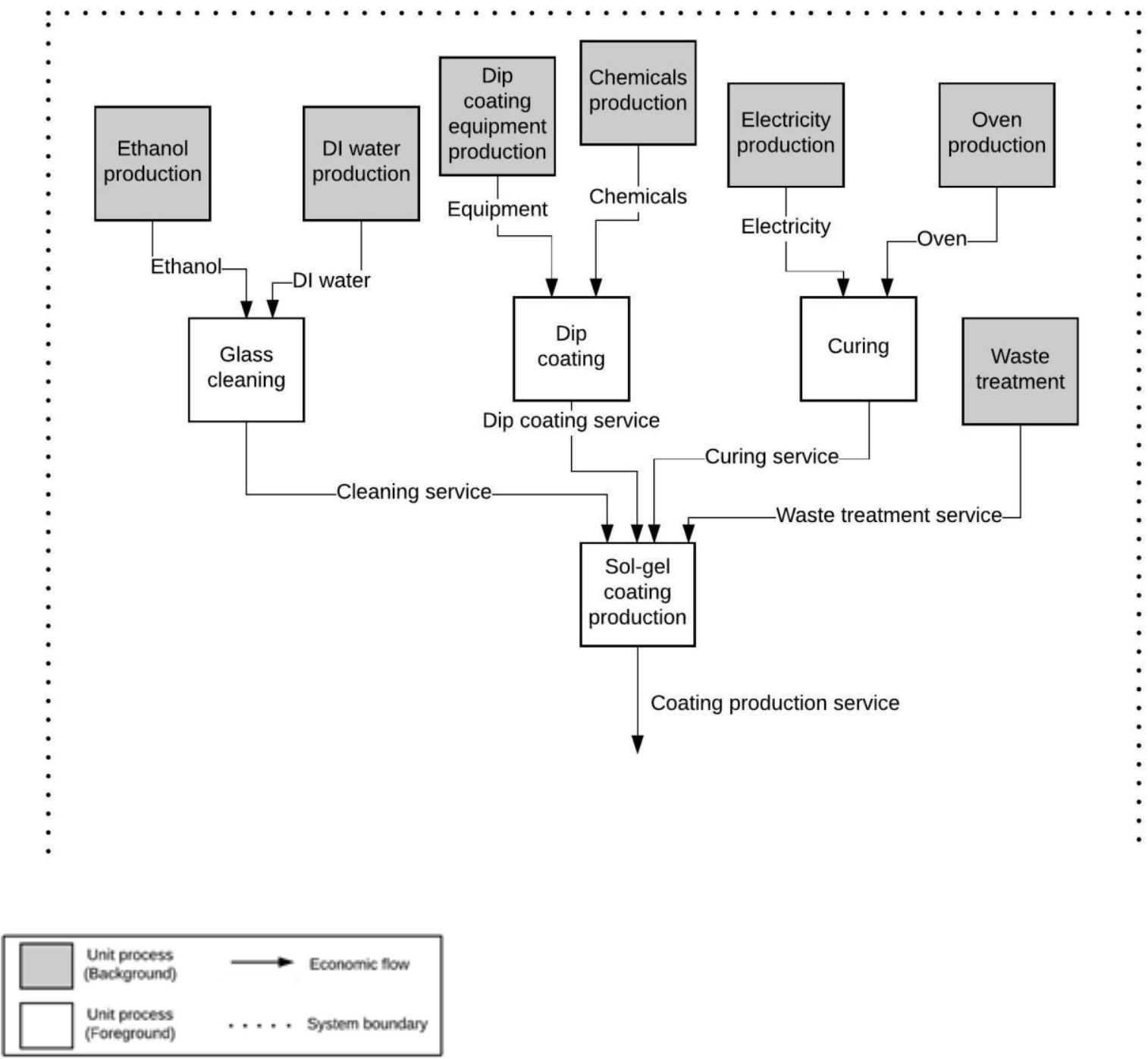

Figure 4.6. Flowchart for sol-gel coating production unit process (author's image)

\subsubsection{DATA COLLECTION}

Data collection for the references is reported in Appendix B, Section 11.2.3. In the following subsections, the description of the data collection for 'Dip coating' product system is given. The calculations related to modelling can be found in Appendix B, Section 11.2.1 and 11.2.2. The product system of 'Dip coating' is composed of five main foreground processes such as greenhouse glass production, packing, use, and the end-of-life phase which is the preparation of glass for recycling.

\subsubsection{GREENHOUSE GLASS PRODUCTION}

The production of greenhouse glass consists of different steps such as manufacturing of low-iron glass in China, glass tempering, packing and transport of uncoated glass to TNO where sol-gel coating is produced on its surface. 


\subsection{LOW-IRON GLASS PRODUCTION}

The low-iron glass was modelled as being manufactured in the Chinese plant. The choice of China as a country of glass production was made in this study based on the fact that TNO buys glass from the Chinese glass manufacturers as the price of it is much cheaper compared to that produced in Europe. In the structured low-iron glass manufacturing process, the raw materials such as silicon dioxide sand (73\%), soda (15\%), limestone (10\%), and additives (2\%) are mixed and loaded to the melting tank (AGC, 2012). Then the molten glass undergoes the structuring process by flowing through the special cooled rolls which leave the pattern on the solidified glass surface, and then is annealed (HilgenFeld, 2011). The production process for specifically structured glass was not found in Ecoinvent V2.2. According to Guinée et al. (2002, p.56), approximation of the process by a similar process in the modelling could be made in LCA in case of lack of data. The structured low-iron glass production process involves the same manufacturing stages as in unstructured low-iron glass. The only difference in those glass production processes is that the forming process in the manufacturing of the unstructured glass is replaced by the patterning process in the production of the structured glass (AGC, 2012) (Figures 1.1 and 1.2). It is expected that the highest environmental contribution would come from the raw materials extraction, melting, and annealing processes but not from the forming or rolling processes. Thus, Ecoinvent V2.2 process [G1253] Solar glass, low-iron, at regional storage[RER] was modelled as the manufacturing process of structured low-iron glass. This inventory includes the infrastructure, internal and manufacturing processes such as transportation of raw materials, addition of cullet, melting, forming, cooling, cutting and storage of glass.

\subsection{GLASS TEMPERING}

The structured glass is tempered to be strengthened. Tempered glass is four to five times stronger than annealed (Pressman, 2007). It breaks into innumerable pieces, and therefore, cannot be cut or drilled after fabrication so that pre-cutting phase should be before the tempering phase.

\subsection{PACKING OF UNCOATED GLASS}

\subsection{RAW MATERIALS EXTRACTION FOR PACKING MATERIALS}

Low-iron glass is packed into wooden boxes to be shipped to TNO. The wooden box which was used for transport of glass from China to TNO was modelled in this LCA study. The parts of the wooden box were weighed, and those values were used for the modelling. Table 11.1 in Appendix D depicts the weight values of the parts of the wooden box.

\subsection{BOX PRODUCTION PLANT}

The uncoated glass is packed in China for the transport to the coating plant in the Netherlands. [G2000] Packaging box production unit[RER] was used for designing the buildings and machines for the box production process. The electricity for the operation of the machines for the production of the wooden boxes and packing of glass was modelled using data of the specifications of the automatic machine for the wooden box manufacturing and packing processes (Alibaba.com, 2017b). 


\subsection{TRANSPORT OF UNCOATED GLASS}

The packed glass is transported from the Chinese glass manufacturer to TNO in Eindhoven. It was assumed that the glass is delivered by ship. [G103] Transport, transoceanic freight ship[OCE] was used for modelling shipment of uncoated glass. This module includes processes such as [G2228] Transoceanic freight ship[OCE], [G2222] Maintenance, transoceanic freight ship[RER], [G2225] Operation, transoceanic freight ship[OCE], [G2224] Operation, maintenance, port[RER], and [G2227] Port facilities[RER]. The shipment was modelled using the values of the distance of travel and the mass of the glass. The distance of the transport was assumed to be the ship route from the largest Chinese port Shaghai to the port of Rotterdam through Suez Canal. The route of the trip is shown in Figure 4.7.

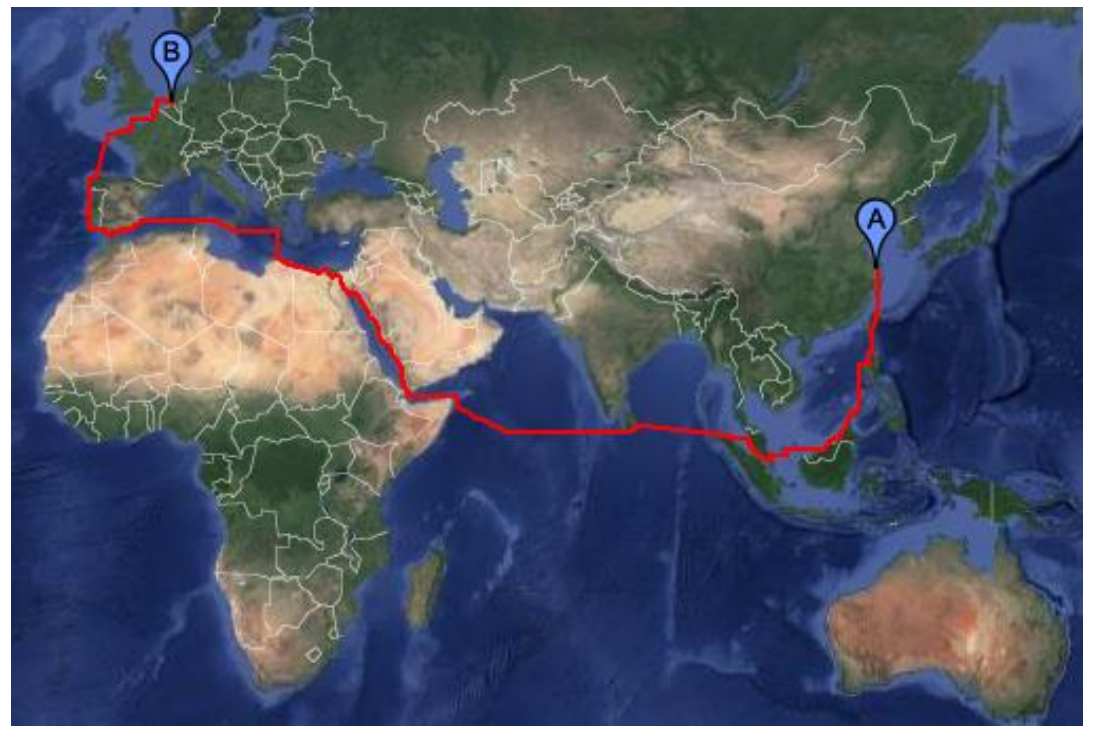

Figure 4.7. Shipment of glass from the port of Shanghai (A) to the port of Rotterdam (B) (Ports.com, n.d.)

\subsection{WASTE TREATMENT}

The used wooden box is disposed after arrival to TNO. The end-of-life of the wooden box was modelled as the disposal of its parts such as wood, fiber board, screws, and the rope using Ecoinvent V2.2. The module includes the waste treatment processes for wood, packaging cardboard, aluminum, and polypropylene, respectively.

\subsection{SOL-GEL COATING PRODUCTION}

Data for sol-gel coating production process was collected from TNO laboratory. The production of 'Dip coating' consists of several steps. Firstly, glass is cleaned, then it is covered by sol-gel, after that it is dried, and then cured. In the cleaning process, the glass is washed with ethanol and DI water. The sol-gel solution is prepared using ethanol as the solvent.

Solutions for glass cleaning and sol-gel were modelled using Ecoinvent V2.2 database. The data on the chemicals used for the production of 'Dip coating' was provided by TNO. The information is confidential, and therefore, is not reported in this thesis work. After the sol-gel preparation step, 10x15 $\mathrm{cm}$ glass is covered by sol-gel using dip coating machine (DipMaster 201, Chemat Technology, INC.). The 
photo of the dip coating apparatus DipMaster 201 which is used at TNO is shown in Figure 4.8, photo on the left.
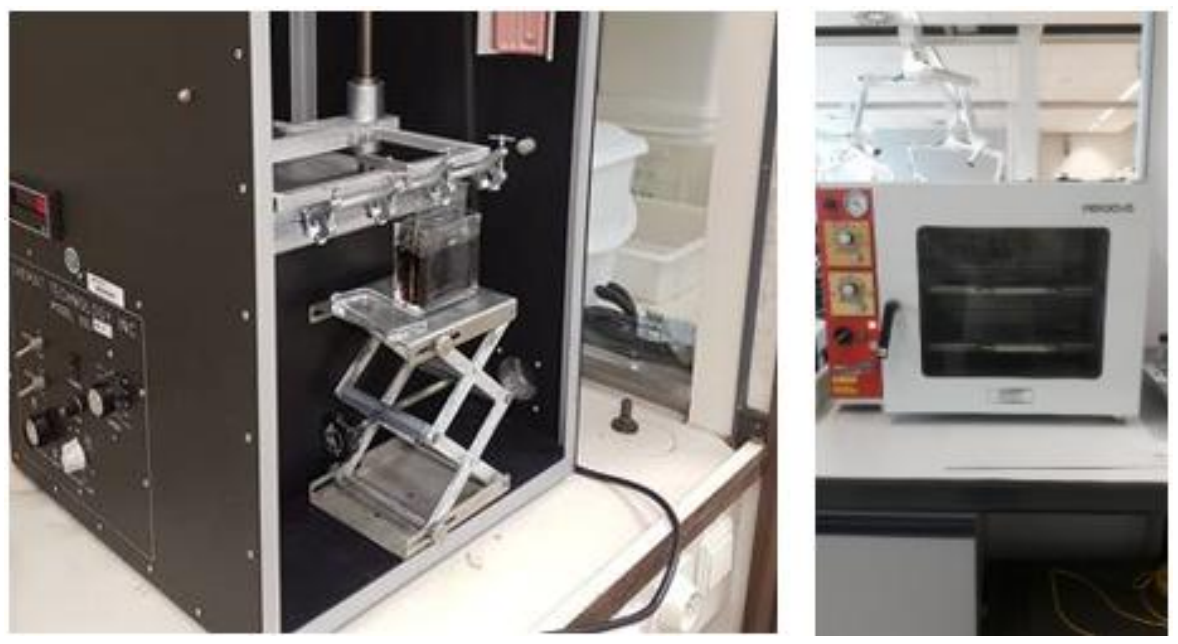

Figure 4.8. DipMaster 201 and Heraeus D-6450 Hanau oven (Photo credits to Dr. Aike Wypkema and Natalya Tsoy)

The glass is dried at an ambient temperature, and then cured at $400{ }^{\circ} \mathrm{C}$ for 1 hour in the electric oven. Data on the oven was collected based on the parameters of Heraeus D-6450 Hanau oven which is used by TNO (Figure 4.8, photo on the right). The amount of electricity used for curing in the oven was measured with ELRO Plug-in Consumption Meter M12 device.

\subsubsection{PACKING OF GREENHOUSE GLASS}

The coated glass is packed in the wooden box to be transported to the greenhouses. The same data inputs as in the packing of uncoated glass was used in this unit process. The only difference is in the countries of the electricity production of wooden boxes and packing of glass. Those processes associated to uncoated glass involve the electricity produced in China, while in the case of the coated glass, the electricity is produced in the Netherlands.

\subsubsection{USE OF GREENHOUSE GLASS}

\subsection{DISTRIBUTION}

The greenhouse glass is transported from TNO to a greenhouse by a lorry. It was assumed that the end destination is the Greenport Westland-Oostland as it is the largest international greenhouse cluster in the Netherlands (Greenport Holland, n.d.).

\subsection{WASTE TREATMENT}

The waste treatment involves the disposal of the wooden box used for the transport of the greenhouse glass. The same processes were included in the modelling of the disposal of the wooden box as in the case of the disposal of the box used for the transport of uncoated glass. 


\subsection{GLASS CLEANING}

Poot Kasdekreiniging, a company which specializes in the mechanical greenhouse glass washing in the Netherlands (Poot Kasdekreiniging, 2015), was asked to share the details of the cleaning procedure for the thesis project.

\subsection{WATER SUPPLY}

Poot Kasdekreiniging reported that the greenhouse glass is washed inside the greenhouse once a year, while the outside washing is performed twice a year. The amount of water required for cleaning inside of the greenhouse glass is around $100 \mathrm{~L} / \mathrm{min}\left(6 \mathrm{~m}^{3} /\right.$ hour $)$, and the amount of water used for cleaning outside of the greenhouse is around $40 \mathrm{~L} / \mathrm{min}\left(2.4 \mathrm{~m}^{3}\right.$ / hour). Poot Kasdekreiniging uses less water for cleaning the glass outside than inside because there is a limitation in weight of the machines driving upon the greenhouses so that thick hoses used for the delivery of greater amount of water cannot be used. [G71] Tap water, at user[RER] was used for the modelling of water needed for washing the greenhouse glass.

\subsection{PRODUCTION OF CLEANING MACHINES}

Poot Kasdekreiniging informed that the cleaning machines Van der Waay Aqua Jet roof cleaner (Appendix C, Figure 11.6) and Van der Waay Top cleaner machine (Appendix C, Figure 11.7) are utilized for inside and outside cleaning of the greenhouse glass, respectively. Aqua Jet machine was modelled using [G495] Industrial machine, heavy, unspecified, at plant[RER] process. This Ecoinvent V2.2 module provides inventory of the most important materials for an unspecified machine and transportation of its parts to the assembly factory. Data of the materials and weights of the parts used for construction of Top cleaner was found in the machine specifications in the Van der Waay website. Therefore, Van der Waay company was contacted to share this information. According to Van der Waay, the Top Cleaner 400 Standard edition frame is made from aluminum and weights $302 \mathrm{~kg}$, the rest of the parts such as cable/hose, guides on reels, etc. weigh about $161.8 \mathrm{~kg}$. The mass values of the parts of Top Cleaner machine are provided in Table 11.2, Appendix D.

The volume of petrol required for Aqua Jet roof cleaner and the amount of electricity needed for Van der Waay Top cleaner to wash $1 \mathrm{~m}^{2}$ of greenhouse glass for 30 years were estimated using the machine specifications provided by Van der Waay.

\subsection{WASTE WATER TREATMENT}

Waste water from cleaning of greenhouses goes to the waste water treatment plant. Ecoinvent V2.2 was used for modelling the waste water treatment process which includes three phases of waste water treatment such as mechanical, biological, and chemical.

\subsubsection{PREPARATION OF GLASS FOR RECYCLING}

The used greenhouse glass is prepared for recycling. The technology for the separation of sol-gel coating from glass has not been established in the waste recycling industry in the Netherlands yet. Thus, in the modelling, $\mathrm{SiO}_{2}$ coating is recycled together with glass, not being removed. Sol-gel, which is composed of amorphous synthetic $\mathrm{SiO}_{2}$ nanoparticles, is not usually treated as hazardous material to environment and human health due to the fact that it is produced from sand (Rhodia, 2012). 
The glass is collected and transported to the sorting plant where it is sorted, washed, dried and then milled into glass cullet. Dutch Waste Management Association reported that $70 \%$ of float glass cullet is used in the glass packaging production, $15 \%$ in the float glass production, and $15 \%$ in the glass wool production (Han van de Wiel, 2015). Recycling of glass in the glass packaging, float glass, and wool production plants was not modelled in this study as it was considered out of scope of this research. Ecoinvent V2.2 process was used for the modelling of waste water treatment process which is composed of mechanical, biological, and chemical phases.

\subsubsection{MULTI-FUNCTIONALITY AND ALLOCATION}

Some background processes which were used in this research from Ecoinvent V2.2 are multi-functional. In Ecoinvent V2.2, economic allocation is used by default in order to split economic flows and environmental interventions of the product system to the functional unit (Frischknecht et al., 2005). All foreground unit processes are mono-functional so that there is no need in allocation.

\subsubsection{DEVELOPMENT OF WHAT-IF SCENARIOS}

What-if scenarios were developed to evaluate the environmental performance of 'Dip coating' at laboratory, pilot, and industrial scales. In order to construct scenarios, simplified MGMA was created. In MGMA, social-political factors were not included as the focus of the study was to optimize the system of the production of 'Dip coating' to industrial scale. The resulted pilot and industrial scale scenarios for 'Dip coating' were discussed with Dr. Aike Wypkema, Professor at Materials Solutions at TNO in Eindhoven, who is working in the field of coating technology. An expert consultation regarding the curing process for the coatings was provided by Dr. Andrzej Stankiewicz, Professor at the Process and Energy Department at Delft University of Technology.

\subsubsection{IDENTIFICATION OF VARIABLES FOR MORPHOLOGIACAL FIELD}

Contribution analysis of sol-gel production process for 'Dip coating' showed that the highest impacts come from electricity production and ethanol manufacturing. Thus, the laboratory processes related to those processes were determined as the variables for the Morphological field. The rows in grey of the morphological field depict variables (Figure 4.9).

\subsubsection{DETERMINATION OF VARIABLE CONDITIONS FOR MORPHOLOGICAL FIELD}

\subsection{VARIABLE CONDITIONS FOR LABORATORY SCALE SCENARIO}

The variable conditions for 'Dip coating at laboratory scale' scenario are the values of the electricity amount and volumes of solutions and hazardous waste measured at laboratory at TNO.

The production of 'Dip coating' is divided into several steps. The glass is cleaned, then it is coated with sol-gel, dried, and cured. In the cleaning process, 6 glass plates with the dimensions of $10 \times 15 \mathrm{~cm}$ (total area $=0.09 \mathrm{~m}^{2}$ glass) are washed with $90 \mathrm{~g}$ of DI water and $71.04 \mathrm{~g}$ of ethanol. The volume of sol-gel required to cover $0.09 \mathrm{~m}^{2}$ glass was calculated. It was assumed that the thickness of the sol-gel coating on glass is $10 \mu \mathrm{m}$, and thus, the volume of sol-gel solution required to cover $1 \mathrm{~m}^{2}$ glass equals to $10 \mathrm{~mL}$ and for covering 2 sides of $1 \mathrm{~m}^{2}$ of glass is $20 \mathrm{~mL}$. The volume needed for covering $0.09 \mathrm{~m}^{2}$ glass is $1.8 \mathrm{~mL}$. This value was used to calculate the mass of ethanol used as the solvent:

$$
\begin{gathered}
\rho \text { (ethanol for sol-gel coating) }=0.789 \mathrm{~g} / \mathrm{cm}^{3} \\
m \text { (ethanol for sol-gel coating) }=\rho^{*} V=0.789 \mathrm{~g} / \mathrm{cm}^{3} 1.8 \mathrm{~mL}=1.420 \mathrm{~g}
\end{gathered}
$$


where: $\rho$ - density, $m$ - mass, $V$ - volume

Thus, $1.420 \mathrm{~g}$ of ethanol is needed to cover $0.09 \mathrm{~m}^{2}$ glass. Assuming that there is a laboratory efficiency of $10 \%$, the mass of ethanol for the bath solution for covering $0.09 \mathrm{~m}^{2}$ glass was calculated:

$$
m \text { (ethanol for bath solution) }=\frac{1.420 \mathrm{~g}}{0.1}=14.20 \mathrm{~g}
$$

The mass of other chemicals was estimated using the ratio of those chemicals to ethanol. Production of ethanol and other reagents were modelled using Ecoinvent V2.2.

The electricity for dip coating machine was assumed to be negligible as only approximately 18 seconds is required for the machine to withdraw $0.09 \mathrm{~m}^{2}$ glass from sol-gel. The total mass of the sol-gel solution equals to $15.21 \mathrm{~g}$. Approximately $90 \%$ of chemicals is wasted after use. Therefore, $13.69 \mathrm{~g}$ of chemicals is disposed after coating process. The coated glass is dried and then cured at $400^{\circ} \mathrm{C}$ for 1 hour. The amount of electricity required to cure $0.09 \mathrm{~m}^{2}$ glass equals to $0.747 \mathrm{kWh}$. Chromium steel was used as a material for the production of dip coating apparatus and electric oven in the modelling.

\subsection{VARIABLE CONDITIONS FOR PILOT SCALE SCENARIO}

DI water without ethanol is used in the cleaning process of glass at pilot scale. At industrial scale, a dip coating machine with solution displacement apparatus is used so that it enables reduction of solution from 30 to $70 \%$ (Petropoulos et al., 1998). It was assumed that there is a reduction of DI water for glass cleaning and the volume of sol-gel solution by $35 \%$ at pilot scale.

TNO uses the speeds for the withdrawal of glass from sol-gel of 1, 2, 4, and $8 \mathrm{~mm} / \mathrm{s}$ at laboratory scale. The highest speed of the dip coating machine at laboratory scale was assumed as the work speed both for pilot and industrial scales $8 \mathrm{~mm} / \mathrm{s}$, and thus, the work of the dip coating apparatus requires $0.0468 \mathrm{kWh}$ which is the same amount of electricity needed for it to perform work at industrial scale. It was assumed that the dip coating machine for the pilot scale was produced to mimic work of the machine at industrial scale. According to Sánchez-Cruces et al. (2014), the electricity consumption for curing $0.09 \mathrm{~m}^{2}$ glass is $0.297 \mathrm{kWh}$. This amount of electricity was used for the input of the electricity needed for the curing process at pilot scale.

Chromium steel production for dip coating machine and oven was excluded in the modelling to make the comparison of the 'Dip coating' consistent to the references where the equipment is not introduced into the system. A waste reduction by $35 \%$ was modelled in the pilot scale scenario.

\subsection{VARIABLE CONDITIONS FOR INDUSTRIAL SCALE SCENARIO}

DI water is used for glass cleaning at industrial scale. The volume of DI water and sol-gel solution was reduced by $70 \%$ based on the patent of the dip coting apparatus used at industrial scale (Petropoulos et al., 1998). The electricity required for the work of the dip coating machine was calculated. The power of the dip coating apparatus used at industrial scale is $15 \mathrm{~kW}$ (Alibaba.com, 2017a). It was assumed that the highest speed is used at industrial scale of $8 \mathrm{~mm} / \mathrm{s}$. The amount of electricity needed for the dip coating machine to withdraw glass was estimated as follows:

$$
\begin{gathered}
\text { Industrial scale speed: } 8 \mathrm{~mm} / \mathrm{s}=48 \mathrm{~cm} / \mathrm{min} \\
\text { Time for withdrawal of } 1 \mathrm{~m}^{2} \text { glass }=\frac{1 \mathrm{~m} * 1 \mathrm{~min}}{0.48 \mathrm{~m}}=2.0833 \mathrm{~min} \\
\text { Time in hours }=\frac{2.0833 \mathrm{~min} * 1 \mathrm{hour}}{60 \mathrm{~min}}=0.0347 \mathrm{hour} \\
\text { Amount of electricity for dip coater for withdrawal of } 1 \mathrm{~m}^{2} \mathrm{glass}=15 \mathrm{~kW}+0.0347 \text { hour }=0.5205 \mathrm{kWh}
\end{gathered}
$$


The time for the dip coating machine to dip and withdraw the glass from DI water to clean it and to dip the glass from sol-gel is considered to be negligible. However, the time for the withdrawal of glass from sol-gel solution is crucial as this speed determines the thickness of the coating. Therefore, the amount of electricity for the work of the dip coating apparatus was estimated to be $0.5205 \mathrm{kWh}$ to cover $1 \mathrm{~m}^{2}$ glass. Chromium steel production for the dip coating machine and electric oven was not designed in the modelling.

The optimization of the curing process for the anti-reflective coating was consulted with Dr. Andrzej Stankiewicz, and he recommended to consider other options for scaling-up of curing process rather than electric oven, for instance micro-wave assisting curing. Other optimization processes e.g. reduction of the volume of sol-gel solution were discussed with Dr. Aike Wypkema. According to Dr. Aike Wypkema, the curing process of the coatings is performed in the tempering step in the factories nowadays. Thus, tempering was modelled as a process which includes the curing process of 'Dip coating at industrial scale' scenario. In Ecoinvent V2.2, [G628] Natural gas, burned in industrial furnace low-NOx $>100 \mathrm{~kW}[R E R]$ is used for the tempering process by default. This process requires $0.846 \mathrm{MJ}(0.235 \mathrm{kWh})$ of natural gas for tempering $0.09 \mathrm{~m}^{2}$ of glass. Assuming that the efficiency for the conversion of natural gas to electricity is 39\% (EURELECTRIC, 2003, p.8), the amount of electricity produced would be 0.092 kWh.

\subsubsection{CONSTRUCTION OF MORFOLOGICAL FIELD}

Morphological field was constructed using variables and variable conditions. Figure 4.9 depicts Morphological field for this study. Three scenarios such as 'Dip coating' at laboratory, pilot, and industrial scales were developed. The variables are shown in grey, and the corresponding variable conditions are depicted in white. All parameters are given per $0.09 \mathrm{~m}^{2}$ of glass.

\begin{tabular}{|c|c|c|c|c|c|}
\hline & $\begin{array}{l}\text { Amount of } \\
\text { electricity } \\
\text { for coating } \\
\text { (0.09 } \mathrm{m}^{2} \text { glass) }\end{array}$ & $\begin{array}{l}\text { Amount of } \\
\text { electricity } \\
\text { for curing } \\
\left(0.09 \mathrm{~m}^{2}\right. \\
\text { glass) }\end{array}$ & $\begin{array}{c}\text { Volume of } \\
\text { sol-gel } \\
\text { solution } \\
\text { (0.09 } \mathrm{m}^{2} \\
\text { glass) }\end{array}$ & $\begin{array}{c}\text { Volume of } \\
\text { waste }\left(0.09 \mathrm{~m}^{2}\right. \\
\text { glass })\end{array}$ & $\begin{array}{c}\text { Volume of cleaning } \\
\text { solution }\left(0.09 \mathrm{~m}^{2}\right. \\
\text { glass })\end{array}$ \\
\hline $\begin{array}{l}\text { Laboratory } \\
\text { scale scenario }\end{array}$ & $0 \mathrm{kWh}$ & $0.747 \mathrm{kWh}$ & $15.21 \mathrm{~g}$ & $13.69 \mathrm{~g}$ & $\begin{array}{c}\text { DI water: } 90 \mathrm{~g} \\
\text { Ethanol: } 71.037 \mathrm{~g}\end{array}$ \\
\hline $\begin{array}{l}\text { Pilot scale } \\
\text { scenario }\end{array}$ & $0.0468 \mathrm{kWh}$ & $0.297 \mathrm{kWh}$ & $9.88 \mathrm{~g}$ & $8.90 \mathrm{~g}$ & $\begin{array}{c}\text { DI water: } 58.5 \mathrm{~g} \\
\text { Ethanol: } 0 \mathrm{~g}\end{array}$ \\
\hline $\begin{array}{l}\text { Industrial scale } \\
\text { scenario }\end{array}$ & $0.0468 \mathrm{kWh}$ & $0.092 \mathrm{kWh}$ & $4.56 \mathrm{~g}$ & $4.11 \mathrm{~g}$ & $\begin{array}{c}\text { DI water: } 27 \mathrm{~g} \\
\text { Ethanol: } 0 \mathrm{~g}\end{array}$ \\
\hline
\end{tabular}

Figure 4.9. Morphological field for this study (author's image) 


\subsubsection{CONSISTENCY CHECK AND GENERATION OF SOLUTION SPACE}

Consistency check and generation of solution space were not performed in this study as the variable conditions represent the exact numbers for the variables, and have already been paired with them. Morphological field was discussed with Professors at Material Solutions at TNO.

\subsubsection{CONSTRUCTION OF LABORATORY, PILOT, AND INDUSTRIAL SCALE SCENARIOS}

Three scenarios of 'Dip coating' at laboratory, pilot and industrial scale were modelled using the Morphological field. What-if scenarios will answer the questions such as:

1) "Which environmental impacts will be caused by 'Dip coating' in the condition if 'Dip coating' is produced at laboratory scale?"

2) "Which environmental impacts will be caused by 'Dip coating' in the condition if 'Dip coating' is produced at pilot scale?"

3) "Which environmental impacts will be caused by 'Dip coating' in the condition if 'Dip coating' is produced at industrial scale?"

Comparative, Contribution and Sensitivity analyses will be performed in order to answer sub-questions formulated at the beginning of the research.

\subsection{IMPACT ASSESSMENT}

\subsubsection{CLASSIFICATION, CHARACTERIZATION, AND NORMALIZATION}

Impact Assessment gives the view on the magnitude of the impacts caused by a product system on environment. In general, two main characterization methods of analysis are distinguished in LCA: midpoint and end-point. The midpoint method provides indicators at a level of cause-effect chain between emissions/resource consumption and the endpoint level in order to compare environmental interventions (EU-European Commission, 2011b). Some examples of midpoint method are CML 2001, CML2001 Baseline, reference World, 2000, ReCiPe (midpoint), and IMPACT2002+ (midpoint). The endpoint method evaluates the environmental implications at the end of cause-effect chain and provides indicators at the level of Areas of Protection (natural environment's ecosystems, human health, resource availability) or at a level close to the Areas of Protection level (EU-European Commission, 2011b). Some examples of endpoint method are Ecolndicator 99, ReCiPe (endpoint), and IMPACT2002+ (endpoint). In this LCA study, mid-point method was chosen for the analysis due to the fact that the endpoint methods are still being developed, therefore, they are not comprehensive and have a higher uncertainty level (Guinée et al., 2002). Based on the guidelines by Guinée et al. (2002), it was decided to use CML 2001 Baseline, reference World, 2000 method.

\subsubsection{CLASSIFICATION}

Classification is the process where the environmental flows from Life Cycle Inventory are assigned to relevant impact categories. This is done by transforming the Life Cycle Inventory results to the same unit of the impact categories with the use of the characterization factors which are derived from characterization models. Table 11.4 in Appendix E summarizes data on characterization models, category indicators, characterization factors, and units used for each of those impact categories. The short description of the selected impact categories is as follows: 


\section{1) Land Use, Competition}

Land Use, Competition is referred to the land loss as a resource being temporary unavailable (Guinée et al., 2002). It is important to evaluate this impact category in this study because infrastructure for greenhouse glass production, packing and waste treatment factories occupy a large area of the land, so that probably, this could negatively affect the land usage making this space unavailable as a resource for other purposes.

\section{2) Eutrophication}

Eutrophication is the nutrient over-enrichment of waters. It can cause the dissolved oxygen reduction leading to the aquatic animal loss (Correll, 1998). It is useful to cover this impact category in this work because probably, the sewage of chemicals could contribute to Eutrophication.

\section{3) Acidification}

Acidification can be defined as the protons release to ecosystem so that this can be harmful for water, soil, living organisms and buildings (Guinée et al., 2002). Different acids are used in the manufacture of anti-reflective coatings, e.g. fluocilisic acid is one of the main chemicals used for the production of 'Acid etching'. Thus, the acid residuals from the coating production which could be leaked from the waste disposal could lead to Acidification. Therefore, it would be important to include this impact category in this LCA study.

\section{4) Photochemical Oxidation}

Photochemical Oxidation can result in the synthesis of tropospheric ozone which at high concentrations can adversely affect human health and in lower concentrations could be damaging for the vegetation (Stranddorf et al., 2005). Photochemical Oxidation is an important impact category for this analysis as gas emissions from fossil fuels during glass production could be the main contributors to the formation of tropospheric ozone.

\section{5) Climate Change}

Climate Change can negatively affect environmental resources, services, and human health (Field et al., 2012). Greenhouse gasses from the production and transport of glass could cause the greenhouse effect.

\section{6) Terrestrial Ecotoxicity}

This impact category is defined as the exposure of the terrestrial ecosystems by toxic substances (Haye, 2007). Different poisonous chemical compounds are used to produce coatings so that they could be released to environment.

\section{7) Freshwater Aquatic Ecotoxicity}

Freshwater Aquatic Ecotoxicity is the exposure of the sediment of freshwater ecosystem by poisonous chemicals (Guinée et al., 2002). It is important to analyze Freshwater Aquatic Ecotoxicity as probably, cleaning of greenhouse glass could contribute to this impact category. 
8) Stratospheric Ozone Depletion

Thinning of the stratospheric ozone layer which leads to the increased level of UV-radiation can be harmful for living organisms (Stranddorf et al., 2005). Some processes e.g. waste disposal can emit chlorine containing Volatile Organic Compounds which could serve as the precursors for Stratospheric Ozone Depletion.

9) Human Toxicity

Human Toxicity is referred to an exposure of toxics by humans causing allergies and illnesses (Stranddorf et al., 2005). Various chemicals released from different processes of glass and coatings production could adversely affect human health.

\subsubsection{CHARACTERIZATION}

Characterization is the aggregation of the category impact results. Comparative analysis of 'Dip coating at laboratory scale' scenario and the references such as 'Uncoated glass', 'Acid etching', and 'Sputtering' was performed based on characterized impact results to determine if 'Dip coating' would have higher environmental impacts than other alternatives. Comparative analysis of 'Dip coating at pilot scale' and 'Dip coating at industrial scale' scenarios showed by which degree an improvement of the environmental performance of 'Dip coating' could be. Then characterization results of 'Dip coating' at pilot and industrial scales were compared to the reference alternatives.

\subsubsection{NORMALIZATION}

Normalization is defined as an estimation of indicator results relative to reference information which refers to a particular community e.g. Europe or World over a certain period of time (Guinée et al., 2002, p.90). The method CML2001 Baseline, reference World, 2000 involves normalization which uses the reference to the impact results for the World in 2000. Normalization was not performed in this LCA analysis as it was considered to be inappropriate to this case study due to the fact that the normalized results are related to an outdated database.

\subsubsection{INTERVENTIONS FOR WHICH CHARACTERIZATION FACTORS ARE LACKING}

The interventions for which characterization factors are lacking are reported in Appendix $E$.

\subsection{INTERPRETATION}

\subsubsection{CONSISTENCY AND COMPLETENESS CHECK}

Consistency and completeness check were performed. As the scenarios for the pilot and industrial scales of 'Dip coating' were constructed based on the laboratory scale data and literature, the variables and variable conditions within those scenarios were reviewed by the experts in the dip coating industry, Professors at Materials Solutions at TNO, and the expert in the curing process, Dr. Andrzej Stankiewicz.

\subsubsection{CONTRIBUTION ANALYSIS}

Contribution analysis gives the insights on the environmental hotspots throughout the processes of the life-cycle of the coating technologies. Furthermore, this analysis interprets why one alternative has lower environmental impacts compared to others. Also, contribution analysis of the processes of 'Dip 
coating' at laboratory, pilot, and industrial scales was done, and the results were compared to see the changes in the contributions of the processes influenced by their modifications in the scenarios development phase.

\subsubsection{SENSITIVITY ANALYSIS}

\subsubsection{DEGRADATION OF DIP COATING AND INCREASED LIGHT TRANSMITTNCE}

Sensitivity analysis of degradation time and increased light transmittance of 'Dip coating' were done. Degradation of 'Dip coating' after 20 years and 30 years rather than after 10 years were analyzed. In the first case, it was assumed that the light transmittance of 'Dip coating' is $96.5 \%$ for the first 20 years. After 20 years, the light transmittance decreases by $0.62 \%$ each year. This results in the decrease of the mass of the tomatoes obtained under 'Dip coating' by $0.454 \mathrm{~kg}$ per year. The overall mass of tomatoes grown during 30 years period is $1731.23 \mathrm{~kg}$. In the second case, the light transmittance of 'Dip coating' is the same $96.5 \%$ for 30 years and the mass of tomatoes obtained each year is $58.84 \mathrm{~kg}$. The overall mass of tomatoes grown during 30 years is $1756.20 \mathrm{~kg}$.

The effect of the increase of the light transmittance of 'Dip coating' up to 99\% was examined. The mass of tomatoes obtained under 'Dip coating' with the light transmittance of $99 \%$ is $60.06 \mathrm{~kg} / \mathrm{m}^{2}$ per year. After 10 years the light transmittance of 'Dip coating' decreases by $0.31 \%$ each year, and this results in the decrease of the tomatoes production yield by $0.303 \mathrm{~kg}$ per year. Over 30 years, the mass of tomatoes under 'Dip coating' with 99\% light transmittance is $1738.17 \mathrm{~kg}$. Figure 4.10 shows the effect of the change of degradation time and light transmittance of 'Dip coating' on the yield of tomatoes obtained under 'Dip coating' over 30 years. Reference is referred to 'Dip coating at industrial scale' scenario where the degradation time of 'Dip coating' is after 10 years and the light transmittance is 96.5\%.

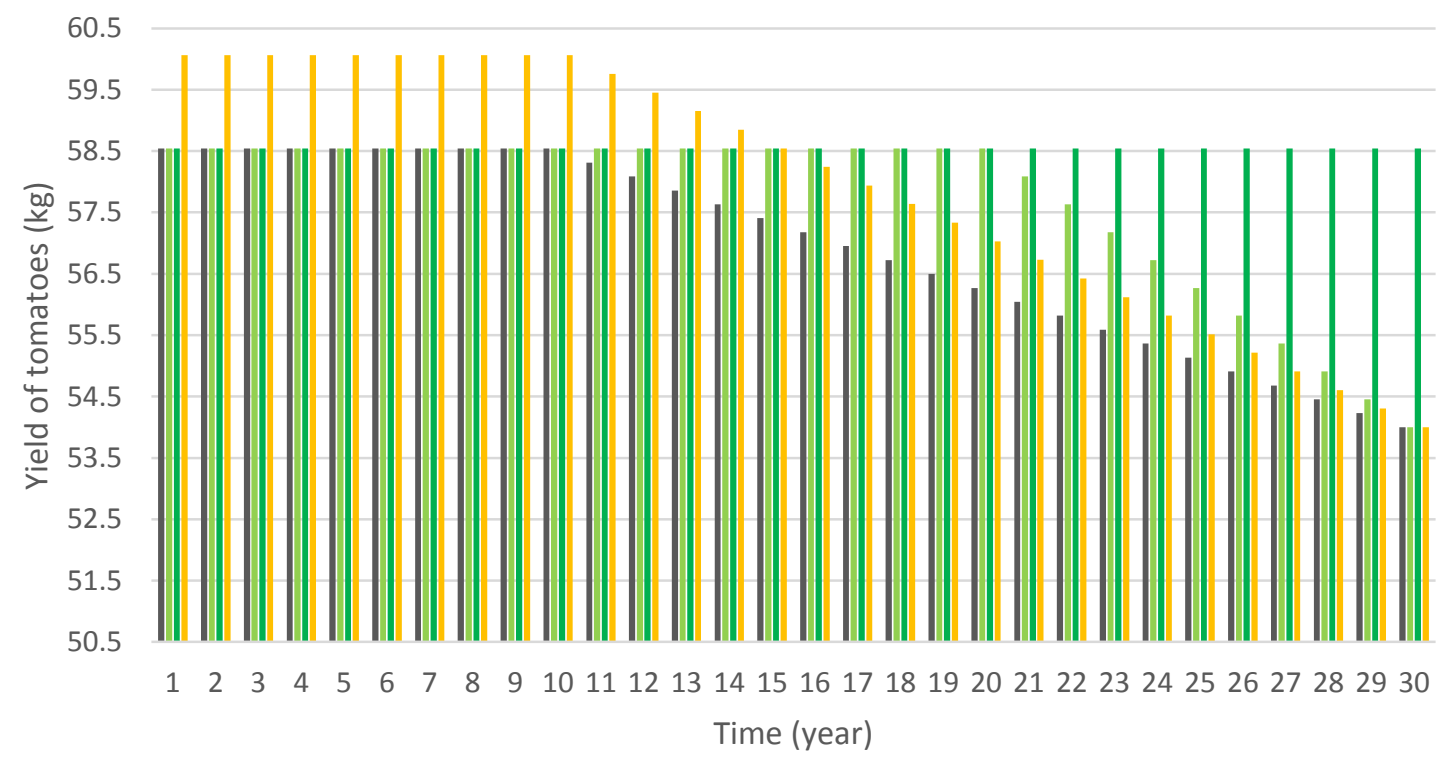

- Reference $\square$ Deagradation after 20 years $\square$ Degradation after 30 years $\square$ Transmittance of $99 \%$

Figure 4.10. Yield of tomatoes obtained under 'Dip coating' over 30 years period (author's image) 


\subsubsection{SOURCES OF ETHANOL PRODUCTION IN DIP COATING MANUFACTURING}

Ethanol constitutes the major part of the volume of sol-gel for 'Dip coating'. It was assumed that ethanol is produced from ethene rather than biomass. The details of the modelling part for this case can be found in Appendix B, Section 11.2.2.

\subsubsection{COATING FACTORY FOR DIP COATING IN CHINA}

Greenhouse companies prefer to buy greenhouse glass from the glass manufacturers in China rather than in Europe due to the lower price of greenhouse glass. Thus, the case where the coating factory is located in China was considered. Some changes in the modelling were added (Appendix B, Section 11.2.2).

\subsubsection{GLASS PRODUCTION FOR DIP COATING IN THE NETHERLANDS}

The option when the plant for the glass production is located at the same place as the coating factory in the Netherlands was assumed. The modifications added to 'Dip coating' system at industrial scale were added (Appendix B, Section 11.2.2).

\section{RESULTS}

\subsection{IMPACT ASSESSMENT}

\subsubsection{COMPARATIVE ANALYSIS RESULTS}

The environmental impacts of conventional greenhouse glass were estimated to be used as references. For this, three standards were chosen: 'Uncoated glass', 'Acid etching', and 'Sputtering' treated glass. For the novel coatings three scenarios were developed: laboratory scale production of the new coating ('lab-scale'), pilot scale production ('pilot scale'), and industrial scale production ('industrial scale'). In Figure 5.1, the relative environmental impacts for the references and three novel coating scenarios are compared with respect to the highest result per impact category.

Laboratory scale scenario shows relatively low environmental impacts exceeding the references by approximately $17-45 \%$. The pilot and industrial scale scenarios are within a few percent difference compared to the references. It was expected that 'Uncoated glass' would have higher impacts compared to the coated glass alternatives, however it is competitive to them. It could be observed that the impacts for 'Dip coating at pilot scale' and 'Dip coating at industrial scale' was reduced by approximately more than $20 \%$ and $30 \%$ compared to 'Dip coating at laboratory scale', respectively, in most of the impact categories. Surprisingly, 'Acid etching' has the highest impacts even compared to the laboratory scale scenario in Acidification and Photochemical Oxidation. 


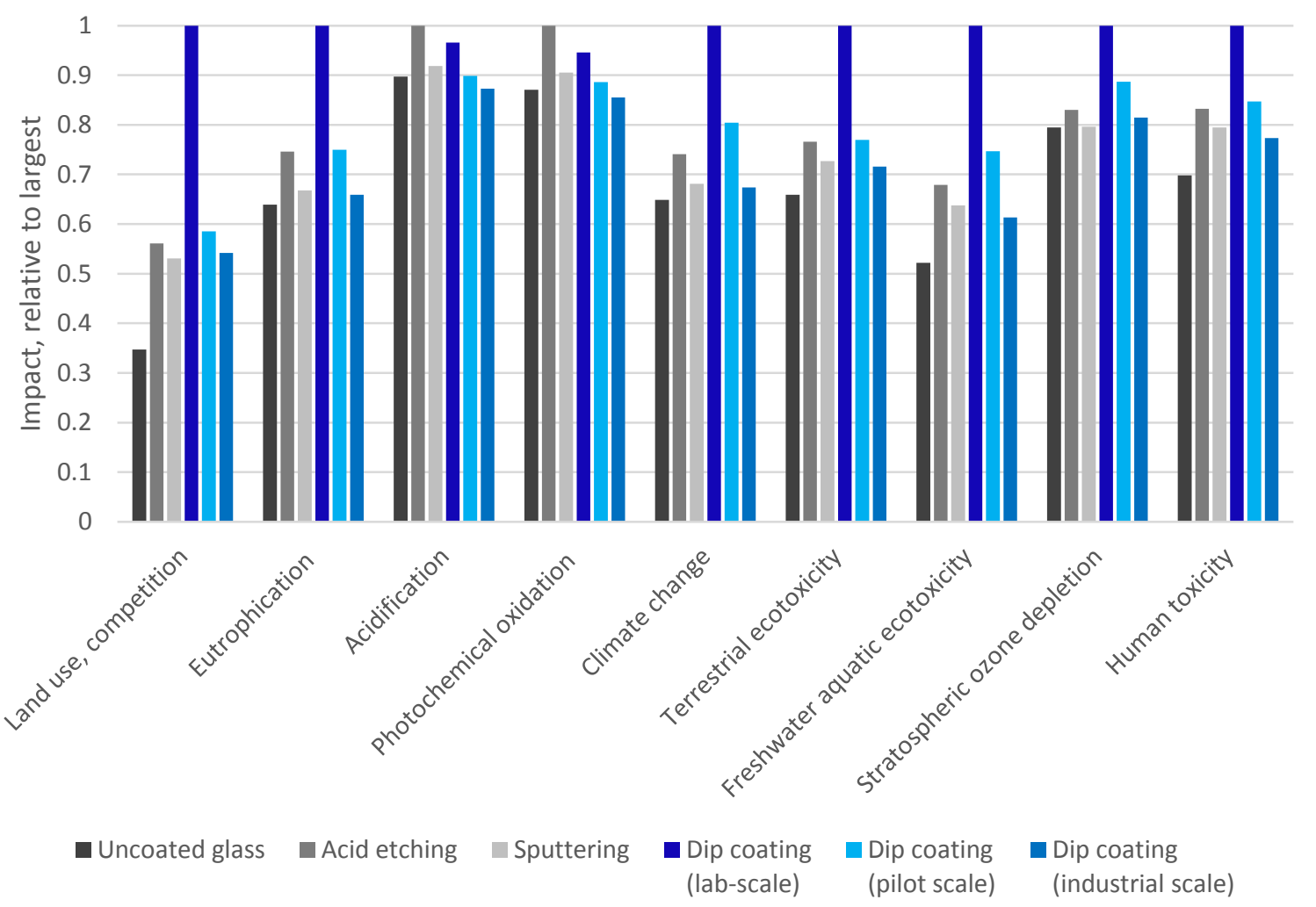

Figure 5.1. Comparative analysis of 'Dip coating' scenarios and the references (author's image)

\subsection{INTERPRETATION}

\subsubsection{CONTRIBUTION ANALYSIS RESULTS}

\subsubsection{REFERENCES}

The breakdown of processes responsible for the accumulated environmental impact for three references such as 'Uncoated glass', 'Acid etching', and 'Sputtering' were estimated and displayed in Figure 5.2.

For all three references and all impact categories the environmental impacts are largely dominated by the low-iron glass production. Use process is the second main contributor to most of the impact categories. Packing and other greenhouse glass production processes, in which the main constituent is packing of uncoated glass, have high contributions to Land Use. Coating production in 'Acid etching' and 'Sputtering' does not show high contributions which are approximately within 3-17\%. Coating production for 'Acid etching' has higher contributions than that in 'Sputtering' by nearly $5 \%$.

Contribution analysis of low-iron glass production was performed in order to find out what are the main causes of the high impacts of 'Acid etching' in Acidification and Photochemical Oxidation as it shows the highest impacts than other alternatives in the comparative analysis (Figure 5.1). Figure 11.8 in Appendix $\mathrm{C}$ shows the contribution analysis results of low-iron glass production processes. It was revealed that the electricity production in China and transport of raw materials by ship are the main contributors to Low-iron glass production in Acidification and Photochemical Oxidation. Specifically, the 
highest contributions to these impact categories come from emissions of sulfur dioxide to air released from the burning process of hard coal in power plant for the electricity production and operation of transoceanic freight ship.
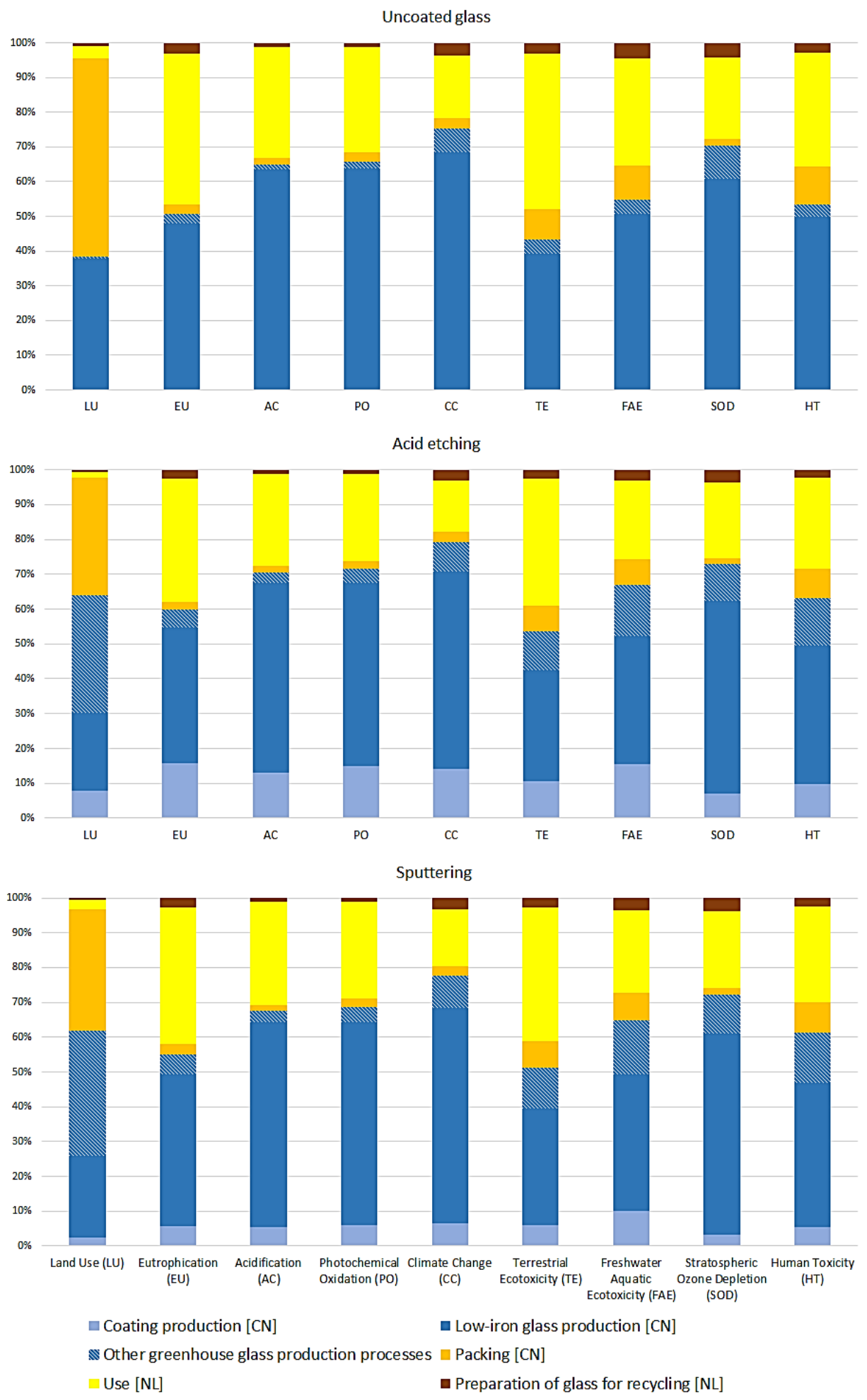

Figure 5.2. Contribution analysis results of the processes for the references (author's image) 
Contribution analysis of coating production for 'Acid etching' and 'Sputtering' was performed. According to Figure 5.3, electricity production is the main contributor to most of the impact categories. The amount of electricity required for coating glass with 'Acid etching' is greater than that needed for 'Sputtering' (Appendix D, Table 11.3), and thus, 'Acid etching' shows greater impacts than 'Sputtering' in the comparative results (Figure 5.1). Fluosilicic acid production and transport of raw materials are the second main causes of the impact categories for 'Acid etching' and 'Sputtering', respectively.

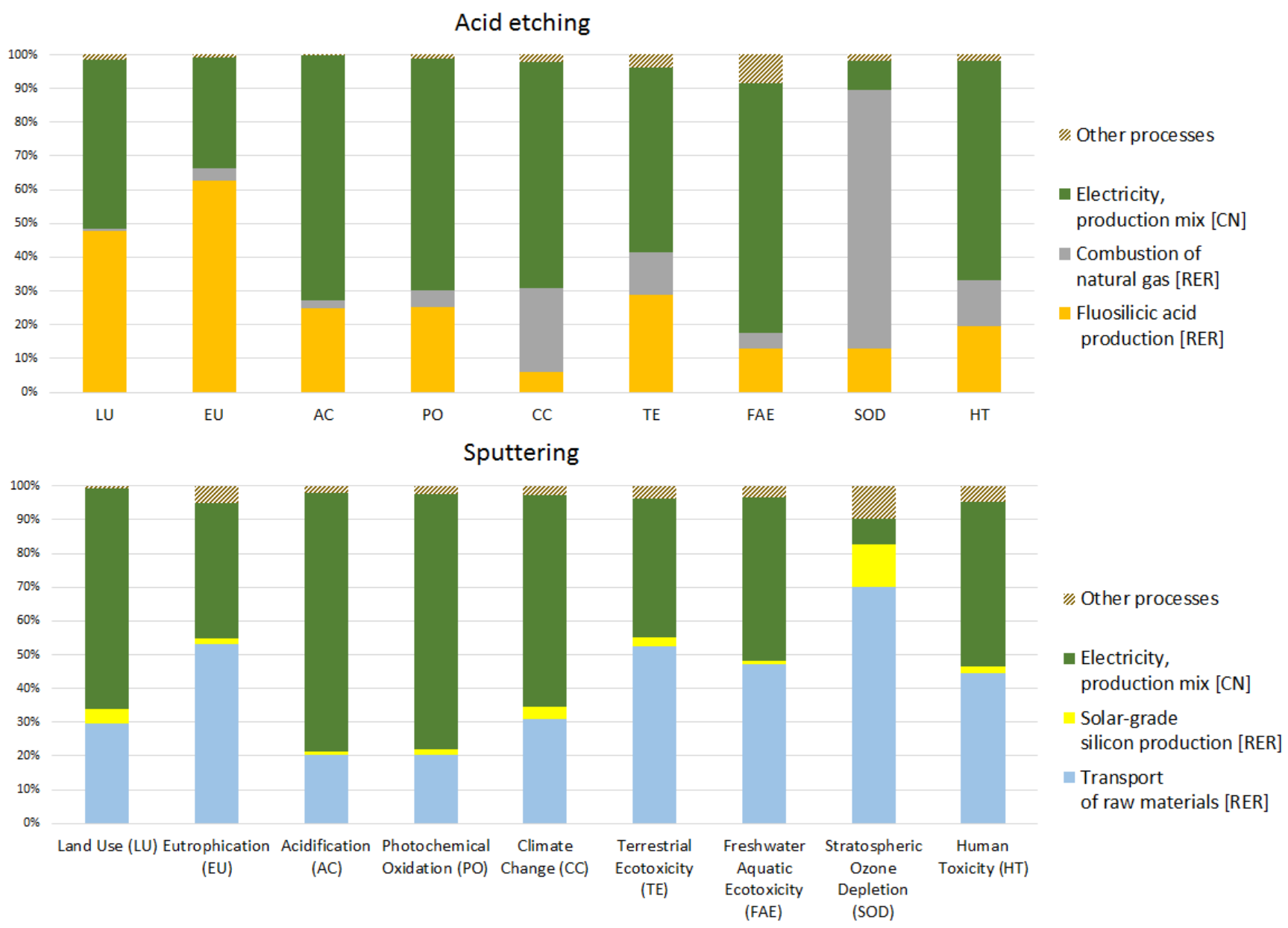

Figure 5.3. Contribution analysis results of coating production process for 'Acid etching' and 'Sputtering' (author's image)

\subsubsection{2 'DIP COATING'}

Contribution analysis of 'Dip coating' at different scales was performed. Figure 5.4 shows that low-iron glass production has the highest impacts in most of the impact categories among other processes. Land Use is mainly dominated by packing. Transport of glass by ship from China to the Netherlands shows contributions of $10-30 \%$. Use process has higher impacts in Terrestrial Ecotoxicity compared to other categories. Sol-gel production, packing, and preparation of recycling processes contribute 3-35\%. It can be observed that with larger scales the impacts coming from electricity production and ethanol manufacturing for sol-gel preparation decrease gradually. 
Dip coating at laboratory scale
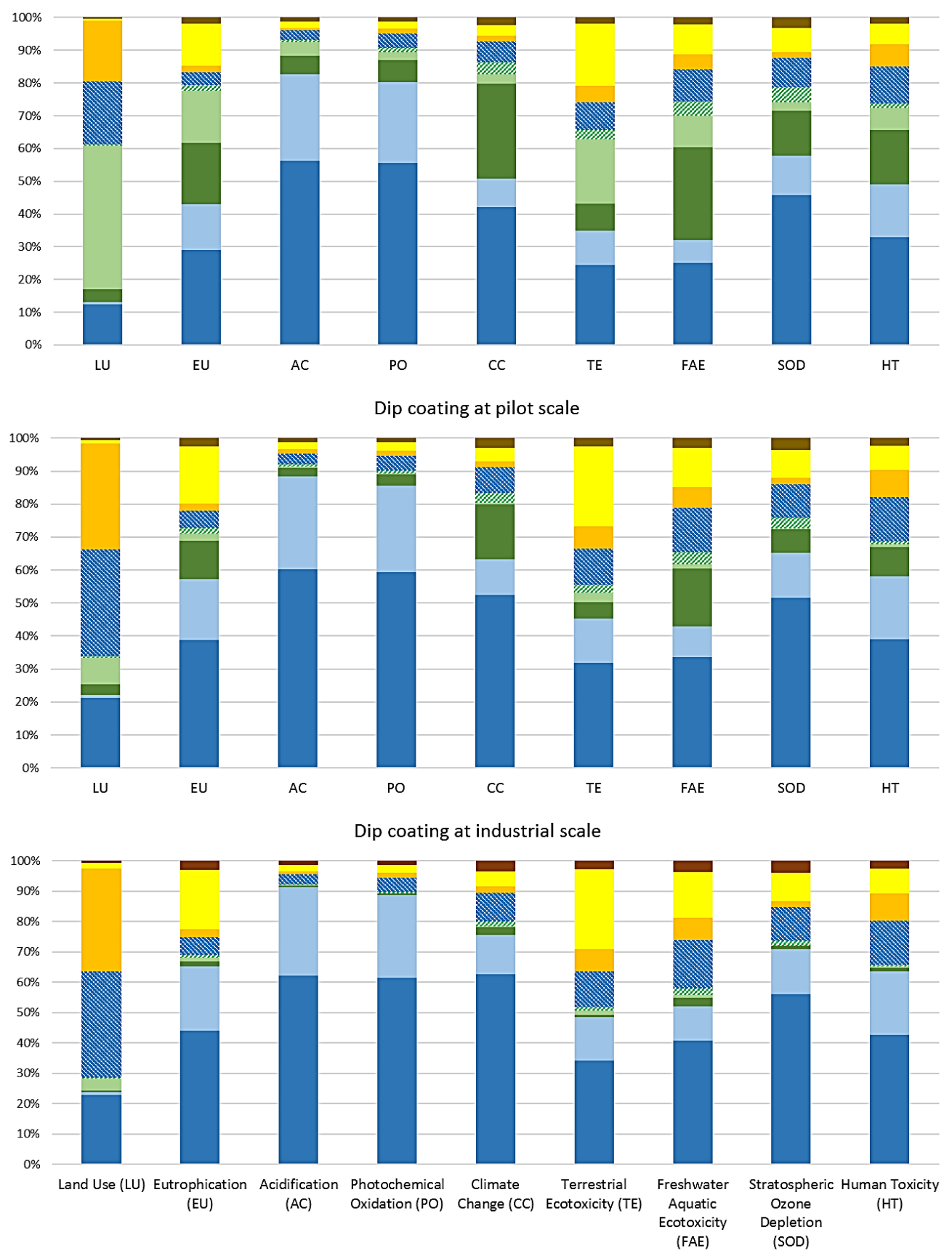

- Low-iron glass production [CN]

- Sol-gel: Electricity, production mix [NL]

\% Sol-gel: Other processes

$\square$ Packing [NL]

a Preparation of glass for recycling [NL] $\square$ Transport of uncoated glass by ship [OCE]

$\square$ Sol-gel: Ethanol, production from biomass [CN]

Other greenhouse glass production processes

Use [NL]

Figure 5.4. Contribution analysis of the processes for 'Dip coating' scenarios (author's image) 


\subsubsection{SENSITIVITY ANALYSIS RESULTS}

Sensitivity analysis for 'Dip coating at industrial scale' scenario was performed in order to explore which technological development options could result in improved environmental performance of 'Dip coating' in the future (Figure 5.5). Reference refers to 'Dip coating at industrial scale' scenario, the case where 'Dip coating' has the degradation time after 10 years and the light transmittance of $96.5 \%$, ethanol is produced from biomass, glass is manufactured in China, and the coating process is performed in the coating factory in the Netherlands. The Sensitivity results show that all alternatives do not show significant difference in the impact results within approximately $8 \%$ difference. The largest improvement is observed when the glass production plant is located in the Netherlands.

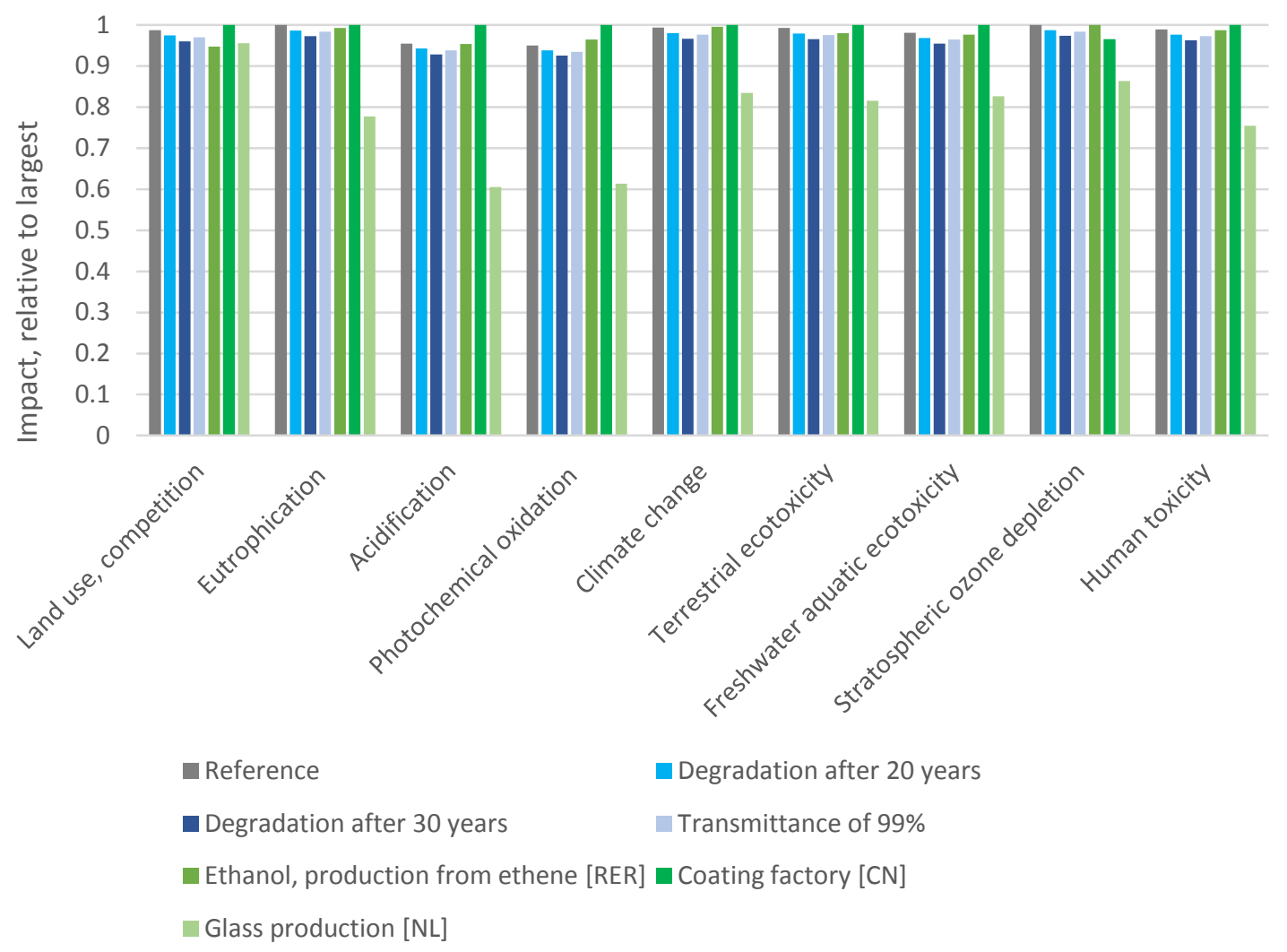

Figure 5.5. Sensitivity analysis results for 'Dip coating at industrial scale' scenario (author's image)

\section{DISCUSSION}

LCA has been accepted worldwide as a reliable framework for the analysis of the environmental performance of technologies. However, LCA was created as a method to analyze conventional technologies based on the existing data and is not applicable for the evaluation of innovations due to the uncertainties associated with them. Anticipatory LCA was evolved as an approach to explore possible environmental outcomes of innovations. In this study, Anticipatory with the aid of What-if scenarios was applied to analyze potential environmental impacts of 'Dip coating' early on R\&D. 
The main research question formulated at the beginning of the project "What are the possible paths which could lead to improved environmental performance of 'Dip coating' in the future?" was answered referring to the sub-questions:

a. "Do conventional coatings have lower environmental impacts than 'Dip coating' synthesized at laboratory scale?"

Comparative analysis of 'Dip coating at laboratory scale' scenario and the references was performed in order to answer this sub-question. It was expected that 'Dip coating' would have impact results greater than those of the references more than $50 \%$. However, the comparative analysis shows that the difference between 'Dip coating' and the references is not of high magnitude. This could be due to the fact that dip coating is a simple coating method where most of the processes do not require complex equipment.

Interestingly, 'Acid etching' shows greater impact results than 'Dip coating at laboratory scale' in Acidification and Photochemical Oxidation. This is due to the emissions of sulphur dioxide to air from burning hard coal used for the electricity production in China and from the operation of ship for transport of raw materials used for low-iron glass production. In addition, there is a release of sulphur dioxide to air from the silicon tetrafluoride manufacturing used for the production of fluosilicic acid production (atomistry.com, n.d.).

b. "Which changes should be made in the life-cycle processes in order to optimize 'Dip coating at laboratory scale'?"

Contribution analysis of 'Dip coating at laboratory scale' shows that the highest contributions come from electricity production and ethanol manufacturing in the sol-gel production process. The model employed for scaling-up largely was based on a simple scaled machine so that the impacts were affected mainly by a decrease of the coating volume, waste volume, and more efficient electricity consumption for the up-scaled system. It can be observed that with changes in the laboratory parameters related to electricity production and ethanol manufacturing, there is a decrease of the contribution results by 3.5326.38\% and 2.31-39.89\% at industrial scale, respectively. Overall, comparative analysis shows that 'Dip coating' improves its environmental performance with larger scales: the impacts for 'Dip coating' was decreased by more than $20 \%$ at pilot scale and more than nearly $30 \%$ at industrial scale compared to 'Dip coating at laboratory scale'.

c. "Does Dip coating have lower environmental impacts than 'Uncoated glass', 'Acid etching', and 'Sputtering'?"

The comparative results of 'Dip coating' and the references revealed that 'Dip coating at industrial scale' scenario has approximately the same environmental impacts as 'Acid etching' and 'Sputtering'. The small differences in the impact results among the alternatives is mainly due to the amount of electricity used for the production of the coatings. For example, 'Acid etching' shows higher impact results than 'Sputtering' and 'Dip coating' as it requires more electricity to produce anti-reflective coating for a certain area of glass than its counterparts. 'Dip coating at industrial scale' scenario performs environmentally better than 'Sputtering' in most of the categories (Figure 5.1) even though it requires the same amount of electricity for the coating production. This is due to the difference in the countries of electricity production: the electricity used in the sputtering factory is produced with mostly hard coal (79\%) in China, whereas the electricity used in the dip coating factory is produced mostly with natural gas (62\%) in the Netherlands. 
Given the lower transmittance of 'Uncoated glass', it was expected that 'Uncoated glass' would have greater impact results than other alternatives. However, the additional burdens of coating production make coated glass to have approximately the same environmental impacts. It can be concluded that probably, 'Acid etching', 'Sputtering', and 'Dip coating' bring economic benefits in terms of increased production yield of tomatoes because they can produce the same amount of tomatoes in a faster amount of time but do not bring significant benefits in terms of the environmental performance to greenhouse glass.

Sensitivity analysis was performed to answer the main research question: "What are the possible paths which could lead to improved environmental performance of 'Dip coating' in the future?" Different possible coating development pathways were examined in order to investigate in which cases 'Dip coating' could show lower environmental impacts compared to the references. Those cases included the slowing down of degradation and increase of the light transmittance of the coating, the change of the source of ethanol production from biomass to ethene, change of the location of the coating factory from the Netherlands to China, and the location of the glass production plant from China to the Netherlands. All of the alternatives have approximately the same environmental impacts. The case when glass is produced in the Netherlands shows the best results. This is due to the decreased distance of the transport of glass and the source of energy for the electricity production at the glass manufacturing plant. Thus, in order to reach the lowest possible environmental performance for the coating, it is recommended to use glass manufacture in the Netherlands rather than in China.

Contribution analysis for the processes of the references show that low-iron glass production has the highest contribution in most of the categories for all three references. Use process is the second main contributor to most of the impact categories. In the use phase, transport of greenhouse glass by ship has the highest impacts (Figure 11.10 in Appendix C). Land use is related to the contribution of packing of uncoated and coated glass. This is due to the occupation of softwood forest for packing of greenhouse glass into wooden boxes (Figure 11.9 in Appendix C). Probably, another packing alternative could be used for transport of glass instead of wooden boxes. On the one hand, this would result in the reduced impact results in Land Use, but on the other hand, this would probably lead to increased impacts in other impact categories. Coating production does not result in large impacts for 'Acid etching' and 'Sputtering'. Preparation of glass for recycling contributes the least to all impact categories.

Contribution analysis for the processes of 'Dip coating at industrial scale' scenario was performed. Most of the categories are largely related to low-iron glass production process. Land Use is mainly dominated by packing as in the case of the references. Transport of uncoated glass by ship from China to the Netherlands shows contributions between $10-30 \%$. Use process has higher impacts in Terrestrial Ecotoxicity among other impact categories, and this is mainly due to the release of chromium to agricultural soil (64\%) from the treatment of sewage in the waste water treatment (Figure 11.10 in Appendix C). Sol-gel production, packing, and preparation of recycling processes constitute in total of 3$35 \%$.

\section{RECOMMENDATIONS TO TNO}

The study revealed that 'Dip coating at industrial scale' scenario would have approximately the same impact results as conventional coatings such as 'Acid etching' and 'Sputtering'. Some recommendations 
regarding the improvement of the environmental performance of 'Dip coating' can be given. It would be beneficial in terms of the environmental aspects if TNO could achieve its aim in slowing down the degradation time of 'Dip coating'. For instance, degradation of 'Dip coating' after 20 years and 30 years rather than 10 years would give improved impact results by approximately $2 \%$ and $5 \%$ respectively. The increase of the light transmittance of the novel coating would also result in decreased impact results. The increase of the light transmittance up to $99 \%$ would have nearly the same impacts as the coating with the degradation time after 20 years. The change of the source of ethanol production from biomass to ethene would improve the environmental performance of 'Dip coating' in the Land Use impact category. However, this change would lead to the increased impacts in Photochemical Oxidation.

Dutch greenhouse companies prefer to buy coated glass from the Chinese manufacturers, and thus, the case where the location of the coating factory is in China rather in the Netherlands was considered. This option shows increased impacts of 'Dip coating' due to the fact that Chinese plant would operate using the electricity produced from hard coal. The option when glass is produced in the Netherlands rather than in China was investigated. It would be recommended to use glass manufacture in the Netherlands since this would result in the best environmental performance of 'Dip coating' among other examined possible options.

\section{METHODOLOGICAL REFLECTION AND SUGGESTED IMPROVEMENTS}

The thesis work recommends the use of LCA as an explorative approach for the environmental assessment of innovations in the early stages of technological development. It shares the same aim as Responsible Research and Innovation and Technology Assessment which is to guide technology towards improved environmental performance. Based on the research carried out in this thesis work, it could be concluded that Anticipatory LCA could be successfully used in the environmental analysis of innovations early in R\&D. However, the following study has its drawbacks in the methodology part of the research.

Some suggestions to the improvement of the methodology applied in Anticipatory LCA can be made. At the beginning of the research, it would be useful to perform stakeholder analysis to map the relevant stakeholders for the research. This assessment would help to view their level of interest and influence in the project. The determined stakeholders could be asked for the participation in the construction of What-if scenarios. Probably, the uncompleted list of stakeholders would consist of the researchers at TNO, Universities, experts from the coating and curing process fields, competitors of TNO such companies as DSM, Sunarc, and AGC, greenhouse glass manufacturers and suppliers, Greenports, local residents, and the Government.

Some changes in the data collection stage could be added. Firstly, the processes such as packing of greenhouse glass and preparation of glass for recycling were modelled using literature and websites due to the time constraints. Probably, data collection based on the interviews of the companies would give complete up-to-date information rather than data from literature and websites. This approach was used in data collection of greenhouse glass cleaning process: Poot Kasdekreiniging and Van der Waay companies provided required data on the washing process via phone conversations and emails. Secondly, the end-of-life phase of greenhouse glass was modelled assuming that there is no separation of sol-gel coating from the glass substrate in the preparation of glass for recycling process. The technology for the removal of the coatings composed of nanoparticles from glass has not been 
practiced in the Netherlands yet. In general, $\mathrm{SiO}_{2}$ nanoparticles are not considered to be hazardous to environment and human health (Rhodia, 2012). However, the in-depth research of $\mathrm{SiO}_{2}$ nanoparticles toxicity has not been conducted in literature. Cytotoxicity of $\mathrm{SiO}_{2}$ nanoparticles is currently studied by the researchers (Petushkov et al., 2010). Probably, it would be better to consider the case when sol-gel coating is separated from glass and to study possible end-of-life pathways of nanoparticles.

Each type of scenarios e.g. Normative scenarios or Backcasting can be used to a particular case study. The system of 'Dip coating' does not exhibit various options of complex contextual environment. Thus, What-if scenarios were used with the purpose to scale-up 'Dip coating', and explore different pathways of possible technological development not considering more complex systems such as e.g. socio-economic.

Some difficulties were raised in the methodology development for the scenarios construction. TNO is synthesizing the coating in the laboratory scale, and this technology has not been implemented in larger scales yet. No information was found on the required data for the modelling of dip coating method at industrial scale in different companies' websites. Therefore, three companies AGC, Prinz Optics $\mathrm{GmbH}$, and SCHOTT AG, which use dip coating method for covering glass with the coatings at industrial scale, were contacted via phone calls and e-mails. They were asked to share data on the dip coating process from their factories. Unfortunately, they could not provide this information due to the confidentiality issue. Thus, literature was used for the development of What-if scenarios. The variables were chosen based on the results of the contribution analysis of 'Dip coating at laboratory scale'. Expert consultation on the variables and variable conditions was given by Dr. Aike Wypkema and Dr. Andrzej Stankiewicz.

\section{CONCLUSION AND FUTURE RESEARCH}

\subsection{CONCLUSION}

Anticipatory LCA was performed to guide R\&D of sol-gel coating technology at TNO based on LCA impact results. 'Dip coating' is being synthesized in the laboratory scale and has not been implemented in the market yet. Scaling-up of 'Dip coating' to pilot and industrial scales was performed using What-if scenarios method, and comparative LCA of 'Dip coating' and conventional alternatives was done. The results show that the difference in the impacts between 'Dip coating at laboratory scale' scenario and the references is not of a high magnitude as it was expected. This could be due to the fact that dip coating technique is a simple method which does not require complex equipment. 'Dip coating at industrial scale' scenario has approximately the same environmental impacts as the reference coatings. It should be noted that 'Uncoated glass' has nearly the same impact results as its counterparts. It could be concluded that 'Acid etching', 'Sputtering', and 'Dip coating' do not add any benefits to greenhouse glass in terms of environmental performance. Instead, there is an economic advantage of using coated glass such as increased yield of tomatoes.

Several recommendations were given to TNO to further decrease the environmental impacts of 'Dip coating'. Those cases involve retardation of degradation time and increase in the light transmittance of 'Dip coating' up to 99\%, change in the source of ethanol production from biomass to ethene, and change of the location of glass production plant. The best environmental performance 
among these options shows the option when the glass manufacturing factory is located in the Netherlands rather than in China.

\subsection{SUGESSIONS FOR FUTURE RESEARCH}

\subsubsection{SCENARIO RESEARCHERS}

Recommendations for the future research can be drawn concerning the scenarios development for this project. First of all, What-if scenarios construction could be done differently than the way it was done in this work. The pilot and industrial scale scenarios for 'Dip coating' of this LCA study were created based on the modifications of 'Dip coating at laboratory scale' scenario using literature and discussed with the experts in the coating and curing technologies. One of the options for the scenario development could be to use data of 'Dip coating' from the industry. This attempt was done contacting three companies which use dip coating method but due to the confidentiality concerns this data was unavailable. Probably, other companies could be contacted, and negotiation between the researcher and the company could be established so that the company could become the second commissioner for the project. In case data cannot be received from the factory, and scenario researcher would decide to apply the same What-if scenario approach as in this thesis work, GMA is recommended to be used instead of MGMA. Shared opinions from different experts of 'Dip coating' and scaling-up methods would probably give other sets of variables and variable conditions for the scenarios development.

\subsubsection{LCA RESEARCHERS}

Suggestions for future research regarding LCA part of the project could be given based on the experience gained from the LCA analysis. Different reference alternatives for the case study could be selected. In this research, 'Uncoated glass', 'Acid etching', and 'Sputtering' were analyzed, however, other conventional coatings produced by e.g. thermal deposition method or spin coating could be evaluated as well. These coating techniques are not in Ecoinvent V2.2 database as acid etching and sputtering methods, and thus, data should be collected from the factories.

Data collection step could be performed differently than in this research. Data for the modelling of the foreground processes obtained by contacting the companies and industries could give more completed data on the process performed in the real life in the certain location of the case study. However, some of the foreground processes e.g. preparation of glass for recycling were constructed using literature due to the limitation of time. It would be recommended to design such processes using data received directly from the industries via questionnaires and interviews. Such approach was successfully used in the data collection in this case study for the production of 'Dip coating at laboratory scale' from TNO and cleaning procedure of the greenhouses and cleaning machines from Poot Kasdekreiniging and Van der Waay companies, respectively.

The modelling part of this research could be improved. For instance, some of the processes could be modelled in more detail. For example, recycling process of the used glass was not considered in the modelling of the references and 'Dip coating' to avoid uncertainties which could be added by allocation. It could be suggested to model closed loop or open loop recycling of used glass in the future research to see how the impact results of different alternatives would change. However, appropriate allocation 
method e.g. economic, mass, or energy should be selected precisely with the low probability of uncertainty.

Sensitivity analysis on the degradation time and increased light transmittance of 'Dip coating', change of the source of ethanol production, change of the location of the coating factory and glass production plant was performed in this study. It is suggested that Sensitivity analysis on other possible pathways of the future sustainable development of 'Dip coating' could be done for the LCA research. For instance, the case where the wooden packing of glass is changed to another packing alternative would be checked to see how this would affect the Land Use impact category and determine if other categories would be influenced or not.

Anticipatory LCA of this research was focused only on the environmental aspect, and probably, for the future research it could be a good idea to conduct Life Cycle Cost Analysis for 'Dip coating at industrial scale' scenario as a part of the economic assessment in addition to LCA. 


\section{REFERENCES}

\subsection{SCIENTIFIC LITERATURE}

Aegerter, M. A., \& Mennig, M. (Eds.). (2013). Sol-gel technologies for glass producers and users. Springer Science \& Business Media.

Andersson, B. A., \& Jacobsson, S. (2000). Monitoring and assessing technology choice: the case of solar cells. Energy Policy, 28(14), 1037-1049.

Avison, J. (2014). The world of physics. Nelson Thornes.

Baran, M. L. (Ed.). (2016). Mixed Methods Research for Improved Scientific Study. IGI Global.

Bhander, G. S., Hauschild, M., \& McAloone, T. (2003). Implementing life cycle assessment in product development. Environmental Progress, 22(4), 255-267.

Bijker, W. E., Hughes, T. P., \& Pinch, T. (1987). The social construction of technological systems: New directions in the sociology and history of technology. MIT press.

Blengini, G. A., Busto, M., Fantoni, M., \& Fino, D., 2012. Eco-efficient waste glass recycling: Integrated waste management and green product development through LCA. Waste management, 32(5), 1000-1008.

Börjeson, L., Höjer, M., Dreborg, K. H., Ekvall, T., \& Finnveden, G. (2006). Scenario types and techniques: towards a user's guide. Futures, 38(7), 723-739.

Both, A. J. (2002). Greenhouse glazing. Horticultural Engineering Newsletter. Rutgers Cooperative Extension, 17, 5-6.

Brinker, C. J., Frye, G. C., Hurd, A. J., \& Ashley, C. S. (1991). Fundamentals of sol-gel dip coating. Thin solid films, 201(1), 97-108.

Çamurlu, H., Kesmez, Ö., Burunkaya, E., Kiraz, N., Yeşil, Z., Asiltürk, M., \& Arpaç, E. (2012). Sol-gel thin films with anti-reflective and self-cleaning properties. Chemical Papers, 66(5), 461-471.

Coates, J. F. (2001). A 21st century agenda for technology assessment. Technological Forecasting and Social Change, 67(2), 303-308.

Correll, D. L. (1998). The role of phosphorus in the eutrophication of receiving waters: A review. Journal of Environmental Quality, 27(2), 261-266.

Donald, M., \& Wajcman, J. (1986). Introductory Essay: The Social Shaping of Technology. idem (eds), 2-25.

Dueck, T., Janse, J., Li, T., Kempkes, F., \& Eveleens, B. (2012). Influence of diffuse glass on the growth and production of tomato. In VII International Symposium on Light in Horticultural Systems 956 (pp. 75-82).

European Commission. (2011a) DG Research workshop on Responsible Research \& Innovation in Europe.

European Commission. (2011b). International Reference Life Cycle Data System (ILCD) HandbookRecommendations for Life Cycle Impact Assessment in the European context. First edition. EUR 24571 EN. Luxemburg. Publications Office of the European Union; 2011.

European Commission. (December 13, 2016). HORIZON 2020 - Work Programme 2016 - 2017 Science with and for Society

Field, C.B., Barros, T.F. Stocker, Qin, D., Dokken, D.J., Ebi, K.L., Mastrandrea, M.D., Mach, K.J., Plattner, G.K., Allen, S.K., Tignor, M. and P.M. Midgley. (2012). IPCC report. Managing the Risks of Extreme Events and Disasters to Advance Climate Change Adaptation. Cambridge University Press. p. 582.

Fisher, E., Mahajan, R. L., \& Mitcham, C. (2006). Midstream modulation of technology: governance from within. Bulletin of Science, Technology \& Society, 26(6), 485-496. 
Frey, H., \& Khan, H. R. (2010). Handbook of thin film technology. Springer.

Frischknecht, R., Jungbluth, N., Althaus, H.-J., Doka, G., Dones, R., Heck, T., Hellweg, S., Hischier, R., Nemecek, T., Rebitzer, G., \& Spielmann, M., 2005, The ecoinvent database: Overview and methodological framework, International Journal of Life Cycle Assessment 10, 3-9.

Gibbons, M., Limoges, C., Nowotny, H., Schwartzman, S., Scott, P., \& Trow, M. (1994). The new production of knowledge: The dynamics of science and research in contemporary societies. Sage.

Gilbert, P. U. P. A., \& Haeberli, W. (2008). Physics in the Arts. Academic Press.

Gorman, M. E., Groves, J. F., \& Catalano, R. K. (2004). Societal dimensions of nanotechnology. IEEE Technology and Society Magazine, 23(4), 55-62.

Grunwald, A., \& Achternbosch, M. (2013). Technology assessment and approaches to early engagement. In Early engagement and new technologies: Opening up the laboratory (pp. 15-34). Springer Netherlands.

Grunwald, A. (2014). Technology assessment for responsible innovation. In Responsible Innovation 1 (pp. 15-31). Springer Netherlands.

Guinée, J.B.; Gorrée, M.; Heijungs, R.; Huppes, G.; Kleijn, R.; Koning, A. de; Oers, L. van; Wegener Sleeswijk, A.; Suh, S.; Udo de Haes, H.A.; Bruijn, H. de; Duin, R. van; Huijbregts, M.A.J. 2002. Handbook on Life Cycle Assessment Operational Guide to the ISO Standards. I: LCA in Perspective. Ila: Guide. Ilb: Operational Annex. III: Scientific Background. Dordrecht: Kluwer Academic Publishers.

Gupta, S., K. (2010). Engineering Physics: Vol. 1. Krishna Prakashan Media

Hanan, J. J. (1997). Greenhouses: advanced technology for protected horticulture. CRC press.

Han van de Wiel. (2015). Closing the glass recycling loop. Glass has eternal life. Dutch Waste Management Association. [Online] Available at:

http://www.wastematters.eu/uploads/media/DWMA_Closing_the_glass_recycling_loop.pdf [Accessed on February 21, 2017]

Harris, D. C. (1999). Materials for infrared windows and domes: properties and performance. SPIE press.

Haye, S., Slaveykova, V. I., \& Payet, J. (2007). Terrestrial ecotoxicity and effect factors of metals in life cycle assessment (LCA). Chemosphere, 68(8), 1489-1496.

Hébert, M., Hersch, R. D., \& Emmel, P. (2015). Fundamentals of optics and radiometry for color reproduction. Handbook of Digital Imaging.

Hellström, T. (2003). Systemic innovation and risk: technology assessment and the challenge of responsible innovation. Technology in Society, 25(3), 369-384.

Hemming, S., Kempkes, F. L. K., \& Mohammadkhani, V. (2009). New glass coatings for high insulating greenhouses without light losses-energy saving, crop production and economic potentials. In International Symposium on High Technology for Greenhouse Systems: GreenSys2009 893 (pp. 217226).

Hetherington, A. C., Borrion, A. L., Griffiths, O. G., \& McManus, M. C. (2014). Use of LCA as a development tool within early research: challenges and issues across different sectors. The International Journal of Life Cycle Assessment, 19(1), 130-143.

Hill, C. T. (1996, June). The congressional office of technology assessment a retrospective and prospects for the post-OTA world. In Technology and Society Technical Expertise and Public Decisions, 1996. Proceedings., 1996 International Symposium on 1996 Jun 21 (pp. 4-12). IEEE.

Hillman, K. M., \& Sandén, B. A. (2008). Exploring technology paths: the development of alternative transport fuels in Sweden 2007-2020. Technological Forecasting and Social Change, 75(8), 1279-1302. 
ISO 14040 International Standard (2006). Environmental management - Life Cycle Assessment - Principles and framework. International Organization for Standardization: Geneva.

Kushnir, D., \& Sandén, B. A. (2011). Multi-level energy analysis of emerging technologies: a case study in new materials for lithium ion batteries. Journal of Cleaner Production, 19(13), 1405-1416.

Lipták, B. G., \& Venczel, K. (Eds.). (2016). Analysis and Analyzers (Vol. 2). CRC Press.

Mackay, H., \& Gillespie, G. (1992). Extending the social shaping of technology approach: ideology and appropriation. Social studies of science, 22(4), 685-716.

Marcelis, L. F. M., Broekhuijsen, A. G. M., Meinen, E., Nijs, E. M. F. M., \& Raaphorst, M. G. M. (2005, June). Quantification of the growth response to light quantity of greenhouse grown crops. In $V$ International Symposium on Artificial Lighting in Horticulture 711 (pp. 97-104).

Ohring, M. (1995). Engineering materials science. Academic press.

Owen, R., Baxter, D., Maynard, T., \& Depledge, M. (2009). Beyond regulation: risk pricing and responsible innovation. Environmental Science \& Technology, 43(18), 6902-6906.

Owen, R., \& Goldberg, N. (2010). Responsible innovation: a pilot study with the UK Engineering and Physical Sciences Research Council. Risk Analysis, 30(11), 1699-1707.

Owen, R., Macnaghten, P., \& Stilgoe, J. (2012). Responsible research and innovation: From science in society to science for society, with society. Science and public policy, 39(6), 751-760.

Pastirik, E. (1980). Anti-reflection coatings applied by acid leaching process. Motorola INC.

Petushkov, A., Ndiege, N., Salem, A. K., \& Larsen, S. C. (2010). Toxicity of silica nanomaterials: zeolites, mesoporous silica, and amorphous silica nanoparticles. Advances in Molecular Toxicology, 4, 223-266.

Pini, M., Cedillo González, E. I., Neri, P., Siligardi, C., \& Ferrari, A. M. (2017). Assessment of Environmental Performance of $\mathrm{TiO}_{2}$ Nanoparticles Coated Self-Cleaning Float Glass. Coatings, 7(1), 8.

Pinch, T. J., \& Bijker, W. E. (1984). The social construction of facts and artefacts: Or how the sociology of science and the sociology of technology might benefit each other. Social studies of science, 14(3), 399-441.

Pressman, A. (2007). Architectural graphic standards. John Wiley \& Sons.

Prevo, B. G., Hwang, Y., \& Velev, O. D. (2005). Convective assembly of antireflective silica coatings with controlled thickness and refractive index. Chemistry of materials, 17(14), 3642-3651.

Quist, J. (2013). Backcasting and Scenarios for Sustainable Technology Development. In Handbook of Sustainable Engineering (pp. 749-771). Springer Netherlands.

Ritchey, T. (2011). Wicked problems-social messes: Decision support modelling with morphological analysis (Vol. 17). Springer Science \& Business Media.

Rodríguez, H., Fisher, E., \& Schuurbiers, D. (2013). Integrating science and society in European Framework Programmes: Trends in project-level solicitations. Research Policy, 42(5), 1126-1137.

Sánchez-Cruces, E., Barrera-Calva, E., Lavanderos, K., \& González, F. (2014). Life Cycle Analysis (LCA) of Solar Selective Thin Films by Electrodeposition and by Sol-gel Techniques. Energy Procedia, 57, 2812-2818.

Schittich, C., Staib, G., Balkow, D., Schuler, M., \& Sobek, W. (2007). Glass construction manual. Walter de Gruyter.

Shelby, J. E. (2005). Introduction to glass science and technology. Royal Society of Chemistry.

Spatari, S., Bagley, D. M., \& MacLean, H. L. (2010). Life cycle evaluation of emerging lignocellulosic ethanol conversion technologies. Bioresource technology, 101(2), 654-667.

Stilgoe, J., Owen, R., \& Macnaghten, P. (2013). Developing a framework for responsible innovation. Research Policy, 42(9), 1568-1580. 
Stranddorf, H. K., Hoffmann, L., \& Schmidt, A. (2005). LCA technical report: impact categories, normalization and weighting in LCA. Update on selected EDIP97-data.

Sutcliffe, H. (2011). A report on Responsible Research and Innovation. MATTER and the European Commission.

Swart, R. J., Raskin, P., \& Robinson, J. (2004). The problem of the future: sustainability science and scenario analysis. Global environmental change, 14(2), 137-146.

UMassAmherst. (2016). Cleaning and Disinfecting the Greenhouse. [Online] Available at: https://www.cleanipedia.com/gb/house-exterior/how-to-clean-a-greenhouse [Accessed: December 9, 2016]

Van Den Ende, J., Mulder, K., Knot, M., Moors, E., \& Vergragt, P. (1998). Traditional and modern technology assessment: toward a toolkit. Technological Forecasting and Social Change, 58(1), 5-21.

Villares, M., Işıldar, A., van der Giesen, C., \& Guinée, J. (2017). Does ex ante application enhance the usefulness of LCA? A case study on an emerging technology for metal recovery from e-waste. The International Journal of Life Cycle Assessment, 1-16.

Von Schomberg, R. (2012). Prospects for technology assessment in a framework of responsible research and innovation. In Technikfolgen abschätzen lehren (pp. 39-61). VS Verlag für Sozialwissenschaften.

Wender, B. A., Foley, R. W., Hottle, T. A., Sadowski, J., Prado-Lopez, V., Eisenberg, D. A., ... \& Seager, T. P. (2014). Anticipatory life-cycle assessment for responsible research and innovation. Journal of Responsible Innovation, 1(2), 200-207.

Wender, B. A., \& Seager, T. P. (2011). Towards prospective life cycle assessment: Single wall carbon nanotubes for lithium-ion batteries. In Sustainable Systems and Technology (ISSST), 2011 IEEE International Symposium on (pp. 1-4). IEEE.

Wender, B. A., Foley, R. W., Prado-Lopez, V., Ravikumar, D., Eisenberg, D. A., Hottle, T. A. \& Bates, M. E. (2014a). Illustrating anticipatory life cycle assessment for emerging photovoltaic technologies. Environmental science \& technology, 48(18), 10531-10538.

Williams, R., \& Edge, D. (1996). The social shaping of technology. Research policy, 25(6), 865-899.

Winston, L. R. (2010). Bad ideas? An arresting history of our inventions. Random House.

Zhang, Q., Huang, J. Q., Zhao, M. Q., Qian, W. Z., \& Wei, F. (2011). Carbon nanotube mass production: principles and processes. ChemSusChem, 4(7), 864-889.

Zuel, D. C. (1990). U.S. Patent No. 4,944,986. Washington, DC: U.S. Patent and Trademark Office.

\subsection{NON-SCIENTIFIC LITERATURE}

AGC. (2012). Float glass \& technology. [Online] Available on: http://www.agcglass.eu/English/Homepage/Products/Float-glass-technology/page.aspx/958 [Accessed on March 5, 2017]

Alibaba.com. (2017a). Automatic Ultrasonic Cleaning and Dip Coating Machine. [Online] Available on: https://www.alibaba.com/product-detail/Automatic-Ultrasonic-Cleaning-and-DipCoating_243891436.html?spm=a2700.7724838.0.0.ER84DA [Accessed on May 17, 2017]

Alibaba.com (2017b). Packing palletizing machine/ wood pallet making machine/ wooden box packaging. Available on: https://wholesaler.alibaba.com/product-detail/packing-palletizing-machine-wood-palletmaking_60360678689.html?spm=a2700.7724838.0.0.QQ0Qvz\&s=p [Accessed on May 25, 2017] 
Atomistry.com. (n.d.) Silicon Tetrafluoride. [Online] Available on:

http://silicon.atomistry.com/silicon_tetrafluoride.html [Accessed on May 25, 2017]

Chemat Technology, Inc. (n.d.). Dip Master 201. [Online] Available at:

https://www.laboratorynetwork.com/doc/dip-coater-0001 [Accessed: February 14, 2017]

EURELECTRIC. (2003). Efficiency in Electricity Generation. [Online] Available at:

file:///C:/Users/Natalya/Downloads/EEGJulyrevisedFINAL1-2003-030-0548-2-.pdf [Accessed: February

14, 2017]

FutureAG. (August 20, 2014). KASPRO agricultural simulator. [Online] Available at:

http://futureag.info/tag/kaspro/ [Accessed: January 16, 2017]

France in the UK. 92011). Franco-British workshop on responsible Innovation: From concepts to practice.

[Online] Available at: http://www.ambafrance-uk.org/Franco-British-workshop-on,18791 [Accessed:

February 6, 2017]

Google Maps. (n.d.). Directions for driving from Westland-Oostland Greenport, the Netherlands, to TNO in Eindhoven, the Netherlands. [Online]. Google. Available on: https://www.google.nl/maps/dir/TNO++Locatie+Eindhoven,+De+Rondom,+Eindhoven/2665+Bleiswijk/@51.7601774,4.4127249,9z/data=!3m1! 4b1!4m13!4m12!1m5!1m1!1s0x47c6d8e72b5a4425:0x45938d5d04a8528f!2m2!1d5.4911333!2d51.446 5983 !1m5!1m1!1s0x47c5ce9caebfca09:0x9322ffe85f43de88!2m2!1d4.5380236!2d52.007607 [Accessed on March 5, 2017]

Greenport Holland. (n.d.). Six Greenports. [Online] Available on: http://greenportholland.com/zes-greenports [Accessed on March 19, 2017]

HilgenFeld, F. (2011). Structured Glass: More Efficiency, More Yield. [Online] Available on: http://www.energeticaindia.net/download.php?seccion=articles\&archivo=DYXaU3FcvGrOVByrcHjr6tKENkK95h197NYPFer1kYE 7a3n3Mj56u0.pdf [Accessed on March 5, 2017]

Holland. (2016). Economic significance of the greenhouse sector: massive growth. [Online] Available at: http://www.dutchagrofood.com/english/horticulture/sectors/greenhouse-culture/ [Accessed:

December 8, 2016]

Horti daily. (2016). Dutch horticulture suppliers unified in Holland Horti International. [Online] Available at: http://www.hortidaily.com/article/25187/Dutch-horticulture-suppliers-unified-in-Holland-HortiInternational [Accessed: December 8, 2016]

Monaco, G. (2016). Coating Technology: Evaporation vs Sputtering. Satisloh. [Online] Available at: http://www.satisloh.com/fileadmin/contents/Whitepaper/Coating_Technology_final.pdf [Accessed: December 8, 2016]

Nolan Fuel Oils Ltd. (n.d.) Unleaded Petrol. [Online] Available at: http://www.nolanoils.co.uk/unleaded.php [Accessed on February 21, 2017]

Oxford Vacuum Science. (n.d.). Sputter deposition. [Online] Available on: http://www.oxfordvacuum.com/background/thin_film/sputtering.htm [Accessed on March 15, 2017]

Petropoulos, M. C., Foley, G. M., Swain, E. A., Kilmer, D. J., Thomas, M. S., Pietrzykowski Jr, S. J., ... \& Millonzi, R. P. (1998). U.S. Patent No. 5,725,667. Washington, DC: U.S. Patent and Trademark Office.

Phillips, S. (2016). The Netherlands horticulture market. (pp. 1-13, Rep. No. NL6026). The Hague, the Netherland. Retrieved from USDA Foreign Agricultural Service: 
https://gain.fas.usda.gov/Recent\%20GAIN\%20Publications/The\%20Netherlands\%20Horticulture\%20Ma rket_The\%20Hague_Netherlands_8-3-2016.pdf

Poot Kasdekreiniging. (2015). Greenhouse Roof Cleaning. [Online] Available at:

http://www.pootkasdekreiniging.nl/en/portfolio_page/roofcleaning/ [Accessed on February 21, 2017]

Ports.com. (n.d.). Sea route \& distance. [Online] Available on: http://ports.com/sea-route/port-of-

singapore,singapore/port-of-

rotterdam, netherlands/\#/?a=4595\&b=0\&c=Port\%20of\%20Shanghai,\%20China\&d=Port\%20of\%20Rotter dam,\%20Netherlands [Accessed on March 5, 2017]

Quora. (2014). Why are anti-reflective coatings so delicate? [Online] Available at:

https://qph.ec.quoracdn.net/main-qimg-7e937652f3b8901507067087491d16f1 [Accessed on March 8, 2017]

Rhodia. (2012). Synthetic amorphous silica GPS Safety Summary. [Online] Available at: http://www.solvay.com/en/binaries/Synthetic_amorphous_silica_GPS_rev0_sept12_RHD-139563.pdf [Accessed on March 5, 2017]

Sunarc. (n.d.) Greenhouses. [Online] Available on: http://www.sunarc.net/index.php/ap-processing/greenhouse [Accessed on March 5, 2017]

TNO. (2016). Durable, Easy-Clean Coating for Greenhouse Horticulture. [Online] Available at:

https://www.tno.nl/en/focus-area/urbanisation/buildings-infrastructures/greenhouse-horticultureefficiency-through-the-use-of-innovative-technologies/durable-easy-clean-coating-for-greenhousehorticulture/ [Accessed: October 19, 2016]

Van der Waay. (2017). Top Cleaner greenhouse roof cleaner. file://C:/Users/Natalya/Downloads/Top\%20Cleaner\%20EN.pdf

Van der Waay. (n.d.-a). Van der Waay Aqua Jet roof cleaner. Retrieved from:

http://shop.globalhort.com/site/catalog/images/79994/piperailtrolleys_aquajetgreenhouseroofcleaner _div0000103_001.jpg

Van der Waay. (n.d.-b). Van der Waay Top roof cleaner. Retrieved from:

http://www.vdwaay.nl/fileadmin/fotoalbums/topcleaner/greenhouse_deck_cleaner_4_meter.jpg 


\section{APPENDIX}

\subsection{APPENDIX A: MECHANIZM OF WORK OF ANTI-REFLECTIVE COATING}

Anti-reflective coating can be applied on the surface of the glass in order to enhance its light transmittance. This section will give a theoretical background of the concepts of the light transmittance of uncoated glass and then explain the work of anti-reflective coating.

The light transmittance of the glass can be characterized by refraction and reflection. The refractive index $\left(n_{r}\right)$ is the material constant which describes light transmission through a certain medium, e.g. glass. It can be defined as follows (Ohring, 1995, p. 668):

$$
n_{r}=\frac{c}{\mathrm{~V}}
$$

where $c$ is the speed of light in vacuum, and $v$ is the velocity of light in the medium For instance, the refractive index of glass is $n_{r}=1.52$ which means that light travels 1.52 times faster in a vacuum than in glass (Avison, 2014, p. 25). The light changes direction when goes from one medium to another (Figure 11.1). The refractive index determines how much the light is bent entering the medium (Lipták and Venczel, 2016, p. 1137). Snell's law of refraction shows the relationship between the refractive indices of the media and angles of incidence and reflection. It can be expressed by the following equation (Gilbert and Haeberli, 2008):

$$
\frac{n r(1)}{n r(2)}=\frac{\sin \theta 2}{\sin \theta 1}
$$

where: $n_{r}(1)$ and $n_{r}(2)$ are the refractive indices in adjacent media 1 (air) and 2 (glass)

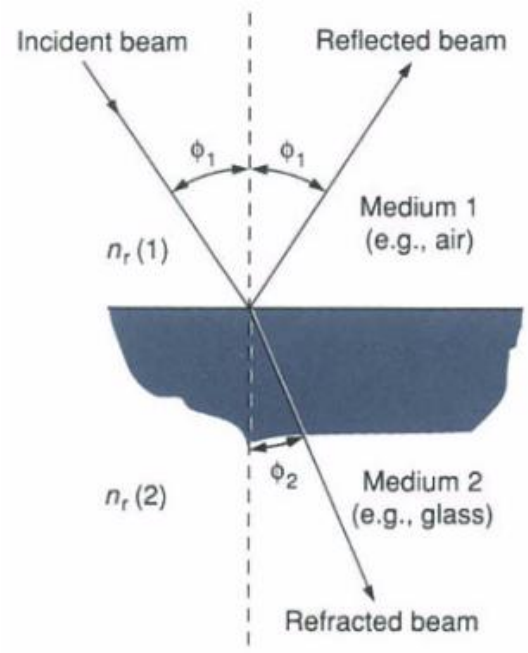

Figure 11.1. Snell's law of refraction (Ohring, 1995)

When the light travels through the glass a part of it is reflected from the interface. This effect is called angular reflectance, and depends on the relative refractive index of the interface $n=\frac{n 2}{n 1}$, the incident angle $\vartheta_{1}$, and the polarization of the incident light. Fresnel's equations for p-polarized light and s- 
polarized light describe the angular reflectance $\left(R_{p 12}\left(\vartheta_{1}\right)\right.$ and $\left.R_{s 12}\left(\vartheta_{1}\right)\right)$ in the cases when the light oscillates parallelly and perpendicularly to the plane of incidence respectively (Hébert et al., 2015):

$$
\begin{aligned}
& R_{p 12}\left(\vartheta_{1}\right)=\left(\frac{\tan (\theta 1-\theta 2)}{\tan (\theta 1+\theta 2)}\right)^{2}=\left(\frac{n \cos \theta 1-\cos \theta 2}{n \cos \theta 1+\cos \theta 2}\right)^{2} \\
& R_{s 12}\left(\vartheta_{1}\right)=\left(\frac{\sin (\theta 1-\theta 2)}{\sin (\theta 1+\theta 2)}\right)^{2}=\left(\frac{\cos \theta 1-n \cos \theta 2}{\cos \theta 1+n \cos \theta 2}\right)^{2}
\end{aligned}
$$

For normal incidence p-polarized, s-polarized, and unpolarized lights have the same reflectance (Hébert et al., 2015):

$$
R_{p 12}(0)=R_{s 12}(0)=R_{12}(0)=\left(\frac{n-1}{n+1}\right)^{2}
$$

The transmission value $T$ is equal to $1-R$ with the condition that scattering and absorption are neglected.

The light which goes through the greenhouse glass is partially reflected from the first interface between air to glass and then from the second interface of the other side of the glass from glass to air. The reflectance $(R)$ for the case when the light travels from air into glass with $n_{r}(2)=1.52$ is equal to 0.043 which means that $96 \%$ of light is transmitted. The amount of light loss is the same for the interfaces on both sides of the greenhouse glass. The light can bounce from one medium surface to another for several times being transmitted and reflected each time. Overall, the combined reflectance when the light travels through the glass $r=\frac{2 R}{1+R}$ equals to 0.077 which is $92.3 \%$ of transmittance (Harris, 1999). In practice, the transmittance of the float glass is lower than theoretical value due to the light absorption by impurities present in glass such as $\mathrm{Fe}^{3+}$ and $\mathrm{Cr}^{2+}$ (Gupta, 2010, p.363). It was reported that the actual light transmittance of float glass is $89 \%$ (Hanan, 1997, p.50).

Anti-reflective coating can be applied to decrease the reflectance of the glass. A porous $\mathrm{SiO}_{2}$ film with $\mathrm{n}<1.45$ is the most frequently used anti-reflective coating among single-layer coatings (Çamurlu et al., 2012). Anti-reflective coating is able to increase the light transmittance by the destructive interference effect. The thickness of anti-reflective coating should be regulated in such a way that it is $1 / 4$ of the length of the light wave in the layer. Then the light reflected from the second interface will move further by $1 / 2$ of its wavelength so that it becomes out of phase to the light reflected from the first interface resulting in a partial or total cancellation (Figure 11.2). Reflectance of the glass covered with anti-reflective coating can be calculated using the simplified form of Fresnel's equation (Prevo et al., 2005):

$$
R=\frac{\left(n s-n c^{2}\right)^{2}}{\left(n s+n c^{2}\right)^{2}}
$$

According to this equation, zero reflectance can be achieved if $n_{c}=\sqrt{ } n_{s}$. The refractive index of glass is $n_{s}$ $=1.52$, and thus, the desired refractive index for anti-reflective coating is calculated to be 1.23 (Çamurlu et al., 2012). 
M.Sc. Thesis // Natalya Tsoy / 07-13-2017

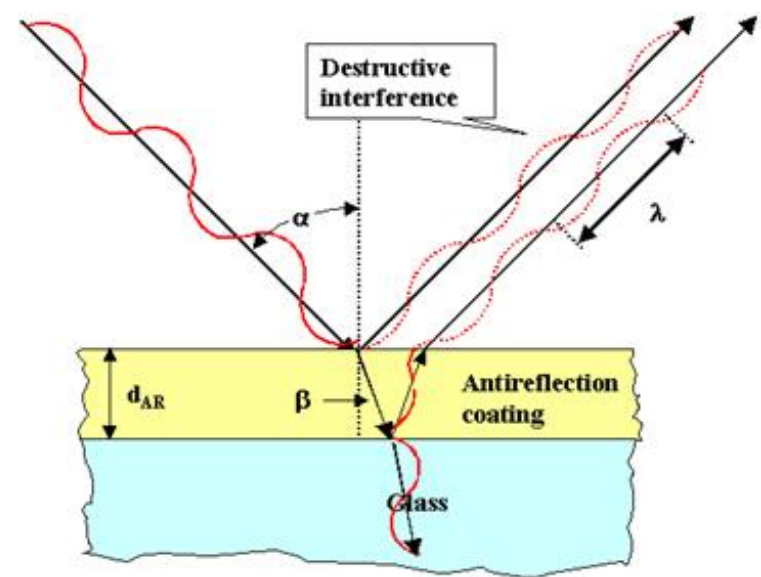

Figure 11.2. Destructive interference in anti-reflective coating (Quora, 2014). 


\subsection{APPENDIX B: MODELLING AND CALCULATIONS}

\subsection{1 'DIP COATING'}

\subsubsection{GREENHOUSE GLASS PRODUCTION}

The mass of glass for 'Dip coating' was weighted to be $7.07 \mathrm{~kg}$. The mass of 6 glass sheets with dimensions of $10 \times 15 \mathrm{~cm}$ (105.5 g per glass sheet) was used in the modelling of greenhouse glass with the mass value of $0.636 \mathrm{~kg}$.

\subsubsection{TRANSPORT OF GLASS}

The transport of glass was modelled using the inputs of the distance and the weight of the good using Ecoinvent V2.2. The distance between the ports in China and the Netherlands is 11999 nautical miles $(22222.15 \mathrm{~km})$ (Ports.com, n.d.). The trip from China to the Netherlands was modelled not including the distance for the return way because it was assumed that the ship transported another good rather than glass on its return trip. [G103] Transport, transoceanic freight ship[OCE] was used for modelling transport. The transport of $0.636 \mathrm{~kg}$ of glass was calculated as follows:

Transport tkm $=$ Total load $t *$ total distance $(\mathrm{km})=(0.000636 \mathrm{t}+0 \mathrm{t}) * 22222.15 \mathrm{~km}=14.13 \mathrm{tkm}$ The input of $14.13 \mathrm{tkm}$ for $0.636 \mathrm{~kg}$ of glass was one in CMLCA.

\subsubsection{SOL-GEL COATING PRODUCTION}

\subsection{MASS OF DIP COATING MACHINE}

The mass of the dip coating machine "Chemat Technology Inc., Model 201" is $20 \mathrm{~kg}$. It is made of steel. The life time of dip coating apparatus is 25 years. The maximum speed of the dip coating machine is 10 $\mathrm{cm} / \mathrm{min}$ (Dip Master 201, Chemat Technology, Inc., n.d.). Therefore, the maximum speed of $10 \mathrm{~cm} / \mathrm{min}$ was used for calculations.

$$
\begin{aligned}
& 1 \mathrm{~min}=\frac{1 \mathrm{~min} * 1 \text { year }}{525600 \mathrm{~min}}=1.903 * 10^{-6} \text { year } \\
& \text { Capacity of dip coater through its whole life }=\frac{0.1 \mathrm{~m} * 25 \text { years }}{1.903 * 10^{-6} \text { year }}=1313715.187 \frac{\mathrm{m}}{\text { dip coater }} \\
& \text { Dipping } 6 \text { glass sheets with the length of } 15 \mathrm{~cm}=\frac{6 * 0.15 \mathrm{~m}}{13137115.187 \frac{\mathrm{m}}{\text { dip coater }}}=6.851 * 10^{-8} \text { dip coater }
\end{aligned}
$$

The mass of dip coater $20 \mathrm{~kg}$ was multiplied by a factor of $6.851 * 10^{-8}$.

\subsection{MASS OF ELECTRIC OVEN}

The capacity of the oven through its whole lifetime was calculated. The lifetime of the oven is 25 years. The maximum permissible load equals to $28 \mathrm{~kg}$.

$$
\begin{aligned}
& \qquad 1 \text { hour }=\frac{1 \text { hour } * 1 \text { year }}{8760 \text { hours }}=1.14155^{*} 10^{-4} \text { year } \\
& \text { Capacity of the oven through its whole life }=\frac{28 \mathrm{~kg} * 25 \text { years }}{1.14155 * 10^{-4} \text { year }}=6132013.49 \mathrm{~kg} / \mathrm{oven} \\
& \text { Curing } 6 \text { glass sheets (the mass of each is } 0.106 \mathrm{~kg} \text { ) for } 1 \text { hour }=\frac{0.636 \mathrm{~kg}}{6132013.49 \frac{\mathrm{kg}}{\text { oven }}}=1.0372 * 10^{-7} \text { Oven }
\end{aligned}
$$

The mass of the oven $40 \mathrm{~kg}$ for curing of glass was multiplied by a factor of $1.0372 * 10^{-7}$. 


\subsubsection{PACKING}

The wooden box contains 20 glass plates of $300 \times 300 \mathrm{~mm}$. [G2000] Packaging box production unit[RER] was used for designing the buildings and machines for the box production process. The lifetime of the plant is 50 years with the box production capacity of $14 \mathrm{kt}$ per year. The mass of one box is $3.8736 \mathrm{~kg}$.

$$
\begin{aligned}
& \text { Mass of boxes produced through one life cycle of the plant }=\frac{14000 t * 50 \text { years }}{1 \text { year }}=700000 t \\
& \text { Box production plant for manufacturing of } 1 \text { box }=\frac{0.0038736 t}{700000 t}=5.5337^{*} 10^{-9}
\end{aligned}
$$

One unit of the box production plant was multiplied by a factor of $5.5337 * 10^{-9}$.

The input and output of greenhouse glass were $1.8 \mathrm{~m}^{2}$.

The mass for waste treatment of the box parts was used from Table 11.1 in Appendix D.

\subsubsection{ELECTRICITY FOR WOODEN BOX PRODUCTION AND PACKING OF GLASS}

It was assumed that automatic machines are used in the wooden box production and packing of glass. The amount of electricity required to produce a wooden box and packing was calculated. The power of the automatic machine for the wooden box production and packing process is $3.5 \mathrm{~kW}$ (Alibaba.com, 2017b). Approximately $2 \mathrm{~min}$ is needed to produce a wooden box and put $1 \mathrm{~m}^{2}$ glass into it. Thus, the amount of electricity was estimated as follows:

$$
\begin{gathered}
\text { Time in hours }=\frac{2 \mathrm{~min} * 1 \text { hour }}{60 \mathrm{~min}}=0.0334 \text { hour } \\
\text { Amount of electricity for wooden box production and packing of } 1 \mathrm{~m}^{2} \mathrm{glass}=3.5 \mathrm{~kW} 0.0334 \text { hour }=0.1169 \\
k W h
\end{gathered}
$$

\subsubsection{USE}

\subsection{TRANSPORT OF COATED GLASS}

Packed greenhouse glass is transported by lorry $>32 \mathrm{t}$. The distance was assumed to be from TNO in Eindhoven to Westland Oostland Greenport. The distance between Westland-Oostland greenport and TNO is $130 \mathrm{~km}$ (Google Maps, n.d.). The area of the Venlo greenhouse is $17500 \mathrm{~m}^{2}$. The mass of $1 \mathrm{~m}^{2}$ glass is $7.07 \mathrm{~kg}$. Thus, the mass of the glass required to cover the surface of Venlo greenhouse is 123725 kg. A lorry of the capacity of greater than 32 tonnes is used [G3398] Transport, lorry >32t, EURO5[RER] for transport of glass. Transport was calculated as follows:

Transport $t \mathrm{~km}=$ Total load $t *$ total distance $(\mathrm{km})=(0.00707 \mathrm{t}+0 \mathrm{t}) *(130 \mathrm{~km}+130 \mathrm{~km})=1.8382 \mathrm{tkm}$

\subsection{GRENNHOUSE GLASS CLEANING}

Poot Kasdekreiniging informed that the washing capacity of Top Cleaner machine for the outside cleaning is $1600 \mathrm{~m}^{2}$ per hour. Aqua Jet cleans $1250 \mathrm{~m}^{2}$ of glass per hour. The water use per square meter for an hour was calculated as follows:

$$
\text { Amount of water for the outside cleaning of } 1 \mathrm{~m}^{2} \text { of glass twice a year }=\frac{2400 \frac{\mathrm{L}}{\text { hour }^{2}} * 2}{1600 \frac{\mathrm{m}^{2}}{\mathrm{hour}}}=3 \mathrm{~L}
$$




$$
\text { Amount of water for the inside cleaning of } 1 \mathrm{~m}^{2} \text { of glass once a year }=\frac{6000 \frac{\mathrm{L}}{\mathrm{hour}}}{1250 \frac{\mathrm{m}^{2}}{\mathrm{hour}}}=4.8 \mathrm{~L}
$$

Therefore, the amount of water needed for the outside washing of $1 \mathrm{~m}^{2}$ of greenhouse glass twice a year for 30 years is $90 \mathrm{~L}$. While the volume for the inside washing of glass for 30 years is $144 \mathrm{~L}$.

The electricity required for Van der Waay Top Cleaner to wash $1 \mathrm{~m}^{2}$ of greenhouse glass for 30 years was estimated. According to Van der Waay (2017), the voltage of Van der Waay Top cleaner is $400 / 480 \mathrm{~V}-50 / 60 \mathrm{~Hz}$, and current equals to $16 \mathrm{~A}$. This is a three-phase electric power system of alternating current power transmission. The value of Power was calculated using a simplified formula:

$$
\text { Power }=16 \mathrm{~A} * 480 \mathrm{~V}=7680 \mathrm{~W}
$$

Top Cleaner washes $1600 \mathrm{~m}^{2}$ per hour, and this means that it requires 2.25 seconds ( 0.000625 hour) to clean $1 \mathrm{~m}^{2}$ of glass.

Energy in kilowatt-hours for cleaning $1 \mathrm{~m}^{2}$ of glass $=7680 \mathrm{~W} * 0.000625$ hour $/ 1000=0.0048 \mathrm{kWh}$ The electricity needed to clean $1 \mathrm{~m}^{2}$ of glass twice a year is $0.0096 \mathrm{kWh}$. The Ecoinvent V2.2 module [G685] Electricity, medium voltage, at grid[NL] was used for modelling the electricity for the work for Top Cleaner. Thus, the amount of electricity needed for Top Cleaner to wash the greenhouse glass twice a year for 30 years equals to $0.288 \mathrm{kWh}$.

Van der Waay reported that Aqua Jet is able to clean from 1000 to $1250 \mathrm{~m}^{2}$ per hour. In the modelling, the cleaning capacity of $1250 \mathrm{~m}^{2}$ per hour for this machine was used. It needs 2.88 seconds ( 0.0008 hour) to clean $1 \mathrm{~m}^{2}$ of greenhouse glass. Van der Waay Aqua Jet requires $5 \mathrm{~L}$ of petrol for an hour work. The volume of petrol used by Aqua Jet for cleaning of $1 \mathrm{~m}^{2}$ of glass was calculated as follows:

$$
\text { Volume of petrol for cleaning } 1 \mathrm{~m}^{2} \text { of glass once a year }=\frac{0.0008 \text { hour } * 5 \mathrm{~L}}{1 \text { hour }}=0.004 \mathrm{~L}
$$

The volume of petrol needed for Aqua Jet to clean $1 \mathrm{~m}^{2}$ of glass for 30 years equals to $0.12 \mathrm{~L}$. The density of unleaded petrol at $15^{\circ} \mathrm{C}$ is $0.724 \mathrm{~kg} / \mathrm{L}$ (Nolan Fuel Oils Ltd., n.d.). Thus, [G1900] Petrol, unleaded, at refinery $[\mathrm{CH}]$ with the mass of $0.0869 \mathrm{~kg}$ was modelled.

Van der Waay was contacted to specify the details such as types of materials used and the mass values of Top Cleaner parts. Table 11.2 in Appendix D shows data of the weights of the Top Cleaner parts provided by Van der Waay. In the modelling, the materials for the construction of Top Cleaner were used from Ecoinvent V2.2. The average life-time of Top Cleaner is 15 years. The calculations were performed to find the amount of materials needed for the construction of Top Cleaner assuming that it needs to clean $1 \mathrm{~m}^{2}$ of greenhouse glass twice a year. It is known that the cleaning capacity of Top Cleaner is $1600 \mathrm{~m}^{2}$ of glass per hour. All of the mass values of the materials used for Top Cleaner were multiplied by a factor of $1.4269 * 10^{-7}$ and used in the modelling of one Top Cleaner machine. The calculations are as follows:

$$
\begin{aligned}
& 1 \text { hour }=\frac{1 \text { hour } * 1 \text { year }}{8760 \text { hours }}=1.14155 * 10^{-4} \text { year } \\
& \text { Cleaning capacity of Top Cleaner through its whole life }=\frac{1600 \mathrm{~m}^{2} * 15 \text { years }}{1.14155 * 10^{-4} \text { year }}=210240462.5 \mathrm{~m}^{2} / \text { Top Cleaner } \\
& \text { Cleaning of } 1 \mathrm{~m}^{2} \text { glass twice a year for } 15 \text { years }=\frac{30 \mathrm{~m}^{2}}{210240462.5 \frac{\mathrm{m}^{2}}{\text { Top Cleaner }}}=1.4269 * 10^{-7} \text { Top Cleaner }
\end{aligned}
$$


The input of two Top Cleaner machines was made to [P4092] Greenhouse glass cleaning (outside)[NL] process. Waste treatment service has been modelled for all parts of Top Cleaner machine using Ecoinvent V2.2. Aqua Jet cleans $1250 \mathrm{~m}^{2}$ of glass per hour. The lifetime of the machine is 10 years.

$$
\begin{aligned}
& \text { Cleaning capacity through Aqua Jet whole life }=\frac{1250 \mathrm{~m}^{2} * 10 \text { years }}{1.14155 * 10^{-4} \text { year }}=109500240.9 \mathrm{~m}^{2} / \text { Aqua Jet } \\
& \text { Cleaning of } 1 \mathrm{~m}^{2} \text { glass once a year for } 30 \text { years }=\frac{30 \mathrm{~m}^{2}}{109500240.9 \frac{\mathrm{m}^{2}}{\text { Aqua Jet }}}=2.7397^{*} 10^{-7} \text { Aqua Jets }
\end{aligned}
$$

The empty weight of Aqua Jet is $550 \mathrm{~kg}$. Therefore, the mass of Aqua Jet machine was multiplied by a factor of $2.7397 * 10^{-7}$. All materials are recycled and therefore disposal is not considered in this case.

It was assumed that waste water from the cleaning of the greenhouse was processed in the medium size municipal waste water treatment plant. Therefore, the sum of the volumes of water used for the inside and outside greenhouse cleaning $234 \mathrm{~L}$ was used for the modelling of the waste water treatment. [W534] Treatment, sewage, to wastewater treatment, class 3 [CH] was used for modelling the water treatment process. This module includes three phase waste water treatments such as mechanical, biological, and chemical. The waste treatment service for the materials of used box was modelled using Ecoinvent V2.2 in the use phase.

\subsubsection{PREPARATION OF GLASS FOR RECYCLING}

One ton of used greenhouse glass is prepared for recycling. The Ecoinvent V2.2 inflow [G1258] Glass, from public collection, unsorted[RER] with the input of 1 ton of waste glass was used to model collection and transportation of used greenhouse glass from a greenhouse to a sorting plant. With the use of Ecoinvent V2.2 inflow [G1257] Glass sorting site[RER] the land use, the construction efforts and materials for the machineries and buildings for sorting site were designed. The lifetime of the sorting site is 50 years with the sorting capacity of $100 \mathrm{kt}$ per year. The sorting site per 1 ton of the waste glass was calculated as follows:

$$
\begin{aligned}
& \text { Mass of glass which could be sorted through the one life cycle }=\frac{100000 t * 50 \text { years }}{1 \text { year }}=5000000 t \\
& \text { Sorting site for sorting of } 1 \text { ton of glass }=\frac{1 t}{5000000 t}=2 * 10^{-7}
\end{aligned}
$$

According to Blengini et al. (2012), the electricity required for sorting, washing, and milling of waste float glass is $26.4 \mathrm{kWh}$. This value was used for the modelling of Ecoinvent V2.2 inflow [G685] Electricity, medium voltage, at grid[NL]. The amount of diesel needed for the bulk solid handing process is $0.5 \mathrm{~L}$ for 1 ton of waste glass (Blengini et al., 2012). The heat value of diesel is $39 \mathrm{MJ} / \mathrm{L}$. Thus, [G156] Diesel, burned in building machine[GLO] with the value of $19.5 \mathrm{MJ}$ of diesel was modelled. In the washing phase, $0.83 \mathrm{~m}^{3}$ for 1 ton of waste float glass is required (Blengini et al., 2012). There was an input of $0.83 \mathrm{~m}^{3}$ of [G71] Tap water, at user[RER]. In the drying step, $103.59 \mathrm{MJ}$ of natural gas is needed (Blengini et al., 2012). [G145] Heat, natural gas, at industrial furnace $>100 \mathrm{~kW}$ [RER] with the energy value of $103.59 \mathrm{MJ}$ was modelled. [G534] Treatment, sewage, to wastewater treatment, class 3[CH] was used for modelling of the waste water treatment. The recycling process of the glass cullet in the packing glass manufacturing, float glass production, glass wool production plants was considered to be out of scope of the study and was not modelled. 


\subsubsection{SENSISITIVITY ANALYSIS}

\subsubsection{DEGRADATION OF DIP COATING AND INCREASED LIGHT TRANSMITTNCE}

Degradation time of 'Dip coating' after 20 years and 30 years were analyzed with the help of Sensitivity analysis. The outputs of tomatoes in the use phase were $1818.45 \mathrm{~kg}$ and $1863 \mathrm{~kg}$, respectively.

\subsubsection{SOURCES OF ETHANOL PRODUCTION IN DIP COATING MANUFACTURING}

Sensitivity analysis of the sources for ethanol production was performed. The same model for 'Dip coating at industrial scale' scenario was used. [G2832] Ethanol, 99.7\% in $\mathrm{H}_{2} \mathrm{O}$, from biomass, at distillation [CN] was replaced by [G204] Ethanol from ethylene, at plant[RER] in the [P4112] Sol-gel coating production (industrial scale)[NL] process.

\subsubsection{COATING FACTORY FOR DIP COATING IN CHINA}

'Dip coating at industrial scale' model was used for Sensitivity analysis. Some changes in the modelling were added. In [4113] Greenhouse glass production (dip coating) (industrial scale), [G103] Transport, transoceanic freight ship [OCE] was removed, and it was assumed that coating of the glass was produced in the same factory where low-iron glass was manufactured. [G928] Electricity, production mix [NL] was replaced by [G2949] Electricity, production mix[CN] in [P4112] Sol-gel coating production (industrial scale)[NL]. [G3398] Transport, lorry >32t, EURO5[RER] was replaced by [G103] Transport, transoceanic freight ship[OCE] in the [P4115] Use (dip coating) (industrial scale)[NL] process.

\subsubsection{GLASS PRODUCTION FOR DIP COATING IN THE NETHERLANDS}

Some modifications in 'Dip coating at industrial scale' scenario was added. In [4127] Greenhouse glass production (dip coating) (industrial scale)-glass prod [NL], [G103] Transport, transoceanic freight ship[OCE] was removed. In [P4131] Flat glass, uncoated, at plant - glass prod [NL], [G2949] Electricity, production mix[CN] was replaced by [G928] Electricity, production mix[NL]. In [P4132] Packing of uncoated glass - glass prod [NL], [G2949] Electricity, production mix [CN] was replaced by [G928] Electricity, production mix[NL] as well.

\subsubsection{REFERENCES}

The life-cycle processes of 'Uncoated glass', 'Acid etching', and 'Sputtering' were modelled in the same way as for 'Dip coating' product system except of the coating production processes and transport of greenhouse glass from China to the Netherlands. In the references models, the glass factory and the coating plant are both in China rather than in the case of 'Dip coating' where the coating plant is situated in the Netherlands. Thus, the electricity production and transport were modelled according to this assumption.

In greenhouse glass production, it was assumed that the mass of 'Uncoated glass' and glass covered with 'Acid etching', 'Sputtering', and 'Dip coating' is the same assuming the mass of the coating is negligible. Thus, the inputs of the mass values to the production of $1 \mathrm{~m}^{2}$ of low-iron glass for all alternatives were $7.07 \mathrm{~kg}$ which is the mass of glass measured at laboratory at TNO.

Ecoinvent V2.2 involves coating of glass by nickel-chromium using cathodic sputtering. In this case study, the coatings based on silica are being compared, and thus, another type of sputtering called 
'Reactive Sputtering' is usually applied. Approximation of the process by a similar process in the LCA modelling could be made in case of unavailability of data (Guinée et al., 2002, p.56). Some modifications were added to the 'Sputtering' model in Ecoinvent V2.2. In this case study, the coatings based on silica are being compared, and thus, the processes such as [G1238] Chromium, at regional storage[RER] and [G477] Nickel, 99.5\%, at plant [GLO] were replaced by [G1593] Silicon, solar grade, modified Siemens process, at plant [RER] in the sputtering process. The processes related to production of flat glass manufacturing were excluded as the process low-iron glass production in the greenhouse glass production process already included those processes. Processes associated to packaging were removed to make the comparison consistent to 'Uncoated glass', 'Acid etching', and 'Dip coating' which did not include packaging in the modelling. Packing of glass using wooden box was modelled in the transport of uncoated glass (except of 'Uncoated glass' product system) and coated glass. 


\subsection{APPENDIX C: FIGURES}

\subsubsection{CASE STUDY}

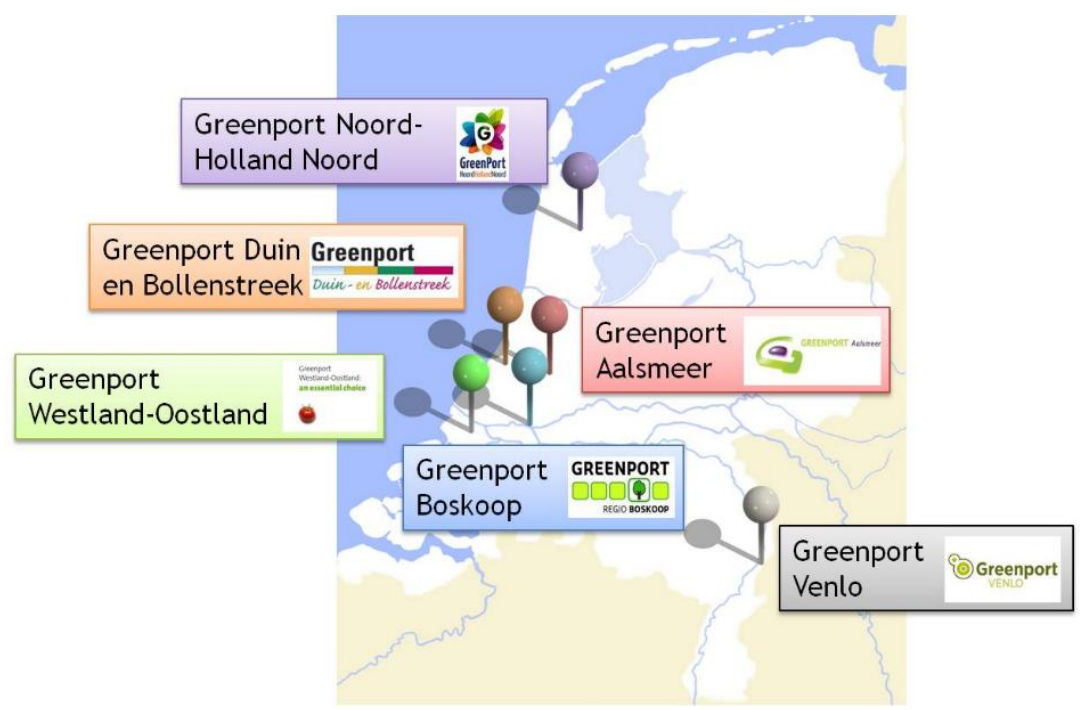

Figure 11.3. Locations of Greenports in the Netherlands (Greenport Holland, n.d.)

\subsubsection{DATA COLLECTION}

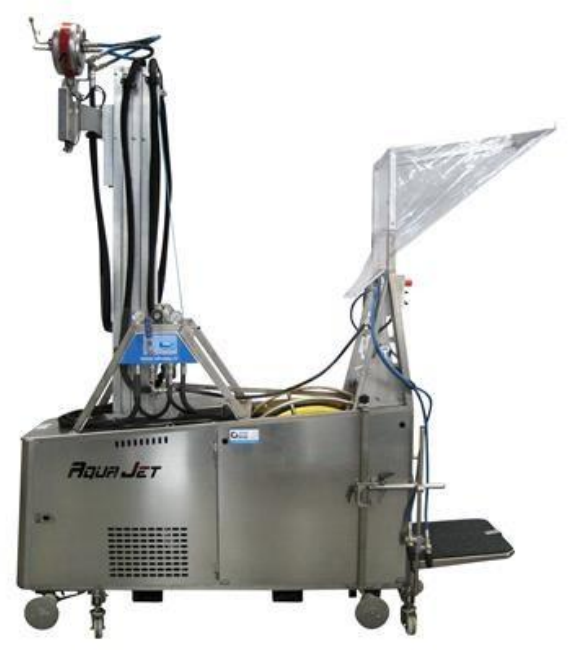

Figure 11.4. Van der Waay Aqua Jet roof cleaner (Van der Waay, n.d.-a) 


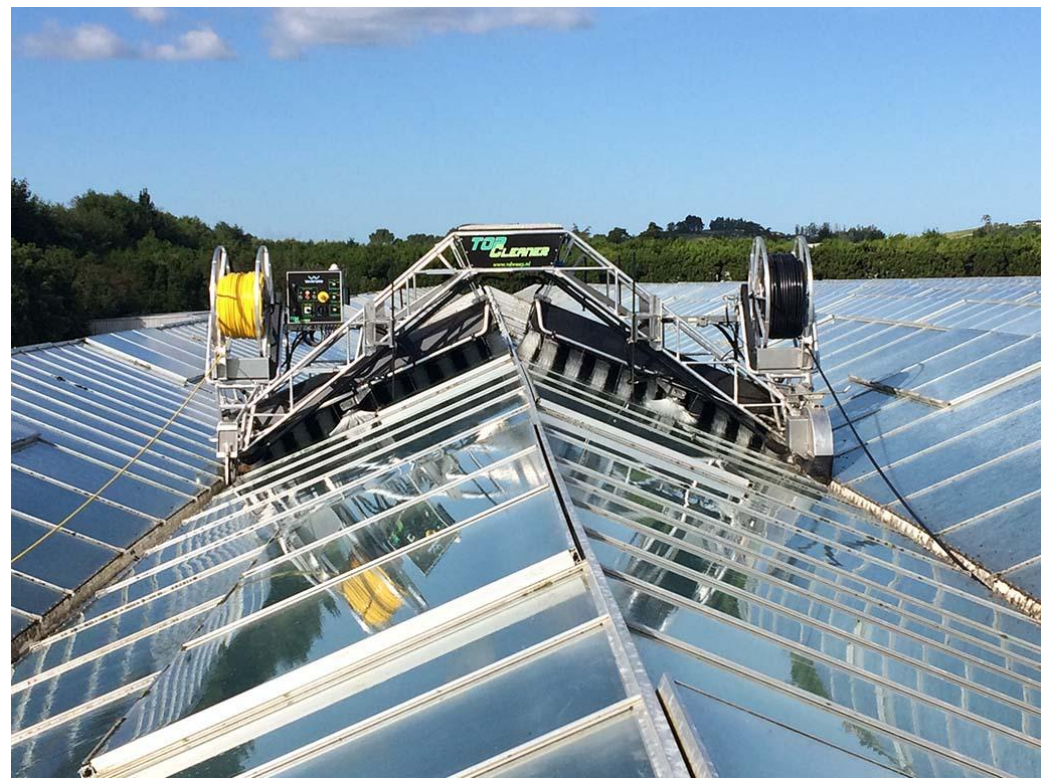

Figure 11.5. Van der Waay Top roof cleaner (Van der Waay, n.d.-b)

\subsubsection{RESULTS}

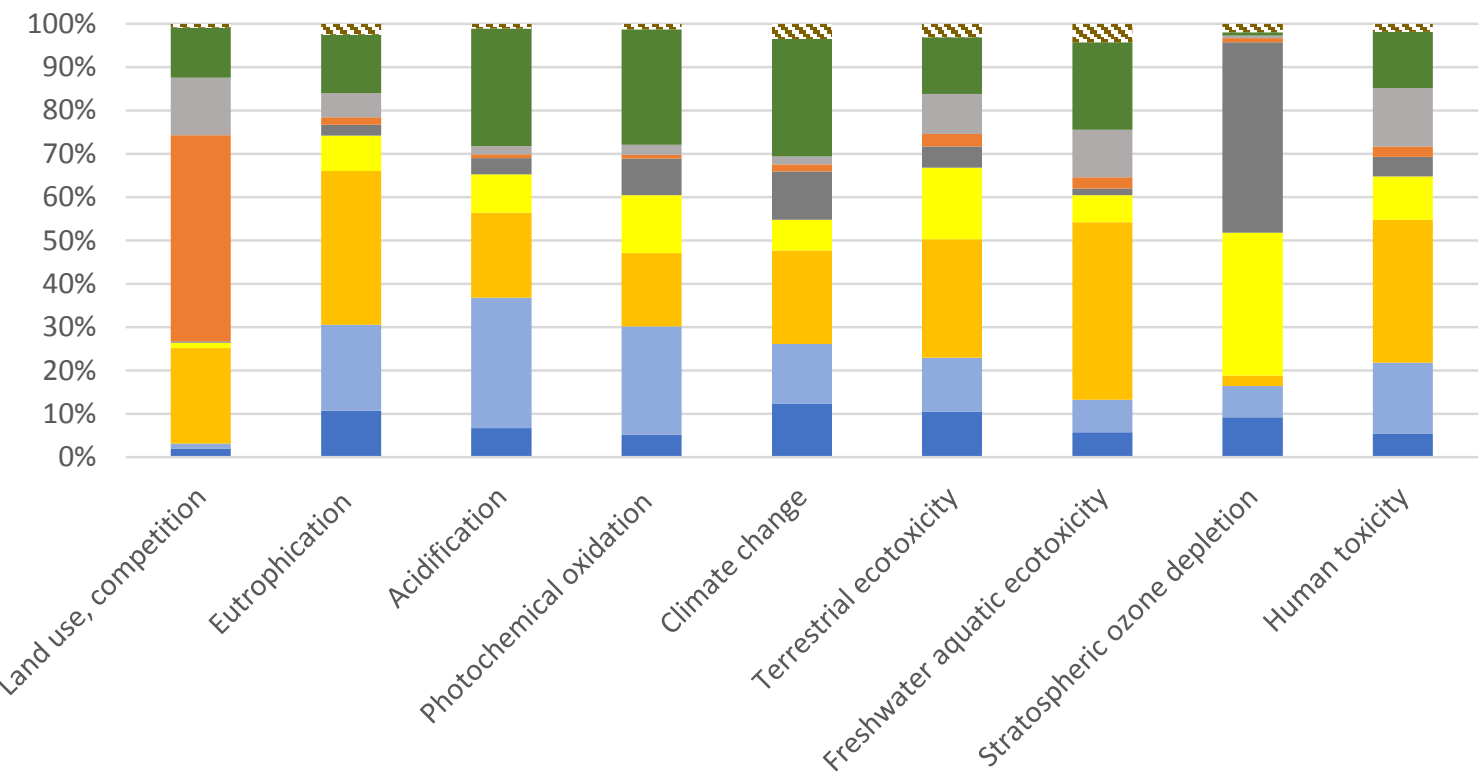

- Transport of raw materials by lorry $>16 t$ [RER] $n$ Transport of raw materials by ship [OCE]

Production of soda powder [RER]

Distribution of fuel oil [RER]

Distribution of natural gas [RER]

- Production of milled limestone $[\mathrm{CH}]$

- Flat glass plant [RER]

- Electricity, production mix [CN]

Other processes

Figure 11.6. Contribution analysis results of the processes for low-iron glass production (author's image) 


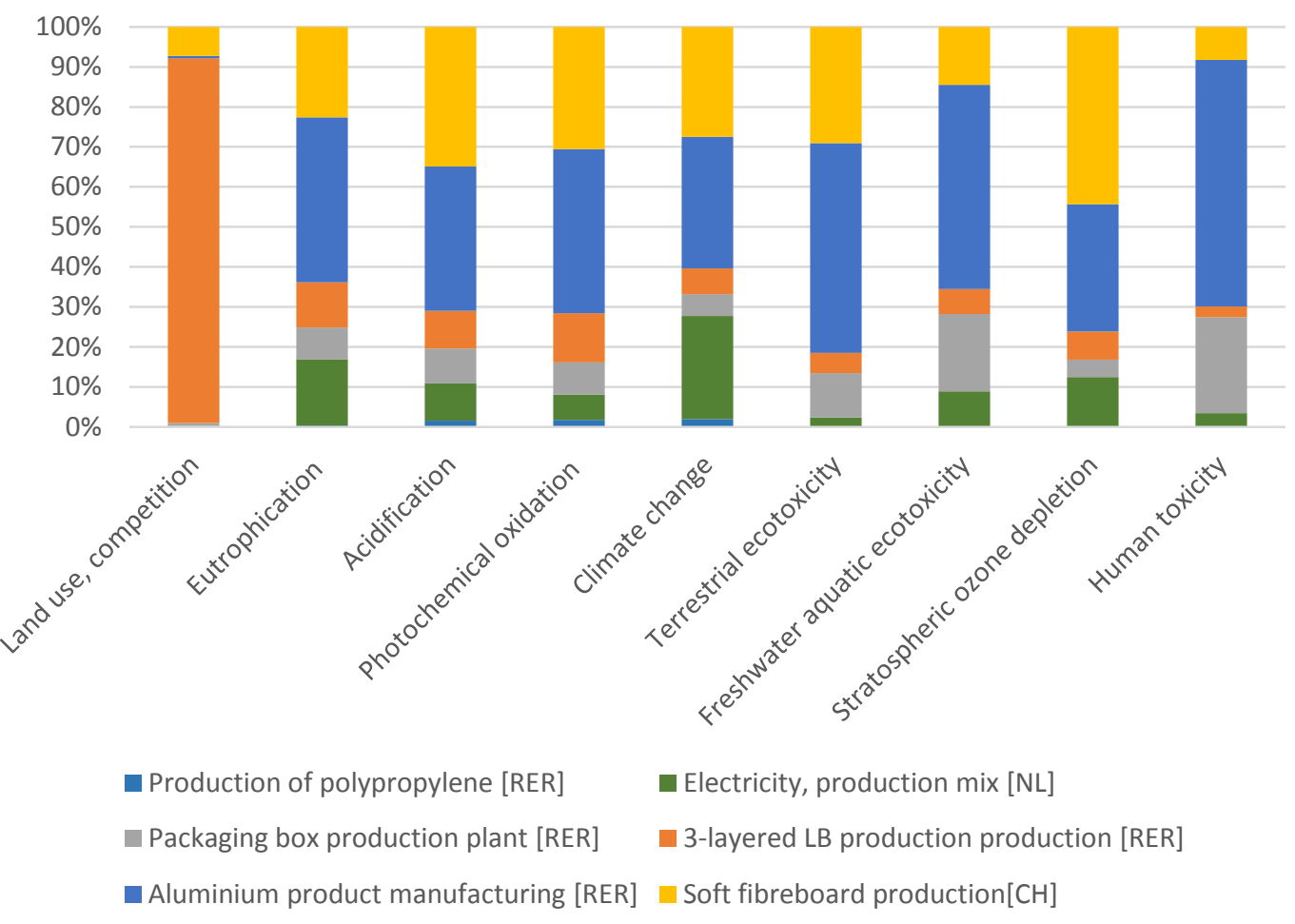

Figure 11.7. Contribution analysis results for packing of greenhouse glass (author's image)

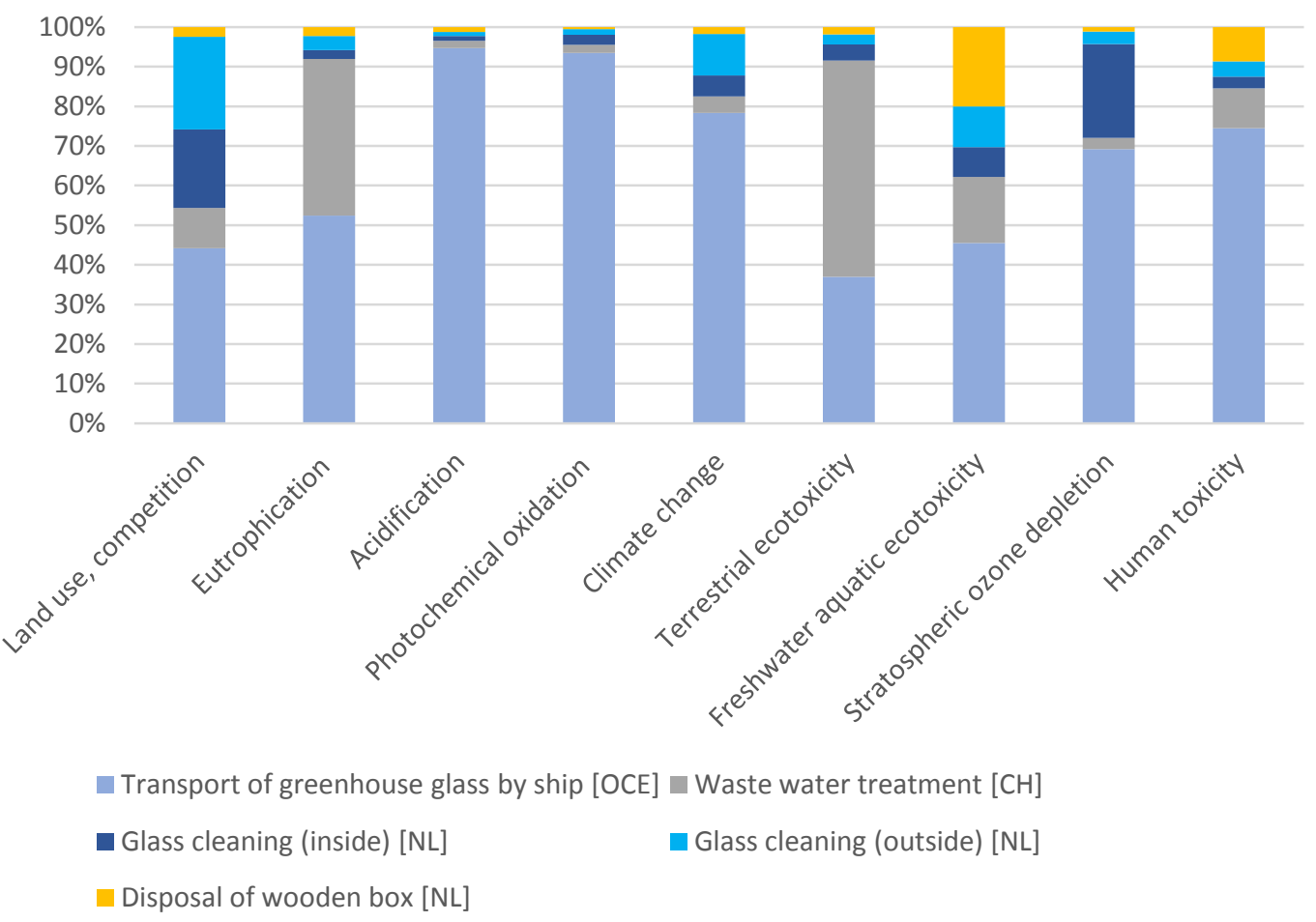

Figure 11.8. Contribution analysis of the use processes for the references (author's image) 


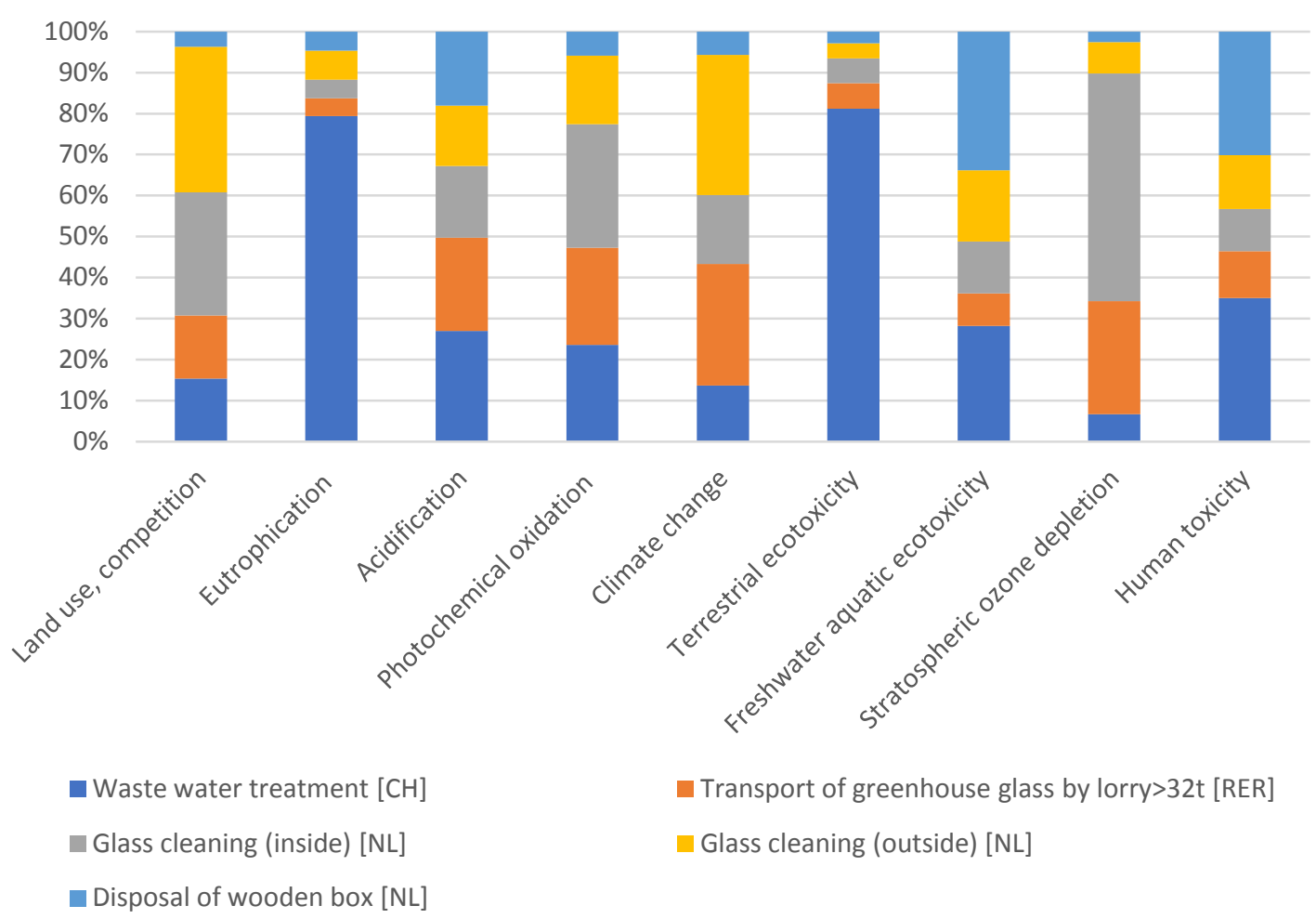

Figure 11.9. Contribution analysis results of the use processes for 'Dip coating' (author's image) 


\subsection{APPENDIX D: TABLES}

\begin{tabular}{|l|c|c|c|c|}
\hline Box parts & Quantity & $\begin{array}{c}\text { Weight of one item } \\
(\mathrm{kg})\end{array}$ & $\begin{array}{c}\text { Volume of one item } \\
\left(\mathrm{m}^{3}\right)\end{array}$ & $\begin{array}{c}\text { Total weight } \\
(\mathrm{kg})\end{array}$ \\
\hline Wood & 1 & $3.255 \mathrm{~kg}$ & 0.00542 & 3.255 \\
\hline Fiber board & 7 & $0.0797 \mathrm{~kg}$ & 0.000219 & 0.558 \\
\hline Screw & 44 & $0.00126 \mathrm{~kg}$ & - & 0.0554 \\
\hline Rope & 1 & $0.00550 \mathrm{~kg}$ & - & 0.00550 \\
\hline & & & & 3.873 \\
\hline
\end{tabular}

Table 11.1 Weights of the wooden box parts used for transport of 20 sheets of $0.09 \mathrm{~m}^{2}$ float glass

\begin{tabular}{|l|c|c|c|c|}
\hline Parts of Top Cleaner 400 Standard Edition & Quantity & Unit & $\begin{array}{c}\text { Unit Weight } \\
\text { (Kg) }\end{array}$ & $\begin{array}{c}\text { Total Weight } \\
\text { (kg) }\end{array}$ \\
\hline $\begin{array}{l}\text { Top Cleaner } 400 \text { Standard Edition } \\
\text { Hose/cable on reels (mounted on top } \\
\text { cleaner) }\end{array}$ & 1 & pc & 302 & 302 \\
\hline $\begin{array}{l}\text { Guides on reels (mounted on top cleaner) } \\
\text { Adjustable disk brush set (mounted on top }\end{array}$ & 1 & m & 0.43 & 90.3 \\
\hline $\begin{array}{l}\text { cleaner) } \\
\text { Open window protection switch (mounted } \\
\text { on top cleaner) }\end{array}$ & 1 & set & 10.5 & 18 \\
\hline $\begin{array}{l}\text { polycarbonate brush cover (mounted on top } \\
\text { cleaner) }\end{array}$ & 1 & set & 7 & 7 \\
\hline $\begin{array}{l}\text { Gutter brush wide (mounted on top } \\
\text { cleaner) }\end{array}$ & 1 & set & 18 & 18 \\
\hline
\end{tabular}

Table 11.2. Weights of the parts of Top Cleaner machine 


\begin{tabular}{|l|c|c|}
\hline Greenhouse glass & $\begin{array}{c}\text { Country of electricity } \\
\text { production }\end{array}$ & $\begin{array}{c}\text { Electricity amount for the } \\
\text { production of coating (kWh) to } \\
\text { cover 1 } \mathrm{m}^{2} \text { of glass }\end{array}$ \\
\hline Uncoated glass & - & 0 \\
\hline Acid etching & $\mathrm{CN}$ & 1.2 \\
\hline Sputtering & $\mathrm{CN}$ & 0.5 \\
\hline Dip coating at lab-scale & $\mathrm{NL}$ & 8.3 \\
\hline Dip coating at pilot scale & $\mathrm{NL}$ & 3.8 \\
\hline Dip coating at industrial scale & $\mathrm{NL}$ & $0.5 *$ \\
\hline
\end{tabular}

Table 11.3. Countries of electricity production and amounts of electricity required for coating production in different greenhouse glass life-cycle processes

*Note: the amount of electricity for the conversion of natural gas to electricity for tempering process was not taken into consideration as Ecoinvent V2.2 does not consider this process. Instead the input of natural gas production process is included for tempering in Ecoinvent V2.2. 
M.Sc. Thesis // Natalya Tsoy / 07-13-2017

12 APPENDIXE

Supplementary material can be found as an attachment in Appendix E: IE_Master_Thesis.xlsx. 